\title{
Influence of Zostera marina on Wave Dynamics, Sediment Suspension, and Bottom Boundary Layer Development within a Shallow Coastal Bay
}

\author{
Emily Lane Thomas \\ B.S.E. Civil and Environmental Engineering \\ University of Michigan, 2011
}

A Thesis presented to the Graduate Faculty of the University of Virginia in Candidacy for the Degree of Master of Science

Department of Environmental Sciences

University of Virginia

May, 2014 


\begin{abstract}
Local effects of flow interaction with seagrass structure modify meadow scale hydrodynamics, resulting in lower current velocities and wave heights within a seagrass meadow. This attenuation promotes the deposition of suspended sediment, increasing the light available locally to benthic organisms. To elucidate the relationship between small scale hydrodynamics that occur at the sea floor and the meadow scale effects of seagrass, high resolution velocity profiles were recorded adjacent to the sediment-water interface within a Zostera marina seagrass meadow in South Bay, Virginia. Additionally, instrumentation was deployed across the meadow to seasonally monitor suspended sediment concentrations and corresponding changes in wave height across the seagrass meadow. Results show that wave height was reduced by $25-49 \%$ compared to an adjacent bare site, and $-19-64 \%$ compared to an analytical model of wave attenuation over an unvegetated seafloor with the same bathymetry. The lowest attenuation of waves values occurred in the winter and the highest attenuation occurred in the summer. Wave attenuation coefficients, $\alpha_{\mathrm{w}}$, calculated for the expanse of meadow ranged from $\alpha_{\mathrm{w}}=0.59$ in the spring to 0.19 in the winter and were highly dependent on wave conditions, with greater attenuation for larger wave height, longer period waves.

Near bed flow characteristics showed a reduction in shear velocity and boundary layer thickness within the seagrass meadow, accompanied by lower average bed orbital velocities. Even in high wave conditions, the contribution to the total shear by turbulent motion was more prevalent than by wave motion within the seagrass canopy; however, overall within canopy turbulent kinetic energy was reduced compared to the bare site. Comparing nearly identical wave conditions, shear velocities $\left(u_{*}\right)$ were the same at both the vegetated and unvegetated sites, suggesting that vertical orbital velocity attenuation through the water column was unaffected by
\end{abstract}


seagrass. Lower wave heights within a seagrass meadow caused by horizontal attenuation of wave motion may be more influential for near bed shear conditions. Accurately predicting the location and thickness of the wave boundary layer was difficult due to the complexities of and non-linear interactions between currents, waves, and vegetation. Measured values of wave boundary layer thickness were an order of magnitude larger than predicted by theory over smooth beds, suggesting that both vegetation and benthic roughness dramatically alter near bed flow conditions. 


\section{TABLE OF CONTENTS}

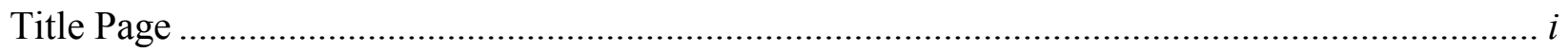

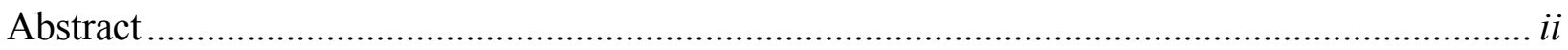

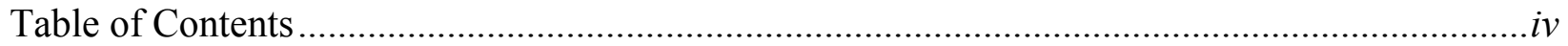

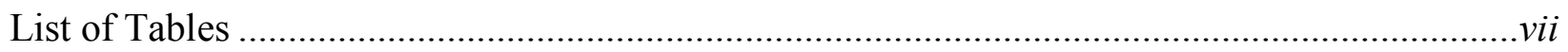

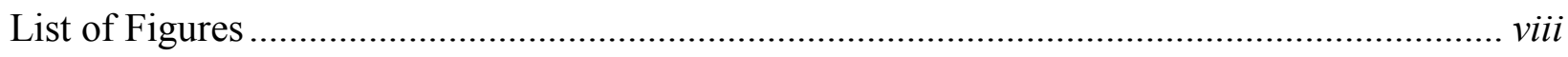

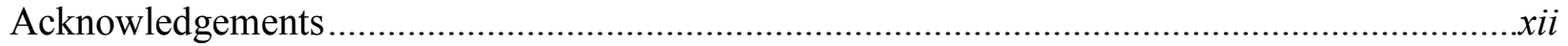

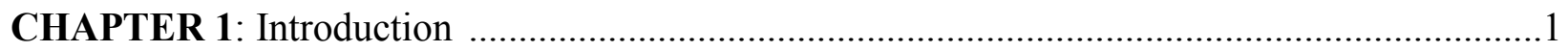

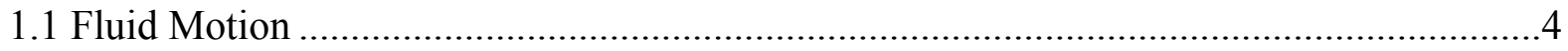

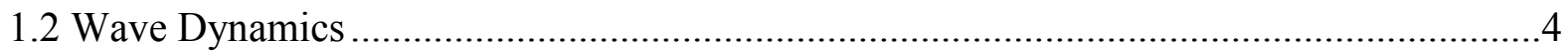

1.3 Combined Wave-Current Boundary Layer ...................................................................6

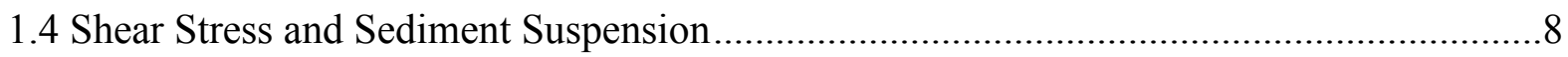

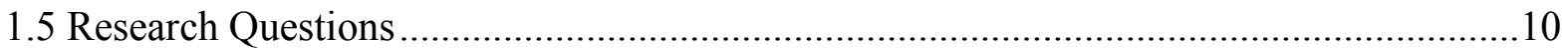

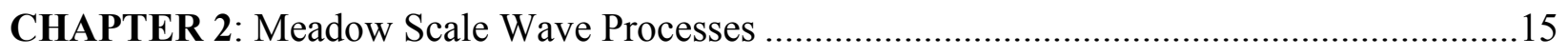

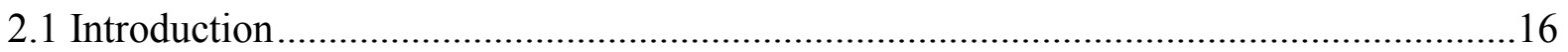

2.1.1 Wave Attenuation ....................................................................................17

2.1.2 Attenuation Coefficients ..............................................................................18

2.1.3 Sediment Dynamics ..................................................................................21

2.1.4 Previous Work in South Bay .......................................................................22

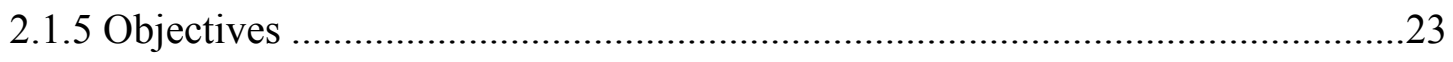

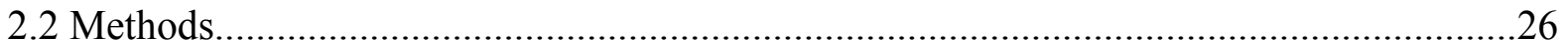

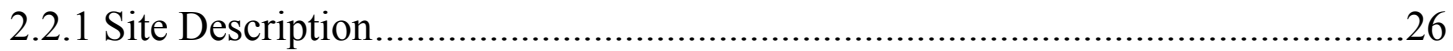

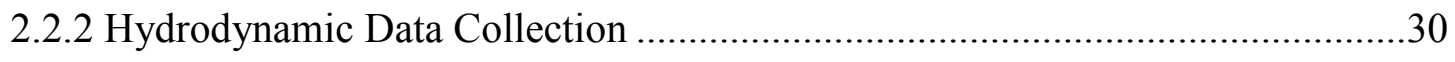

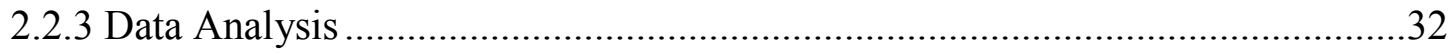

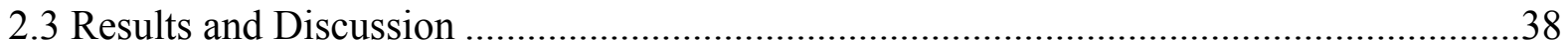

2.3.1 Wave Characteristics ....................................................................................

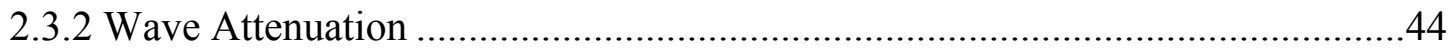


2.3.3 Comparison to Young and Verhagen Model ....................................................47

2.3.4 Wave Attenuation Coefficient ...........................................................................

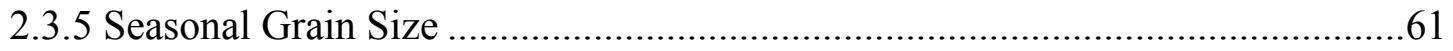

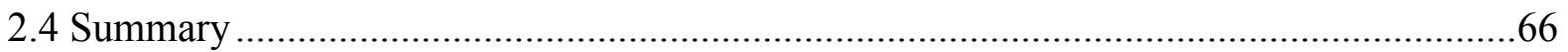

CHAPTER 3: Dynamics of the Wave-Current Boundary Layer ..............................................69

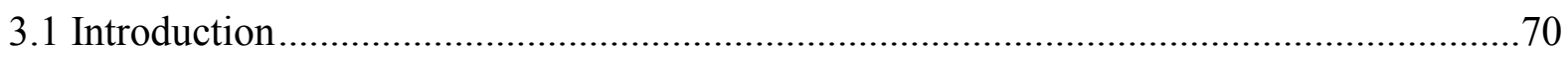

3.1.1 Wave-Current Boundary Layers ……………………………………………....70

3.1.2 Flow within Seagrass Beds .........................................................................72

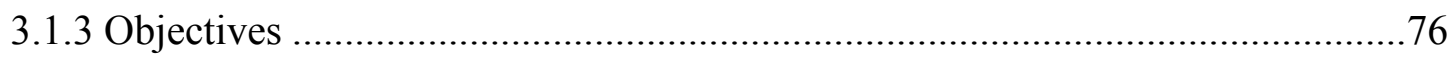

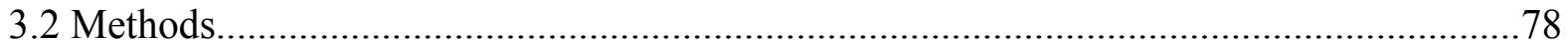

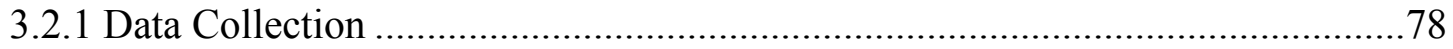

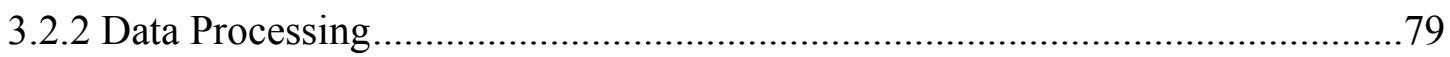

3.2.3 Boundary Layer Depth................................................................................... 81

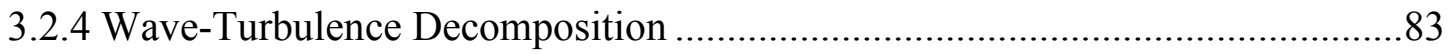

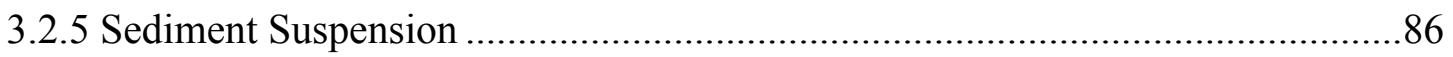

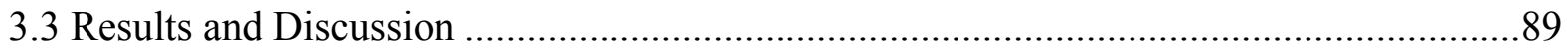

3.3.1 Flow Conditions ..........................................................................................90

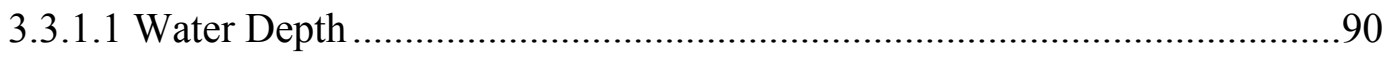

3.3.1.2 Near Bed Current Velocities ....................................................................91

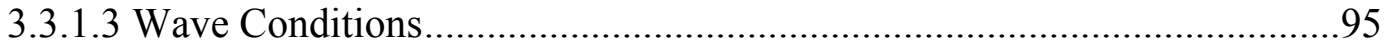

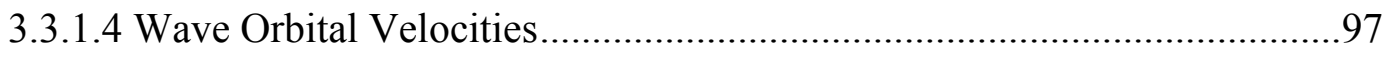

3.3.2 Experimental W-C BL Results ...................................................................103

3.3.3 Theoretical WBL Thickness .......................................................................112

3.3.4 Division of Wave and Turbulent Motion.......................................................115

3.3.5 Turbulent Kinetic Energy …………………………...................................117

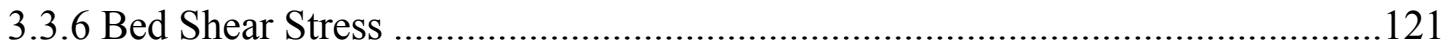

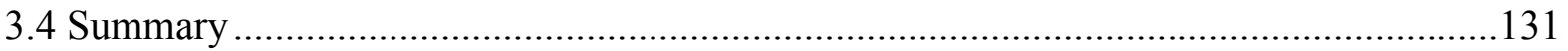


CHAPTER 4: Conclusion

4.1 Summary of Main Findings

134

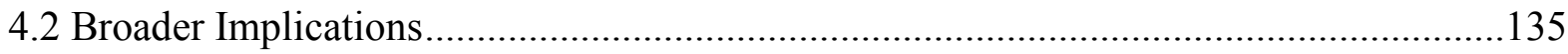

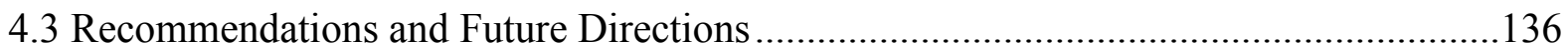

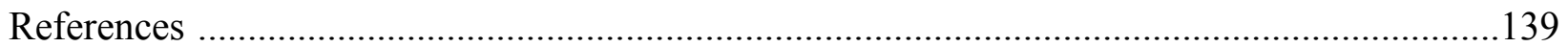




\section{LIST OF TABLES}

Table 2.1: Physical characteristics of Zostera marina meadow in South Bay, Virginia across five sampling periods spanning 15 months

Table 2.2: Percent difference between observed significant wave heights and significant wave heights predicted by the Young and Verhagen (1996) model at each site

Table 2.3: Seasonally averaged wave attenuation coefficients, separated by wind direction 51

Table 2.4: Sediment grain size in South Bay, sampled seasonally over one year at one vegetated and one bare location.......

Table 2.5: Summary of average attenuation statistics calculated using each method. All values for each season were averaged into these values, therefore these are presented only for purposes of general seasonal comparison.

Table 3.1: Wave properties and environmental conditions for each Vectrino II run.

Table 3.2: Summary of flow conditions during each deployment, including the water depth, current velocities, and wave orbital velocities

Table 3.3: Experimental wave-current bounday layer properties, calculated from logarithmic profiles of near bed velocity data.

Table 3.4: Quantifying the wave and depth characteristics of the two profiles compared in Figure 3.16 (July 24, 2012 at 17:00 at the seagrass site and July 26, 2012 at 11:00 at the southern bare site), and comparing the resulting boundary layer characteristics depicted in Figure 3.16 numerically

Table 3.5: Theoretical boundary layer depth, and parameters used in calculation of theoretical depth

Table 3.6: TKE averaged over ten minutes of velocity data across a $3 \mathrm{~cm}$ vertical profile at the start and end of each hourly deployment.

Table 3.7: Comparison of bed shear stresses calculated using the separation of wave and current shear from Wiberg and Smith (1983), the log profile method, and the modified TKE method. 126

Table 3.8: Suspended sediment concentrations recorded at the center seagrass site in South Bay with calibrated OBS sensors 


\section{LIST OF FIGURES}

Figure 1.1: Global seagrass abundance and diversity 1

Figure 1.2: Flattening of wave orbitals with depth in shallow water conditions.

Figure 2.1: Delmarva Peninsula and South Bay 26

Figure 2.2: Site locations superimposed on an aerial photograph modified from Orth et al (2012). 28

Figure 2.3: Fetch lengths for bare and center sites 31

Figure 2.4: Wind speed from the Wachapreague NOAA MET station for each sampling period.

Figure 2.5: Water depth at the bare site and center seagrass site averaged across each sampling period, ranging from 14 to 19 days 39

Figure 2.6: Seasonally averaged flow velocities across each sampling period at $70 \mathrm{~cm}$ above the bed, measured using a Nortek Aquadopp from October 2011 through January 2013.

Figure 2.7: (A) Average significant wave height ( $\pm 1 \mathrm{SE})$ and $(B)$ average significant wave period $( \pm 1 \mathrm{SD})$ for the center vegetated site and nearby bare site, across 8 seasonal deployments

Figure 2.8: Significant wave height at the center vegetated site compared to significant wave height at the nearby bare site over four seasons

Figure 2.9: Wave height comparison between Young and Verhagen model output and measured values at the center seagrass site during April 2013 (top). Time series of percent attenuation between measured and modeled wave height during April 2013 sampling period (bottom) 48

Figure 2.10: Wave frequency versus wave attenuation coefficient $\left(\alpha_{\mathrm{w}}\right)$ for south winds across four seasons...... 54

Figure 2.11: Water depth versus wave attenuation coefficient $\left(\alpha_{\mathrm{w}}\right)$ for south winds across four seasons. 57

Figure 2.12: Significant wave period (s) versus water depth (m) and significant wave height (m) versus water depth (m) for October 2012 data recorded at the Center site 59

Figure 2.13: Significant wave height $\left(H_{s}\right)$ versus wave attenuation coefficient $\left(\alpha_{\mathrm{w}}\right)$ for south winds across four seasons

Figure 2.14: Percentage of fine sediment (silts and clays with diameter $<74 \mu \mathrm{m}$ ) within the seagrass meadow and at a bare site, compared seasonally from April 2012 through January 2013 
Figure 3.1: Flow intensification near the bed as a result of biomass distribution.....

Figure 3.2: Nortek Vectrino II (Acoustic Doppler Profiler) deployed in South Bay..... 78

Figure 3.3: Aquadopp profiler percent correlation data for the July 2012 deployment at the seagrass site, but typical of Aquadopp data from other deployments 81

Figure 3.4: PSD of the horizontal velocity 84

Figure 3.5: Velocity in the direction of mean flow recorded on October 14, 2012 from 12:00 through 13:00 at 5 mm (blue line) and $27 \mathrm{~mm}$ (red line) above the sea floor. Thirty seconds of data from 12:30:00 through 12:30:30, indicated by the black box in the top plot, are magnified in the bottom plot. 92

Figure 3.6: Velocity in the direction of mean flow recorded on July 1, 2013 from 10:30 through 11:30 at $5 \mathrm{~mm}$ (blue line) and $30 \mathrm{~mm}$ (red line) above the sea floor. Thirty seconds of data from 10:45:00 through 10:45:30, indicated by the black box in the top plot, are magnified in the bottom plot.

Figure 3.7: Velocity in the direction of mean flow recorded on July 13, 2012 from 11:00 through 12:00 at $5 \mathrm{~mm}$ (blue line) and $28 \mathrm{~mm}$ (red line) above the sea floor. Thirty seconds of data from 11:45:00 through 11:45:30, indicated by the black box in the top plot, are magnified in the bottom plot.

Figure 3.8: Velocity in the direction of mean flow recorded on July 24, 2012 from 16:10 through 17:10 at $5 \mathrm{~mm}$ (blue line) and $23 \mathrm{~mm}$ (red line) above the sea floor. Thirty seconds of data from 16:45:00 through 16:45:30, indicated by the black box in the top plot, are magnified in the bottom plot.

Figure 3.9: Spectral density across various frequencies for the two deployments at the unvegetated (bare) site on July 1, 2013 and October 14, 2012.

Figure 3.10: Spectral density across various frequencies for the two deployments at the seagrass site on July 13 , 2012 and July 24, 2012 96

Figure 3.11: Orbital velocities $\left(\mathrm{u}_{\mathrm{orb}}\right)$ recorded at the vegetated center site (green) and unvegetated (bare) site (blue) normalized by the root mean squared velocity $\left(\mathrm{u}_{\mathrm{rms}}\right)$ for high wave data. Wave orbital velocities as predicted by linear wave theory and also normalized by $\mathrm{u}_{\mathrm{rms}}$ are graphed as solid lines. .99

Figure 3.12: Orbital velocities $\left(\mathrm{u}_{\mathrm{orb}}\right)$ recorded at the seagrass site (green) and bare site (blue) normalized by the root mean squared velocity $\left(\mathrm{u}_{\mathrm{rms}}\right)$ for low wave conditions. Wave orbital velocities as predicted by linear wave theory are graphed as solid lines. 100 
Figure 3.13: Theoretical wave orbital velocity profiles expanded to include the depth of the water column during each deployment 101

Figure 3.14: Logarithmic velocity profile for high wave conditions on July 1, 2013 at 10:30 (left) and July 24,2012 at 16:10 (right) 104

Figure 3.15: Logarithmic velocity profiles for low wave conditions on October 14, 2012 at 12:00 (left) and July 13, 2012 at 11:00 (right). 105

Figure 3.16: Average flow velocity on July 13, 2012 at 11:00 (blue dots) and 11:50 (green dots). Data included in calculation of shear velocity $\left(u^{*}\right)$ for each time period are marked by solid grey dots 106

Figure 3.17: Comparison of maximum near bed velocity profiles for data collected on July 24, 2012 at 17:00 at the seagrass site, and on July 26, 2012 at 11:00 at the southern bare site.

Figure 3.18: July 24, 2012 17:00 - Extrapolation of W-C BL log profile compared with velocity data recorded by the Aquadopp current profiler

Figure 3.19: Ten minute average shear stresses for July 1, 2013 from 10:30 to 10:40 at the bare site (left), and July 24, 2012 from 16:10 to 16:20 at the seagrass site (right).

Figure 3.20: October 14, 2012, ten minute average stresses recorded at the bare site from 12:00 to 12:10 (left), and July 13, 2012 at the seagrass site from 11:00 to 11:10 (right)..... 117

Figure 3.21: TKE profiles normalized by flow velocity at the top point of the Vectrino II profile, averaged over 10 minutes from 10:30 to 10:40 on July 1, 2013 at the bare site (blue dots) and from 16:10 to 16:20 on July 24, 2012 at the vegetated site (green dots), both for high wave conditions 119

Figure 3.22: TKE profiles normalized by flow velocity at the top point of the Vectrino II profile, averaged over 10 minutes from 12:00 to 12:10 on October 14, 2012 (blue dots) and from 11:00 to 11:10 on July 13, 2012 at the vegetated site (green dots), both for low wave conditions. 120

Figure 3.23: Bed shear stress (colorbar $-\mathrm{N} / \mathrm{m}^{2}$ ) calculated using vertical turbulent fluctuations (w') at different depths in the water column on July 1,2013 at 10:30 at the bare site 123

Figure 3.24: Bed shear stress distribution calculated using vertical turbulence fluctuations (w') at 16:10 on July 24, 2012 at the seagrass site

Figure 3.25: Significant wave height $\left(\mathrm{H}_{\mathrm{s}}\right)$, total suspended solids (TSS), and bed shear calculated using the combined method for the high wave case at the seagrass site on July 24, 2012 128 
Figure 3.26: Average suspended sediment concentrations displayed for each season within the South Bay seagrass meadow 


\section{ACKNOWLEDGEMENTS}

I would first like to thank my advisor, Matt Reidenbach, for his guidance and feedback throughout this project. My committee members, Patricia Wiberg and Linda Blum, provided helpful advice and insight, ensuring I was technically accurate and reminding me to relate my work to broader applications. This research would not be possible without the staff at the Anhauser-Busch Coastal Research Center (ABCRC), so many thanks to David Boyd, Brooke

Rodgers, Chris Buck, Donna Fauber, and Art Schwarzschild. I appreciate the time David, Brooke, and Art were willing to take to teach me the tricks of marine fieldwork, and their willingness to work boat trips in less than ideal conditions for the benefit of my data. I am indebted to Alia Al-Haj for sharing her wealth of knowledge of the policies of the ABCRC, and to Ross Timmerman for his invaluable assistance with my fieldwork. My officemates, Jon Stocking and Swapnil Pravin, were a huge help for my data analysis; I am especially grateful that Jon was willing to share code and coding advice. Thank you to Ross, Jon, and Swapnil for making time in the lab and field more enjoyable.

I am ever aware of the advice and support that has shaped my academic goals, so this would seem incomplete without acknowledging Steve Wright for his help, advice on graduate school, and continued correspondence. Also, in memory of Jerry Keeler, who encouraged my interest in research as a freshman undergraduate. Thank you also to Tim Dvonch and Emily White for their mentorship during my time at the UMAQL.

Finally, I would like to thank my friends and my family for their continued love and support through everything. I am truly blessed to be surrounded by such inspirational people.

This research was supported by funds from the Virginia Coast Reserve Long Term Ecological Research site and the University of Virginia. 


\section{CHAPTER 1: Introduction}

Seagrasses are distributed worldwide in coastal waters up to 70 meters deep, resulting in a potential habitat of $5-10$ million $\mathrm{km}^{2}$. Of this area, approximately $10 \%$, or $500,000-$ $1,000,000 \mathrm{~km}^{2}$, is inhabited by one or several of the 60 known seagrass species (Spalding et al. 2001, Figure 1.1). Seagrasses have both biological and physical effects on their local environment; providing habitat and protection to other marine species, retaining nutrients for greater ecosystem productivity, trapping and stabilizing sediment, and modifying local and meadow scale hydrodynamics. Seagrass meadows may also be a globally significant blue carbon sink, trapping organic carbon in underlying soils on an order of magnitude similar to that of terrestrial forests and providing a noteworthy contribution to mitigating climate change (Fourqurean et al. 2012).

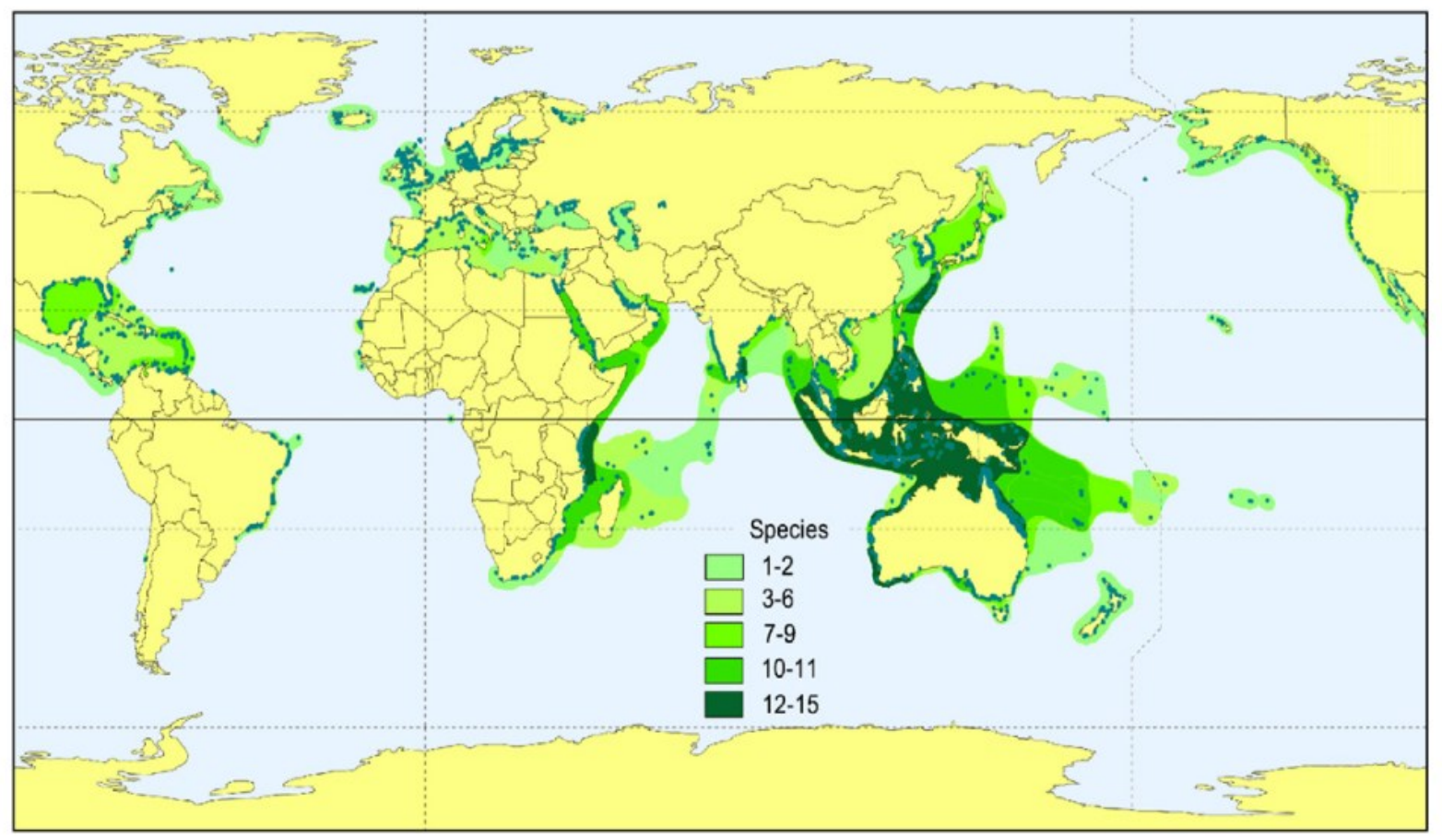

Figure 1.1: Global seagrass abundance and diversity. Shading indicates the number of species reported in an area; points indicate documented reports of seagrass occurrence (from Short et al. 2007). 
One reason seagrasses do not grow to their full depth potential is water clarity. Seagrasses are typically light limited, so their range is restricted by both the depth and clarity of the water column. In shallow coastal bays with low riverine discharge, sediment suspension is the primary factor influencing light attenuation (Lawson 2007). Seagrasses reduce suspension of sediment due to the stabilizing effect of root structure and flow modification caused by the plant structure (Gacia and Duarte 2001), creating a positive feedback loop that increases the light available at the sea floor and promotes primary productivity (Carr et al. 2010). Conversely, high turbidity can collapse a seagrass meadow ecosystem, causing hysteresis to an alternative stable state of bare sediment and macroalgae (van derHeide 2007).

Flow conditions near the ocean floor have the greatest implication for sediment suspension. Sediment grains are mobilized when the bed shear stress acting on a grain surpasses the critical shear stress necessary to initiate the grain's motion. Shear stress is a tangential force imparted to the sea floor by motions in the overlying water. While unidirectional flow may exert shear stress over an extended time, the short impulse of wave orbital motion creates greater instantaneous shear and is the primary mechanism of sediment suspension in many coastal systems (Grant and Madsen 1979). Once a grain is in suspension, it will not return to the bed until a lower shear stress is attained. This is especially relevant for clays, as cohesion between grains greatly increases the critical shear stress necessary to suspend these particles, but water must be nearly stagnant for them to settle as single grains. Other organic substances such as extracellular polysaccharide (EPS) excreted by macroalgae may mimic this resistance to suspension for larger grain sizes (Widdows et al. 2008). As a result, the turbidity of a single suspension event may linger in the water column or be advected to a nearby location before the particles settle, and can have a prolonged effect on water clarity. 
A region of flow that is highly affected by the presence of a boundary is referred to as a boundary layer. Boundary layers are a result of the no-slip condition in fluids; molecules adjacent to a boundary must be moving at the same velocity as the boundary. This condition necessitates a velocity gradient perpendicular to any surface which will start with zero velocity at a stationary boundary and will approach the free stream velocity $\left(u_{0}\right)$, so boundary layers are often defined as the region up to $0.99 u_{0}$ (Koch 2006). Boundary layers also form around any object impeding flow, including the seagrass canopy, individual seagrass blades, and the sea floor; however fluid dynamics within the near bed boundary layer control the shear stress felt by the sediment, so bottom boundary layer flow will be the focus of this thesis.

Coastal waters experience complex hydrodynamics due to the interaction of boundary layers at the sea floor created by both current motion and wave motion. Frictional drag due to bottom roughness slows currents, affecting a greater percent of the water column at shallow depths. Wave orbital motion impacts the sediment when the water depth is less than half a wavelength, whereas this motion is attenuated in a deeper water column before it interacts with the sea floor. As a result of these effects, the bottom boundary layer in shallow coastal waters is a combination of a thin wave boundary layer superimposed over a well-developed current boundary layer that may be orders of magnitude thicker. Wave boundary layers form and decay over the course of a wave period and as a result grow only millimeters to centimeters in thickness, however this flow is important to consider as it interacts directly with the ocean floor and controls sediment suspension. Seagrass meadows often exist within the same near shore regions that experience combined wave-current flow, and will influence the hydrodynamics of near bed flow where they are present. Understanding flow within a combined wave-current boundary layer is critical to estimating bed shear stress, which in turn influences sediment 
suspension, light attenuation, seagrass productivity, and ultimately the ecosystem services provided by a healthy seagrass meadow.

\subsection{Fluid Motion}

Fluid motion $(u)$ in shallow coastal environments is a combination of mean flow due to a current or tide $(\bar{u})$, oscillatory flow due to wave motion $(\tilde{u})$, and small turbulent fluctuations in the flow created by eddy dissipation $\left(u^{\prime}\right)$, or:

$$
u=\bar{u}+\tilde{u}+u^{\prime}
$$

Turbulent movements are often masked by larger amplitude variations caused by waves (Trowbridge 1998), so partitioning the relative velocity contributions of currents, waves, and turbulence is necessary to accurately quantify turbulent mixing and the bed shear stresses that initiate sediment motion. Techniques to separate these components, such as wave turbulence decomposition via the Phase method (Bricker and Monismith 2007), are discussed in Chapter 3.

\subsection{Wave Dynamics}

Waves are defined by several parameters, including wavelength $(\lambda)$, wave height $(H)$, and wave period $(T)$. The wavelength is defined as the horizontal distance between two consecutive wave crests or troughs, wave height is the vertical distance between the crest and trough, and wave period is the time required for a wave to travel one wavelength. Wave frequency $(f)$ is defined as $1 / T$ and represents the number of oscillations at a given point per unit time.

Monochromatic waves that contain only one wave-length, -height, and -period, such as those created by a wave generator in a flume, rarely exist in nature. Instead, natural waves 
consist of oscillations of many frequencies superimposed to form the observed motions, so averaging is necessary to describe wave characteristics. Significant wave height $\left(H_{s}\right)$, the mean of the largest $1 / 3$ of wave heights over a defined time interval, is a commonly used metric to describe wave amplitude. Similarly, significant wave period $\left(T_{s}\right)$ is often used in place of $T$, and calculated as the mean of the largest $1 / 3$ of wave periods. These skewed statistics are useful because they represent larger, more influential waves, whereas actual mean values may be artificially lowered from small capillary waves that are largely inconsequential.

Wave motion for small amplitude waves is described through linear wave theory as a sinusoidal oscillation of a free surface, such that the displacement of the surface follows the relationship:

$$
\eta(x, t)=a \cos (k x-\omega t)
$$

where $a=\frac{H}{2}$ is the wave amplitude, $k=\frac{2 \pi}{\lambda}$ is the wavenumber, and $\omega$ is the wave frequency in radians. As waves oscillate, individual fluid particles within the wave move in a circular orbit, described below in horizontal $(u)$ and vertical $(w)$ velocity components:

$$
\begin{aligned}
& u=a \omega \frac{\cosh k(z+d)}{\sinh k d} \cos (k x-\omega t) \\
& w=a \omega \frac{\sinh k(z+d)}{\sinh k d} \sin (k x-\omega t)
\end{aligned}
$$

where $d$ is the mean water depth (Kundu and Cohen 2008). Orbital motion propagates downward into the water column and is attenuated with depth. Orbits are circular in deep water when wave energy is dissipated prior to interaction with the bed, but are compressed into ellipses in shallower conditions. As these ellipses approach the bed they become more oblong until they 
are flattened into a back and forth motion at the sea floor (Figure 1.2). By interacting with the bed, these flattened orbital motions create the wave boundary layer.

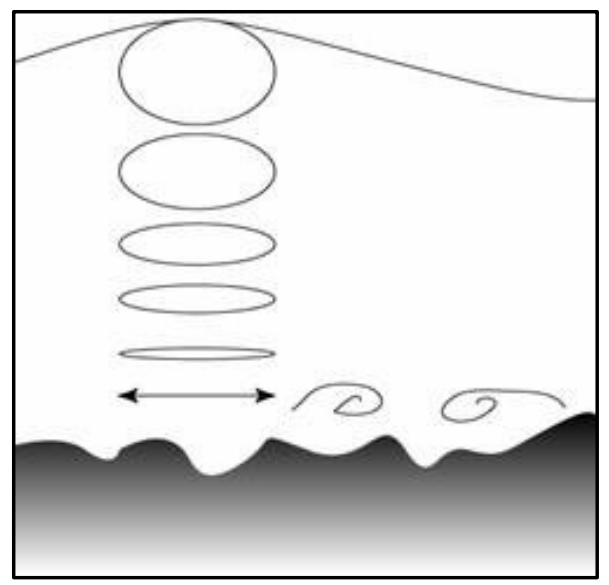

Figure 1.2: Flattening of wave orbitals with depth in shallow water conditions. (www.soest.hawaii.edu)

\subsection{Combined Wave-Current Boundary Layer}

Velocities in steady, uniform, turbulent boundary layers are theoretically governed in the constant stress layer by the von Karman-Prandtl law of the wall:

$$
\bar{u}(z)=\frac{u_{*}}{\kappa} \ln \frac{z}{z_{0}}
$$

where $u_{*}$ is the friction velocity, $\kappa$ is von Karman's constant (typically assumed to be 0.41 ), $z$ is the distance above the bed, and $z_{0}$ is the roughness height. For unidirectional flow, the boundary layer can extend upwards into the water column on the order of meters, however oscillatory flows will have much thinner boundary layers on the order of millimeters to a few centimeters. Near the bed in shallow coastal environments, current and wave boundary layers interact in a 
nonlinear fashion to form the velocity, turbulence, and stress climate controlling the fate of sediment and mass transport from the bed to the overlying flow.

Using the law of the wall (Equation 1.4), Grant and Madsen (1979) predict logarithmic mean flow layers within the wave boundary layer (WBL) and within the overlying current boundary layer $(\mathrm{CBL})$. Equations for mean velocity in each of these layers are:

$$
\begin{gathered}
\left|u_{c}\right|=\frac{\left|u_{c}^{*}\right|}{\kappa}\left(\frac{\left|u_{c}^{*}\right|}{\left|u_{c w}^{*}\right|}\right) \ln \frac{30 z}{k_{b}}, \quad z<\delta_{w} \\
\left|u_{c}\right|=\frac{\left|u_{c}^{*}\right|}{\kappa} \ln \frac{30 z}{k_{b c}}, \quad z>\delta_{w}
\end{gathered}
$$

where $u_{c}{ }_{c}$ is the shear velocity associated with the above current flow, $u_{c w}{ }_{c w}$ is the shear velocity associated with combined wave-current flow in the lower layer, $k_{b}$ is the bed roughness, $k_{b c}$ is an apparent roughness due to the bed roughness and the WBL, and $\delta_{w}$ is the thickness of the wave boundary layer. Oscillatory boundary layers may deviate slightly from the ideal logarithmic profile because the instantaneous turbulence production and dissipation terms are not the same, especially for small wave periods (Fredsoe and Deigaard 1992).

From Equations 1.6 and 1.7, velocities within the combined wave-current boundary layer will be lower than velocities in the overlying flow. The combined layer shear velocity, $u_{c w}^{*}$, is larger than the current shear velocity, $u_{c}^{*}$, because the wave-current boundary layer is much thinner than the CBL however experiences velocity of a similar magnitude, therefore the shear in the thinner layer must be greater due to the sharper velocity gradient. As a result, the $\frac{\left|u_{c}^{*}\right|}{\left|u_{c w}^{*}\right|}$ term in Equation 1.6 will be less than 1, and WBL velocities will be reduced compared to CBL velocities. This also makes intuitive sense if we consider that wave orbital motion is dominating in the WBL, and will induce flow opposite the main current during a portion of each wave 
period. The velocity differential between these two layers necessitates an inflection point in the mean velocity profile at the WBL-CBL interface (Hackett 2011).

Equation 1.7 reflects the influence of the WBL on the overlying flow. The roughness parameter for the WBL velocity equation, $k_{b}$, is the physical bed roughness, however in the CBL velocity equation $k_{b c}$ represents the apparent roughness. The structure of the WBL creates an additional roughness that is felt by the CBL in addition to the physical bed roughness, so the $k_{b c}$ term will always be greater than the $k_{b}$ term, and the roughness experienced by the overlying flow will be enhanced by the presence of the wave boundary layer.

\subsection{Shear Stress and Sediment Suspension}

Sediment suspension is controlled by the stresses exerted on particles at the sea floor. Shear stress in fluids is created by the no slip condition; by creating a velocity gradient, flow moving at a velocity different than an adjoining layer will create a shearing force at the interface between the layers that causes rotation of the fluid. The stress exerted on adjacent fluid layers due to this velocity gradient in laminar flow is described in Newton's law of shear:

$$
\tau_{z x}=\mu \frac{\partial u}{\partial z}
$$

where $\mu$ is the dynamic viscosity of the fluid, $u$ is the velocity parallel to the surface, and $z$ is the distance above the surface. Shear stress experienced at the bed $\left(\tau_{b}\right)$ can be determined as $z$ approaches zero. More generally, for turbulent conditions, bed shear can be approximated as:

$$
\tau_{b}=\rho u_{*}^{2}
$$

where $\rho$ is the fluid density. 
Estimates of the shear velocity $\left(u_{*}\right)$ can be determined from the logarithmic boundary layer profile described in Equation 1.5 (Fonseca and Fisher 1986; Gambi et al. 1990; Kim et al. 2000). Combined wave-current flows have shear stress contributions from both the wave and current components of the flow, such that the total bed shear stress is calculated as follows:

$$
\tau_{b}=\sqrt{\tau_{\text {wave }}^{2}+\tau_{\text {current }}^{2}}
$$

where $\tau_{\text {wave }}$ and $\tau_{\text {currrent }}$ represent the component of bed shear due to wave and current motion respectively.

Sediment suspension occurs when the total bed shear stress acting on a particle exceeds the critical shear stress necessary to initiate the particle's motion, $\tau_{b}>\tau_{\text {critical }}$. Bed shear $\left(\tau_{b}\right)$ is a result of the fluid forces acting on a particle as described above, however a number of confounding factors can influence the critical shear stress necessary for sediment movement. Treated mechanically, the gravitational force of the particle's weight resists any lift force that may cause suspension. However, particles in natural systems are not always independent of surrounding particles, so particle shape, cohesion through charge or organic substances, sediment compaction, and local bedforms can modify the shear stress necessary for suspension. Particles may also aggregate to form flocs, groups of particles that through physical or chemical means act collectively as a larger particle, which typically occur while particles are suspended in the water column and result in higher settling velocities. Due to these complications, critical shear stress defined from established relationships for non-cohesive sediment may not be an accurate representation of the stress necessary to initiate suspension in natural environments. 


\subsection{Research Questions}

Processes over a range of spatial scales affect sediment suspension, starting from the small scale mechanics of wave-current interaction at the sea floor in boundary layers on the order of millimeters to wave development and attenuation across fetch lengths of kilometers. Seagrass can modify hydrodynamics at each of these scales, from turbulence generated by individual shoot wakes to wave attenuation by the meadow as a whole. Large scale modification of wave climate can influence the conditions experienced locally at any point within the meadow, just as the amalgamation of local effects creates large scale trends, so these diverse spatial scales are fundamentally intertwined. This thesis addresses two specific spatial scales through the following questions:

(1) How does seagrass modify current and wave characteristics as flow moves through a meadow, and how much are waves attenuated under various current-wave combinations?

Seagrass beds have been shown to attenuate both wave energy (Fonseca and Cahalan 1992; Granata et al. 2001) and current velocity (Fonseca and Fisher 1986; Gambi et al. 1990; Koch and Gust 1999; Lacy and Wylie-Echeverria 2011), impacting the flow structure both above and within the canopy. In addition to the reduction of in-canopy current velocity and wave orbital velocity, the canopy has been shown to selectively attenuate high frequency motions, while lower frequency motions were able to penetrate to the sea floor (Hansen and Reidenbach 2012). Wave dissipation has been shown to be correlated to the percent of the water column occupied by seagrass (Fonseca and Fisher 1986), likely related to the dissipation of wave orbital 
motion at depths greater than half the wavelength of the surface waves (Wiberg and Sherwood 2008). Seagrass also influences flow structure above the canopy by inducing drag on the mean current. Drag coefficients have been approximated for many varieties of aquatic vegetation through field studies and numeric modeling (Nepf 1999; Bradley and Houser 2009; Maza 2013), but fewer measurements have been done in situ under combined wave-current flows.

Wave height was recorded at sites across a seagrass meadow and at a reference unvegetated (bare) site to compare wave attenuation and calculate a wave attenuation factor for flow moving across moderately dense seagrass. Bed density, wind speed, fetch length, and water depth are likely to be among the controls over wave height reduction, and were also recorded.

(2) How does seagrass alter near bed flow and the wave-current boundary layer compared to wave-current boundary layer development at an unvegetated (bare) site?

While larger scale wave and current conditions create the boundary layer, near bed flows fundamentally control sediment suspension processes. Wave-current boundary layer flow over smooth and rough surfaces has been modeled theoretically (Grant and Madsen 1979; Sleath 1987; Wiberg 1995; Holmedal et al. 2003), measured in laboratory studies (Hay et al. 2012a; Hay et al. 2012b), and been recorded in situ (Hackett 2011), so a general understanding of flow structure and characteristics is present. Characteristics of flow near the boundary within beds of aquatic vegetation are less well understood, and while several models (Lowe et al. 2005) and flume studies (Nepf et al. 1997; Nepf 1999) have begun to address these questions, in situ measurements are largely lacking in the current literature. 
Model results suggest that submerged canopies experience higher in-canopy velocities under oscillatory flows compared to unidirectional currents (Lowe et al. 2005). In emergent vegetation modeled as rigid cylinders, Nepf el al. (1997) shows a modification of the dominant turbulent length scale, shifting to a smaller eddy scale, likely due to stems breaking apart larger eddies. Sparse vegetation densities create turbulence through stem-wake interaction (Nepf 1999), which may modify or obscure the boundary layer structure. However, while these models provide some insight, they consider aquatic vegetation as an array of rigid cylinders. Unlike rigid vegetation, seagrass can provide a shielding effect as blades bend with the dominant current, decreasing in-canopy velocities and turbulence intensities (Gambi et al. 1990; Koch and Gust 1999). This may have a dramatic effect on near bed conditions. Boundary layer dynamics are critical to understanding the mechanics of sediment suspension within seagrass meadows, which control light availability and subsequently the continued survival of the meadow.

To address these gaps in the literature, combined wave-current boundary layers in shallow flow were observed in situ to determine the effect of seagrass on boundary layer structure and turbulence. Detailed velocity profiles were collected directly above the sediment within a seagrass meadow and at an unvegetated (bare) site, allowing direct quantification and comparison of fluid motion within the combined boundary layer at these two locations.

Experiments were conducted in the Virginia Coast Reserve Long Term Ecological Research (VCR LTER) site within a shallow Virginia coastal bay. South Bay was chosen as our study site due to the abundance of data previously collected within the bay describing the bathymetry (Fagherazzi and Wiberg 2009), seagrass expansion (Orth 2012), and hydrologic conditions (Hansen and Reidenbach 2012, Hansen and Reidenbach 2013). An extensive seagrass 
meadow within the bay provided adequate vegetated area to conduct a large scale wave attenuation study, and nearby unvegetated regions provided comparison between vegetated and unvegetated near bed flow conditions.

Chapter 2 addresses the first question of meadow scale modification of flow characteristics, and presents controls on wave dissipation within a seagrass meadow. From these meadow scale measurements, Chapter 3 focuses down in scale to investigate wave-current boundary layer interactions within a seagrass bed. Chapter 4 relates the two chapters and provides conclusions regarding the impact of seagrasses on hydrodynamics and sediment suspension within shallow coastal bays. The goal of this thesis is to relate large scale modification of flow characteristics by a seagrass meadow to the fine scale processes that control sediment suspension within the wave-current boundary layer to understand the impact of seagrass on flow and sediment dynamics. 


\section{CHAPTER 2:}

\section{Meadow Scale Wave Processes}

To determine the effects of benthic vegetation on wave attenuation, wave heights were measured seasonally at three sites, each spaced $1 \mathrm{~km}$ apart, within a Zostera marina seagrass meadow and at one bare site adjacent to the meadow located in a shallow coastal bay (mean water depth 1.2 meters). Results show a reduction in wave height at the vegetated site, with wave heights within the seagrass meadow reduced by $25-49 \%$ compared to an adjacent bare site, and $-19-64 \%$ compared to a bare model of the same area, with the lowest values occurring in the winter and the highest reduction occurring in the summer. Average wave attenuation coefficients (calculated from10 minute averaged wave heights) were determined seasonally and ranged from 0.19 to 0.59 for the South Bay Z. marina meadow, with highest attenuation occurring during the spring. Across seasons, wave attenuation was highest for longer period waves, higher significant wave height, and greater water depths. This suggests that higher, longer period waves interact with the canopy more than small high frequency waves, and that larger waves were able to develop in deeper water conditions. Sediment grain size was monitored seasonally at a bare site and within the meadow, but was statistically the same across sites and seasons. 


\subsection{Introduction}

Wave motion often exerts greater shear stress on bottom sediment than current flow in shallow waters (Grant and Madsen 1979) and is a dominant driver of sediment suspension in these regions (Lawson 2007). Smaller wave heights are associated with a more stable sediment environment, promoting deposition rather than suspension (Hansen and Reidenbach 2012). It is therefore of interest to determine the degree to which the presence of seagrass modifies the wave conditions experienced within a seagrass meadow, thereby elucidating the effect of seagrass on sediment mobilization both within the meadow and in areas that could be sheltered from extreme wave motions by the meadow.

As described previously in Chapter 1, sediment suspension in the water column directly affects the light available for seagrass growth and relates to the overall productivity of the meadow. Additionally, the reduction of wave height by seagrass can also reduce marsh edge erosion (McGlathery et al. 2013). The total wave energy impacting the edge of a marsh, which is also affected by depth variation, is the primary driver of lateral marsh erosion (Mariotti et al. 2010). Therefore, reductions in wave height that occur within a seagrass bed also have implications for the rate at which tidal marshes or other soft-bottom shorelines erode. This chapter will assess the magnitude of wave height reduction derived from a moderately dense temperate seagrass meadow in the Virginia Coast Reserve Long Term Environmental Research site (VCR LTER, Section 2.1), and will explore and quantify the amount of drag the meadow imparts on the overlying flow. Sediment grain size will also be analyzed to investigate seasonal erosion of different grain sizes based on seagrass meadow density. Once wave attenuation 
parameters have been established, Chapter 3 will address the driving mechanisms that relate wave height to sediment erosion in greater detail.

\subsubsection{Wave Attenuation}

Wave attenuation by benthic aquatic vegetation has been previously addressed in the literature, however the degree to which wave height and energy is reduced by seagrass, and how this changes seasonally in a mid-latitude environment, is not yet fully understood. In a field study in a northwest Florida bay, Bradley and Houser (2009) measured changes in wave height across a seagrass meadow using a linear array of pressure sensors. Wave height decayed at an exponential rate once within the meadow, with a total decrease of $30 \%$ across the $39 \mathrm{~m}$ transect, or $0.77 \%$ per $\mathrm{m}$ if approximated as a linear decay. Dissipation was not uniform across all frequencies of wave motion; seagrasses acted as a low-pass filter for wave attenuation by selectively removing high frequency motions due to the slower oscillations of the seagrass blades. Seagrasses were observed to sway with wave oscillations, however Bradley and Houser (2009) noted that at higher velocities, vegetation may become more rigid and extend in the dominant flow direction, becoming less effective at attenuating wave energy. Previous work by Lowe et al. (2007) suggested that shorter period waves which penetrate the canopy more readily than longer period waves may also be selectively attenuated. In addition, Lowe et al. (2007) concluded that the rate of wave energy dissipation was governed by flow structure within the canopy, thereby connecting large scale attenuation to small-scale in-canopy flows. Further analysis of changes in attenuation across different wave frequencies is necessary to better understand the near bed dynamics which control sediment resuspension in shallow coastal bays.

Earlier work in wave attenuation focused on flume studies due to the complications of in situ measurements. Fonseca and Cahalan (1992) compared attenuation of wave energy by four 
different seagrass species including Zostera marina over a $1 \mathrm{~m}$ section in a flume, and found an average wave energy reduction of $40 \%$ per meter of seagrass when the blade length was approximately equal to the water depth. The relation between leaf length and water depth was found to be the most important parameter for all four species studied. As depth increased beyond the canopy height the seagrass was not as effective in attenuating wave height, even at depths less than half a wavelength, where orbital wave motion theoretically interacts with both the canopy and the bed. Similarly, Fonseca and Fisher (1986) found that canopy friction, and hence wave dissipation, was strongly correlated to the percent of the water column occupied by seagrass. In a more recent flume study, Paul et. al (2012) determined that seagrasses are less effective at attenuating wave energy in combined wave-current environments compared to environments with waves alone. Leaf Area Index (LAI), the product of blade length, blade width, and meadow density, was found to be the dominant factor controlling wave attenuation. Paul et al. (2012) suggest that the reduction in attenuation in wave-current environments is a combination of decreased frontal area as seagrass blades are flattened by the current and a reduction in the amount of wave energy transferred to blade motion as individual blade are prevented from swaying with wave orbital motion in the presence of a strong current. Overall, these studies suggest that wave attenuation is a function of water depth, current conditions, wave conditions, vegetation characteristics, and bed density.

\subsubsection{Attenuation Coefficients}

Much of the work in understanding the effect of seagrass on the larger coastal environment is achieved through numerical models. Aquatic vegetation is often approximated in these models as an increase in bottom friction, collapsing the three dimensional effects of form 
drag into a one dimensional representative drag coefficient that can be easily applied to a large aerial extent. In complex flow environments with both currents and waves, aquatic vegetation causes reductions in both the mean current and wave energy. These are separate drag processes that necessitate multiple independent attenuation coefficients.

Drag is fundamentally a process of removing energy from a flow. Form drag reduces momentum in a current dominated flow from the creation of turbulent wakes, and the dissipation of energy within these wakes. The bulk drag coefficient $\left(\mathrm{C}_{\mathrm{D}}\right)$ describes the resistance of an object to mean flow, with higher values of $C_{D}$ indicating that the object creates more resistance (or drag) than lower values of $\mathrm{C}_{\mathrm{D}}$. This drag coefficient can be calculated in pure current environments as well as in environments with waves and currents, however is defined as a measure of momentum attenuation, and is not a measure of wave height reduction. Energy can also be removed from the oscillatory component of flows by aquatic vegetation, leading to a reduction in wave height. The wave attenuation coefficient $\left(\alpha_{\mathrm{w}}\right)$ describes the reduction of wave energy due to vegetative drag, again with higher values indicating a greater reduction in energy. This energy may be transferred to cause the oscillation of aquatic plants or dissipated due to turbulence.

$\mathrm{C}_{\mathrm{D}}$ can be approximated using the geometric properties of the vegetation, employing a deeper understanding of the physical mechanisms which control stem-wake interaction and the generation of turbulence. Dalrymple (1984) developed a model for predicting wave dissipation by approximating a bed of vegetation as an array of rigid vertical cylinders. This model first assumed drag was only dependent on vegetation characteristics and not wave conditions, and was later updated by Mendez and Losada (2004). Additional rigid vegetation models have been developed by both Nepf (1999) and Kobayashi (1993). While both use analytical approaches 
that include the physical properties of vegetation, Kobayashi-type models were developed to predict flow around individual shoots for use in wavy conditions, while Nepf-type models were developed for situations with steady currents (Nepf 1999; Chen et al. 2007). It is mentioned in many of these rigid vegetation models that the physical motion of flexible vegetation will cause deviation from the model predictions. Free-end effects describe any motion of the submerged ends of the vegetation not accounted for in a rigid model such as undulations caused by passing waves or deformation due to currents. Nepf (2004) specifically noted that in submerged canopies, free-end effects decreased the value of $C_{D}$ further from calculations derived from a rigid cylinder approximation.

The wave attenuation coefficient, $\alpha_{\mathrm{w}}$, is calculated using the change in significant wave height measured at two locations along the direction of wave propagation using empirical relationships. This method was first explored by Bretschneider and Reed (1954) and revised by Bretschneider (1957) for wind waves in shallow water with impermeable sediment. Recently this method has been utilized in studies of wave attenuation by mangroves (Mazda et al. 1997; Quartel et al. 2007). Lowe et al. (2007) also calculated a $\alpha_{\mathrm{w}}$ parameter comparing wave velocity spectra above and within a canopy. Using a similar method, Paul and Amos (2011) determined wave attenuation $\left(\alpha_{\mathrm{w}}\right)$ by comparing differences in wave spectra horizontally across a meadow. These methods are different in that the Bretschneider and Reed (1954) approach only considers energy dissipation across the mean of the highest $1 / 3$ of the waves (the significant wave height), whereas Lowe (2007) calculates the total energy dissipation across the entire wave spectra. However, energy loss in the largest, most influential waves is most relevant to coastal erosion, so although only calculating energy loss at the significant wave frequency is a less complete 
measurement of attenuation, it may be a more practical metric to understand marsh edge and shoreline erosion.

\subsubsection{Sediment Dynamics}

Sediment advection in shallow coastal bays is controlled by wave and tidal motions within the water layer adjacent to the ocean floor, which exert shear stress on the bottom sediment. While tidal currents are important for sediment transport, the bed shear stresses generated by wave motions typically exceed those generated by tidal motions by an order of magnitude (Grant and Madsen 1979). Fagherazzi and Wiberg (2009) described additional factors that control suspension events such as the influence of basin morphology, tidal elevation, and wind direction on water depth and fetch. As a result, wave development and water depth interact to cause changes in bed shear stress during different phases of the tidal cycle. Below mean lowest low water (MLLW), increasing water depth was shown to counterbalance increasing fetch and no changes in bed shear occurred. Between MLLW and mean sea level (MSL), changes in depth outpaced the ability of waves to develop and resulted in lower bed shear. However, an increase in fetch caused by the flooding of near shore marshes when water levels rose above MSL led to larger waves and greater bottom shear stress during storms. Suspension events should therefore be a function of both wave climate and water depth, and would be expected when depths are adequately shallow for wave motion to interact with the sea floor.

Seagrass beds have been shown to attenuate both wave energy (Bradley and Houser 2009; Fonseca and Cahalan 1992) and current velocity (Lacy and Wylie-Echeverria 2011), reducing the bed shear stress experienced under the canopy and the potential for any suspended 
particles to advect (Fonseca and Fisher 1986; Hansen and Reidenbach 2012). Granata et al. (2001) observed a reduction in wave orbital velocity and near bed turbulence coupled with a decrease in suspended sediment at sites within a seagrass meadow compared to bare sites. Fine particles in the water column decreased with increasing meadow bed density during calm conditions and a storm event. Suspended sediment is the primary cause of light attenuation in shallow bays, at least for bays not prone to phytoplankton blooms (Lawson 2007), so the stabilization of sediment by seagrass creates a positive feedback loop for seagrass growth by increasing sedimentation and therefore reducing turbidity within these shallow subtidal areas (de Boer 2007).

Few studies have considered grain size fluctuations across a gradient of seagrass densities. Williams (1990) measured sediment grain size at sites vegetated with a mix of seagrass species and several nearby sites that were stripped of all vegetation for two years in the US Virgin Islands and found no difference in grain size between the bare and vegetated sites. Gacia et al (1999) found no pattern of increased particle trapping as a function of meadow density, biomass, or blade height at one study location; however, at a more sheltered site with no observable resuspension, seagrass increased particle deposition with increasing meadow structure. This suggests that seagrass has an observable effect on deposition rates primarily at low suspended sediment concentrations and in absence of strong hydrologic forcings.

\subsubsection{Previous work in South Bay}

Hansen and Reidenbach (2012) compared flow between vegetated sites of varying density at points above and below the seagrass canopy to assess the effect of seagrass on sediment suspension within South Bay. Using two collocated Nortek Vectors to record point 
velocity measurements at different depths, the seagrass canopy was determined to reduce flow velocity, turbulence, and wave orbital velocity compared to above canopy measurements. Higher density beds had lower within-bed turbulence, however this did not correlate with lower suspended sediment concentrations. Attenuation of significant wave height was also observed between a bare site and the vegetated sites, although a pattern of greater attenuation with greater seagrass density did not emerge. Hansen and Reidenbach (2013) continued this work with a seasonal comparison of hydrodynamics between a bare and vegetated site, and found that wave heights were attenuated at the vegetated site in all seasons; however, wave orbital motions were still able to penetrate through the canopy and induce bottom shear stress. Overall, the shear stress experienced in the meadow surpassed the critical shear necessary for sediment suspension $80-85 \%$ of the time in the winter and spring and $55 \%$ of the time in the summer, while the critical shear threshold was surpassed $90 \%$ of the time at the unvegetated site (Hansen and Reidenbach 2013).

This chapter seeks to build upon the work by Hansen and Reidenbach $(2012 ; 2013)$ by quantifying wave attenuation across a seagrass meadow, and studying density effects using seasonal deployments at the same locations across the meadow as opposed to plots of different density throughout the meadow. This reduces effects due to the variability in bathymetry which may modify wave and current properties. With these variables controlled, we will further explore meadow density effects on wave attenuation, and ultimately sediment suspension.

\subsubsection{Objectives}

The primary objective of this chapter is to define a range of attenuation coefficients $\left(\alpha_{\mathrm{w}}\right)$ for waves traversing an established Z. marina meadow in South Bay, which can be generalized 
to represent a moderately dense shallow seagrass system. Temperate seagrasses experience strong morphometric variation seasonally throughout the year due to climatic controls over growth, so rates of wave dissipation are expected to change seasonally. $\alpha_{\mathrm{w}}$ will be calculated during each season to account for changing morphometry, and also on a smaller time scale to account for the effect of wave conditions on attenuation. Several additional methods of measuring attenuation will also be applied and compared to existing literature values. Quantifying attenuation parameters for a seagrass meadow could be beneficial for numerical modelers striving to accurately characterize the system.

A secondary objective is to compare variation in meadow shoot density to seasonal changes in sediment grain size. Wave motion creates shear stress on the sea floor when the water depth is less than half a wavelength, which results in sediment suspension if this shear surpasses a critical value. Larger grains will become suspended when larger waves cause greater bed shear, so grain size is used to represent the shear stress experienced on the sea floor. Differences in sediment grain characteristics may reflect large scale changes in wave attenuation, and exemplify an environmental impact of seasonal shoot density variation. Furthermore, this may predict how sediment characteristics will change as a sparse seagrass bed becomes more established.

The overarching goal of this chapter is aligned with a goal of our research site, the VCR LTER; to explore the connectivity between the subtidal, intertidal, and salt marsh environments present at the site. While focusing on seagrasses in the subtidal environment, this work also seeks to quantify the effect of seagrass on both the sediment fluxes to other environments and the change in wave energy across a seagrass meadow. The availability of sediment is critical to marsh accretion, and the wave energy impacting the marsh edge drives the rate of lateral marsh 
edge erosion (Mariotti et al. 2010). Due to the interconnected nature of this marsh-lagoon system, understanding how seagrass modifies wave height can also contribute to our understanding of marsh erosion and deposition dynamics. 


\subsection{Methods}

\subsubsection{Site Description}

Research was conducted in South Bay, a shallow coastal lagoon located within the Virginia Coast Reserve Long Term Ecological Research site (VCR LTER) on the Delmarva Peninsula, Virginia (Figure 2.1). The VCR LTER consists of a dynamic system of barrier islands, lagoons, and salt marshes which are strongly influenced by semidiurnal tidal variations. Mean water depth in South Bay is $1.0 \mathrm{~m}$, with an average tidal range of $1.2 \mathrm{~m}$ and winds primarily from the SSE-SSW and N-NE (Fagherazzi and Wiberg 2009). Waves in the bay are primarily wind driven, as the barrier island system blocks larger ocean swell from propagating further inland. The dominant vegetation in South Bay is the eelgrass Zostera marina.

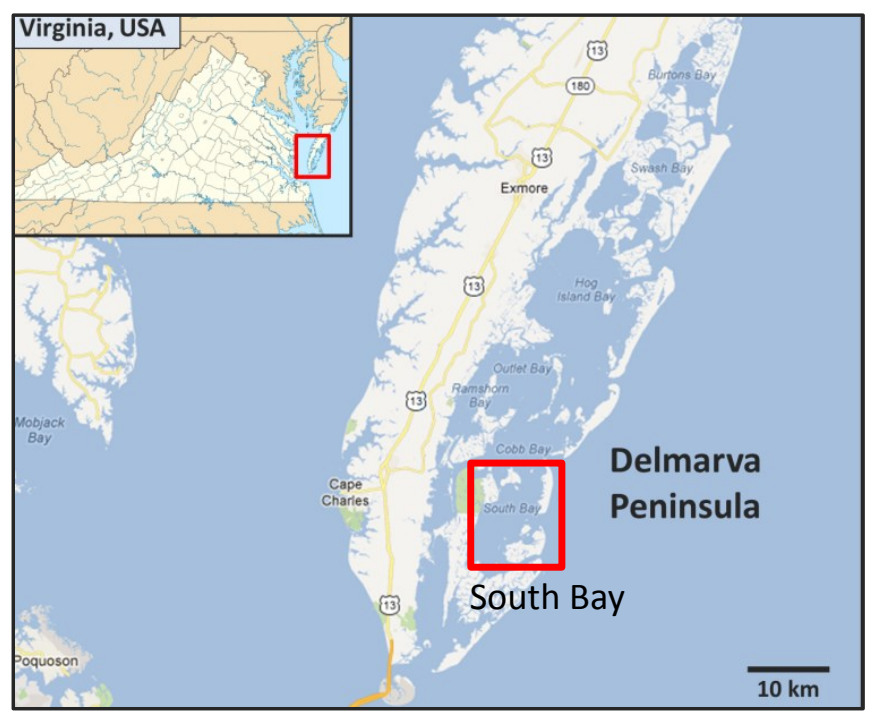

Figure 2.1: Delmarva Peninsula and South Bay

Seagrasses in the coastal bays of the Delmarva Peninsula disappeared in the 1930's due to a combination of a pandemic wasting disease and the 1933 Chesapeake-Potomac hurricane. 
The northern bays of the Delmarva naturally reestablished a Z. marina population, however the southern bays failed to recover at the same rate. In the early 1990's, several natural patches of eelgrass were discovered in the southern bays. Combined with water quality monitoring, this suggested that conditions in the bays could again support eelgrass growth, prompting a restoration effort which started in 1997 and resulted in the current seagrass meadows (Orth 2006). South Bay was a site of eelgrass restoration that was reseeded with Z. marina from 1999 - 2005. As of summer 2010, the reseeded patches had coalesced and grown to a meadow of approximately 1020 ha (Orth 2012).

The following coordinates were selected for study sites:

$\begin{array}{lll}\text { North: } & \text { N 37.16' } 18.7^{\prime \prime} & \text { W -75.48' 48.7" } \\ \text { Center: } & \text { N 37.15' } 48.5^{\prime \prime} & \text { W }-75.49^{\prime} \text { 20.5" } \\ \text { South: } & \text { N 37.15' } 17.3^{\prime \prime} & \text { W }-75.49^{\prime} 15.2^{\prime \prime} \\ \text { Bare: } & \text { N 37.16' } 3.7^{\prime \prime} & \text { W }-75.49^{\prime} 47.8^{\prime \prime}\end{array}$

The north, center, and south sites were in an array spaced approximately $1 \mathrm{~km}$ apart through an established Z. marina meadow in a section of the bay that was identified in Orth et. al (2012) as being vegetated since 2010 . The fourth site was in a bare portion of the bay adjacent to the meadow, approximately $0.5 \mathrm{~km}$ west of the center site (Figure 2.2). Average water depths at the four sites were as follows:

$\begin{array}{ll}\text { North: } & 1.21 \mathrm{~m} \\ \text { Center: } & 1.00 \mathrm{~m} \\ \text { South: } & 1.16 \mathrm{~m} \\ \text { Bare: } & 0.94 \mathrm{~m}\end{array}$




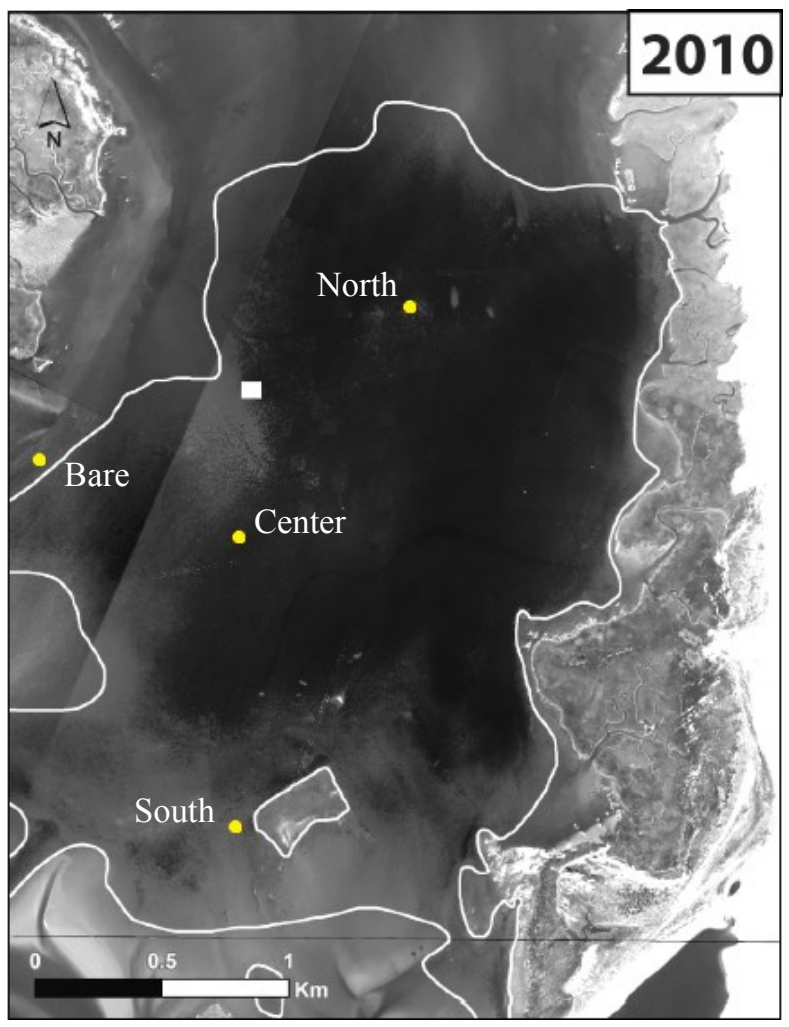

Figure 2.2: Site locations superimposed on an aerial photograph modified from Orth et al (2012). The extent of the seagrass meadow as of 2010 is indicated by the area within the white line. Wreck Island is the land mass on the right side of the image.

A seasonal sampling regime was implemented to assess the impact of morphological changes of the seagrass on the meadow scale hydrodynamics. Data were recorded from October 2011 through July 2013 over eight deployments ranging from 14 to 19 days. The site originally selected as the bare location in October 2011 was found to be vegetated during the April 2012 deployment, therefore the bare location shown in Figure 2.2 was used starting in July 2012. As a result, bare data are not available for the October 2011, January 2012, and April 2012 deployments, but are available for July 2012 through July 2013.

Physical characteristics of the Z. marina bed (shoot density, height, and width) were measured during each deployment at the center site, which was considered representative of the 
established meadow area (Table 2.1). Density was determined in situ via $0.25 \mathrm{~m}^{2}$ shoot counts, and shoots were brought to the laboratory to measure length and width. Lengths and widths were recorded for the longest three blades per shoot. The meadow was most dense with the longest and widest blades during the summer growing season for both years sampled, with values that peaked during July 2013 with a density of $411 \pm 33$ shoots $/ \mathrm{m}^{2}$, blade length of $53 \pm 8$ $\mathrm{cm}$ and width of $0.41 \pm 0.03 \mathrm{~cm}$. Densities were lowest and blades smallest during January 2012 $\left(100 \pm 36\right.$ shoots $\mathrm{m}^{-2}$, length $19 \pm 4 \mathrm{~cm}$, and width $\left.0.21 \pm 0.04 \mathrm{~cm}\right)($ Table 2.1$)$.

Table 2.1: Seasonal morphometric data summarizing characteristics of Z. marina meadow in South Bay, Virginia across five sampling periods spanning 15 months from April 2012 through July 2013. Density was determined as number of shoots per $0.0625 \mathrm{~m}^{2}$ quadrat. Values presented below are averages $\pm 1 \mathrm{SD}$. n $\mathrm{n}_{\text {blades}}$ : number of blades measured; $\mathrm{n}_{\text {density }}$ : number of $0.25 \mathrm{~m}^{2}$ quadrats measured.

\begin{tabular}{lccccc}
\hline & $\begin{array}{c}\text { Blade Length } \\
(\mathrm{cm})\end{array}$ & $\begin{array}{c}\text { Blade Width } \\
(\mathrm{cm})\end{array}$ & $\mathrm{n}_{\text {blades }}$ & $\begin{array}{c}\text { Density } \\
\left(\text { shoots } / \mathrm{m}^{2}\right)\end{array}$ & $\mathrm{n}_{\text {density }}$ \\
\hline April 2012 & $27 \pm 10$ & $0.31 \pm 0.05$ & 15 & $140 \pm 25$ & 10 \\
July 2012 & $47 \pm 7$ & $0.38 \pm 0.06$ & 15 & $347 \pm 73$ & 10 \\
October 2012 & $23 \pm 5$ & $0.25 \pm 0.05$ & 15 & $115 \pm 30$ & 10 \\
January 2013 & $19 \pm 4$ & $0.21 \pm 0.04$ & 15 & $100 \pm 36$ & 10 \\
July 2013 & $53 \pm 8$ & $0.41 \pm 0.03$ & 15 & $411 \pm 33$ & 10 \\
\hline
\end{tabular}

Summer densities are consistent with values reported by Hansen and Reidenbach (2012)

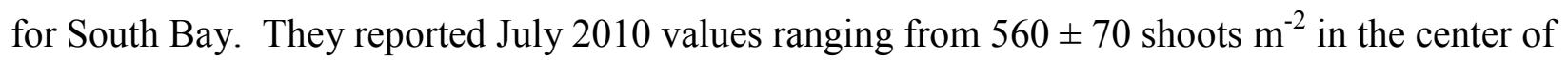
the meadow to $150 \pm 80$ shoots $\mathrm{m}^{-2}$ on the meadow edge. However, spring, fall, and winter values were significantly less than those reported in Hansen and Reidenbach (2013), who reported densities of $310 \pm 60$ shoots $\mathrm{m}^{-2}$ in January 2011. Intraseasonal variation due to summer heat stress and subsequent die-off could explain the lower densities found in 2012 and 2013. Additionally, the blade lengths found in July $2012(47 \pm 7 \mathrm{~cm})$ and July $2013(53 \pm 8 \mathrm{~cm})$ 
were greater than those found at the dense site by Hansen and Reidenbach (2012) in July 2010 (maximum length $33 \pm 3 \mathrm{~cm}$ ), which may indicate that meadow densities were lower because the individual plants were better established and larger.

\subsubsection{Hydrodynamic Data Collection}

Hydrodynamic data were collected at four sites (north, center, south, and bare) across South Bay. The fetch length at each site varied depending on wind angle due to the complex bathymetry of the coastal lagoon system. South Bay is long and narrow, oriented with the long axis in a north to south direction, so that the north and south fetch lengths were the longest (7.5 $\mathrm{km}$ ), while east and west fetch lengths were typically between 1 and $2 \mathrm{~km}$ (Figure 2.3). Changes in fetch due to the submersion of marshes during high tide or storm events were not considered due to the coarse nature of fetch measurements. Estimations of fetch length for each site were determined using aerial photographs of the VCR LTER bays.

Wave motions were recorded at each site using four wave gauges (RBR TWR-1050), which were programmed to measure pressure in bursts of 1024 samples at $4 \mathrm{~Hz}$ every 10 min. These high frequency bursts record waves with periods as small as $0.5 \mathrm{sec}$, and were averaged over four min intervals for tidal variations. Multiple gauges allowed for comparison of wave characteristics as waves propagated across the meadow. 

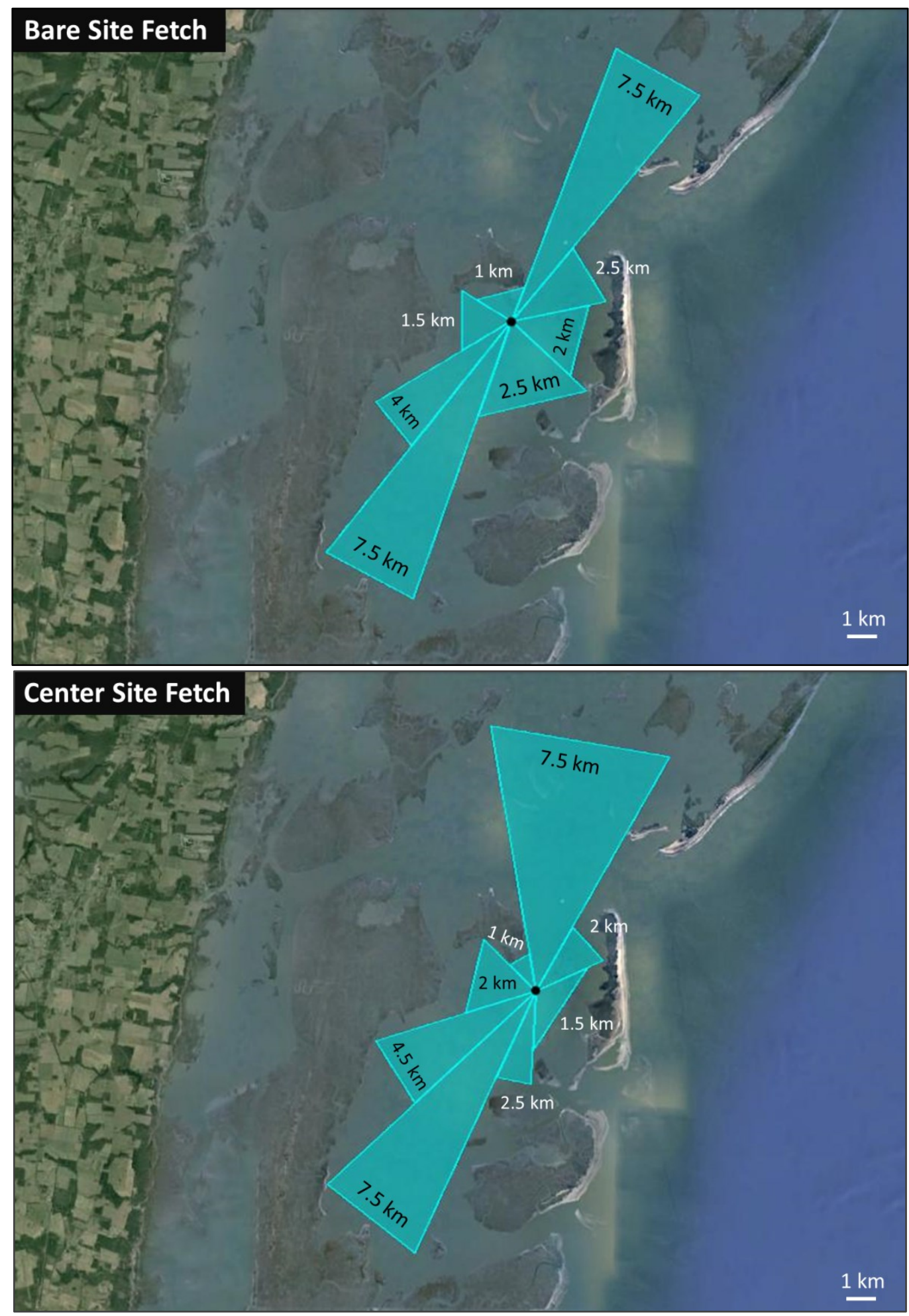

Figure 2.3: Fetch lengths for bare and center sites. Fetch length was averaged across these wedges, and is approximate due to inherent variation in coastlines as well as changing depth conditions with the submersion and emergence of marsh flats across different tidal conditions. Background image from Google Earth. 
Additional instrumentation was deployed at the center site to monitor water velocities and quality within the meadow. A current profiler (Nortek High-Resolution Aquadopp) collected 10 min average velocity profiles up to $0.8 \mathrm{~m}$ above the bed at a rate of $1 \mathrm{~Hz}$ for one out of every ten min to determine the tidally driven current variations at the site. A turbidity sensor (Campbell Scientific OBS 3+) attached to the Aquadopp profiler measured total suspended solid (TSS) concentrations within the water column at the same sampling rate as the Aquadopp. A water quality sonde (YSI 6600-V2) was deployed at the center site primarily as a secondary measure of TSS using an optical turbidity sensor (YSI 6136), but was also used to collect $\mathrm{pH}$, salinity, temperature, dissolved oxygen, and chlorophyll measurements as 10 min averages.

Sediment characteristics were determined through seasonal sampling of $10 \mathrm{~cm}^{3}$ cores $($ depth $=1.75 \mathrm{~cm})$ at the vegetated center site and a nearby bare site. Three replicate cores were collected seasonally at each site. Each sample was sieved through a $2 \mathrm{~mm}$ screen and bleached to remove organic matter prior to analysis. Grain size was analyzed using a laser diffraction particle size analyzer (Beckman Coulter LS 13 320), which returned a grain size distribution curve. Fine sediment was defined as silts and clays with a particle diameter less than $74 \mu \mathrm{m}$, and the percent of fine sediment was assessed for each sample from the grain size distribution curve. $D_{84}$ was also determined from the curve as the diameter $\left(D_{x}\right)$ at which $84 \%$ of the sample is finer than $D_{x}$.

\subsubsection{Data Analysis}

Pressure data recorded by the wave gauges are an absolute pressure, including the contribution from atmospheric pressure and from the overlying water column. Pressure must be corrected by removing the atmospheric contribution prior to determining the water column 
depth. The RBR wave gauge software corrects for this discrepancy using an average atmospheric pressure value of $101.325 \mathrm{kPa}$, however natural deviations from this mean can influence the calculated water depth. This correction was achieved through atmospheric pressure measurements recorded at the nearby Wachapreague National Oceanographic and Atmospheric Administration (NOAA) meteorological (MET) station.

$$
h=\frac{P_{\text {wave gage }}-P_{\text {atm }, \text { Wachapreague }}}{\rho g}
$$

Hydrostatic pressure within a water column is equal to $\rho g h$, where $\rho$ is water density, $g$ is acceleration due to gravity, and $\mathrm{h}$ is the depth of the water column. The corrected water depth is used for all subsequent calculations.

Significant wave height, the mean wave height of the highest third of waves, was determined from pressure data using spectral analysis. Significant wave height $\left(\mathrm{H}_{\mathrm{s}}\right)$ was calculated by the Ruskin RBR software as follows:

$$
H_{s}=4 \sqrt{m_{0}}=4 \sqrt{\int S_{\eta}(f) d f}
$$

where $\mathrm{m}_{0}$ is the first moment, or variance, of the power spectrum, defined as the integral of the spectral density of water surface elevation, $S_{\eta}$, as a function of frequency (Wiberg and Sherwood 2008). Wave period data were also obtained directly from the Ruskin RBR software.

A wave height model created by Young and Verhagen (1996) for bare conditions was used to calculate a value of significant wave height to compare to field observations. The model was used to compliment field data collected at an adjacent bare site, and modeled conditions within the meadow as if there were no vegetation to calculate wave attenuation in the meadow by comparing the model output (bare data) to recorded (vegetated) data. This fetch-limited, finitedepth model was calibrated for fine-grained, cohesive mud, an appropriate approximation for the 
sediment in South bay in absence of vegetation. Fetch length, wind velocity, and water depth were input into the model, which returned a predicted value of significant wave height and peak wave period. Fetch was determined from aerial photographs of the VCR LTER bays, wind velocity from the Wachapreague NOAA MET station, and water depth from the wave gages following the atmospheric pressure correction.

Observed and calculated waves with significant wave heights below $3 \mathrm{~cm}$ were filtered from the data set to reduce contamination from small turbulent fluctuations that could artificially skew attenuation values. Waves of this height are also unlikely to be influenced by bottom drag (Wiberg and Sherwood 2008). Model outputs were compared to the data collected in South Bay, and the percent difference between the modeled and measured values was calculated as follows:

$$
\text { Percent Difference }=\frac{H_{s, \text { model }}-H_{S, R B R}}{\left(\frac{\left(H_{s, \text { model }}+H_{S, R B R}\right)}{2}\right)} * 100
$$

Positive values indicate that the modeled wave heights were greater than the observed wave heights, and potentially influenced by the presence of seagrass.

Wave attenuation was then considered through calculation of an attenuation coefficient $\left(\alpha_{\mathrm{w}}\right)$. Data were first filtered to include only sampling periods during which the wind direction was nearly parallel to a line between the sites. Because waves in South Bay are wind driven, wind direction can be used as an approximation for the direction of wave propagation. A range of $45^{\circ}\left(22.5^{\circ}\right.$ to either side of the line between two sites) was used in the filter to provide adequate data for analysis of attenuation. The three sites were not perfectly along a straight line, so overlapping but distinct filters were employed for the different site combinations.

Waves with a significant wave height lower than $3 \mathrm{~cm}$ were also removed from this data set prior to calculating attenuation coefficients. Small recorded wave heights may be the result 
of random non-wave motion, and have the potential to greatly skew attenuation values when small changes in wave height represent a substantial percent increase or decrease. Larger developed waves are more likely to propagate across the entire meadow and represent the effects of vegetation induced drag. Several wave height filters were considered, and a $3 \mathrm{~cm}$ cutoff was chosen to include an adequate number of data points for statistical analysis.

$\alpha_{\mathrm{w}}$ values were calculated following Mazda et al. (1997), who used a formulation from Bretschneider and Reid (1954) for determining the reduction in wave height for waves propagating across an impermeable bottom with constant depth and no refraction:

$$
H_{2}=H_{1}\left[\frac{f H_{1} \phi_{f} \Delta \mathrm{x}}{K_{S} T^{4}}+1\right]^{-1}
$$

where $H_{1}$ and $H_{2}$ are the initial and final wave heights, $f$ is the friction factor, $\Delta x$ is the horizontal distance the wave traversed, $T$ is the wave period, $K_{s}$ is the shoaling factor, and $\phi_{f}$ is defined as follows:

$$
\phi_{f}=\frac{64 \pi^{3}}{3 g^{2}}\left[\frac{K_{s}}{\sinh \left(\frac{2 \pi h}{L}\right)}\right]^{3}
$$

where $L$ is the wavelength. Bretschneider and Reed (1954) describe $f$ as a "calibrated friction factor" which describes the reduction in wave height caused by bottom characteristics. In Mazda et al. (1997) this is rewritten to replace the friction factor $(f)$ with a measure of wave induced drag, defined in Mazda et al. (1997) as $C_{D}$, but written here as $\alpha_{w}$ to avoid confusion with current induced drag:

$$
\frac{H_{2}}{H_{1}}=\frac{1}{1+\frac{\pi^{5} K_{S}^{2}}{\sqrt{2} g^{2} T^{4}} * \alpha_{w} H_{1} \Delta x\left(\sinh \frac{2 \pi h}{L}\right)^{-3}}
$$


This method estimates flow resistance across the entire height of the plant structure as bottom friction. Equation 2.6 can be simplified for South Bay by setting the shoaling factor $\left(K_{s}\right)$ equal to 1 because South Bay is roughly a constant depth and does not typically induce wave shoaling, so this simplification is appropriate. Solving for $\alpha_{w}$ :

$$
\alpha_{w}=\frac{g^{2} \sqrt{2} T^{4}}{\pi^{5}} * \frac{\left(\sinh \frac{2 \pi h}{L}\right)^{3}}{H_{1} \Delta x} *\left(\frac{H_{1}}{H_{2}}-1\right)
$$

After preliminary analysis, data from the south site were found to have significantly lower wave heights than other two sites, independent of the wind direction. The south site has limited fetch for south winds (Figure 2.2), with a distance of approximately $1.5 \mathrm{~km}$ to a land mass for winds between $180^{\circ}$ and $210^{\circ}$, and $1 \mathrm{~km}$ fetch for winds between $90^{\circ}$ and $180^{\circ}$. As a result of the short fetch lengths, waves may not be fully developed when they reach the south site when winds are blowing from the south to the north, and the processes of wave growth due to wind energy and decay due to seagrass induced drag are competing in a way cannot be easily predicted. Due to this limitation, data from the south site was not considered in further analysis of wave attenuation.

Complex bathymetry within the coastal bay and barrier island system provided a wide variety of fetch lengths to consider for the different transects. The largest fetch length available was for south winds between the center and north site, where waves develop across $6-9 \mathrm{~km}$ prior to impacting the South Bay meadow. As a result of fetch constraints on wave development, these data were chosen as the primary focus for analysis of wave attenuation. Data from north winds along this north to center transect are also analyzed, however a portion of the $45^{\circ}$ window of north winds impacting the north site has a fetch of only $2 \mathrm{~km}$ due to Wreck Island (Figure 
2.3), which may cause varying results due to confounding factors of growth and decay simultaneously influencing wave height. 


\subsection{Results and Discussion}

Wind speed seasonal averages ranged from $2.1 \mathrm{~m} \mathrm{~s}^{-1}$ in July 2012 to $4.8 \mathrm{~m} \mathrm{~s}^{-1}$ in July 2013; however, the deployments captured enough variation that all seasonal means were within one standard deviation. The maximum ten-minute averaged wind speed was $27.8 \mathrm{~m} \mathrm{~s}^{-1}$, and the minimum was $0.1 \mathrm{~m} \mathrm{~s}^{-1}$ (Figure 2.4). No seasonal trends were apparent in the data; the highest and lowest monthly averages both occurred during July, of 2013 and 2012 respectively, although the second and third highest averages both occurred in April, possibly indicating stormier weather and the potential for larger wave development in the spring.

The seasonal average depth at the center study site ranged between $1.28 \mathrm{~m}-0.93 \mathrm{~m}$ in October 2011 and July 2013 respectively, with a standard deviation of $0.42 \mathrm{~m}-0.46 \mathrm{~m}$ (Figure 2.5). At the bare site, the depth range was $1.19 \mathrm{~m}-0.82 \mathrm{~m}$ in October 2012 and January 2013 respectively, with a standard deviation of $0.43 \mathrm{~m}-0.46 \mathrm{~m}$. The mean depths at the bare and seagrass sites were within one standard deviation for all seasons, with a maximum difference of $11 \mathrm{~cm}$ in the mean seasonal values. A semi-diurnal tide drives the variation in water depth in South Bay, so the standard deviation is affected by the tidal range. This variation is remarkably consistent considering the oscillations in the tidal cycle monthly between spring and neap tides and over the course of the year. Differences in mean water depth could be a result of weather systems; wind or barometric pressure variations may force more water towards or away from the shoreline. However none of this variation was significantly different between seasons, nor is there any apparent seasonal trend in the data. 


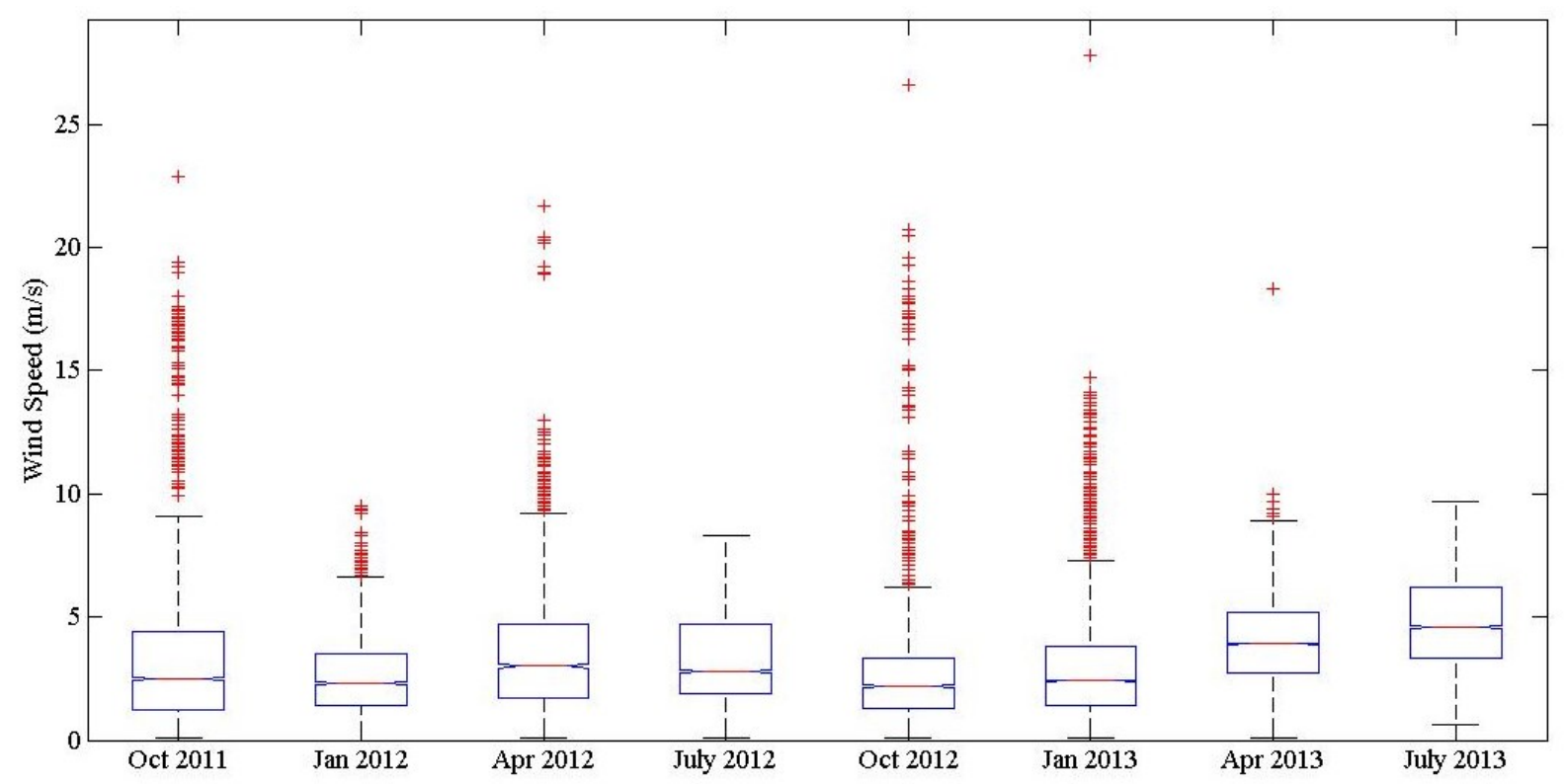

Figure 2.4: Wind speed from the Wachapreague NOAA MET station for each sampling period. Horizontal red line within the box indicates median wind speed, lower and upper edges of the box represent the 25th and 75th percentiles respectively. Red crosses represent outliers. Data were collected for periods ranging from 14 to 19 days.

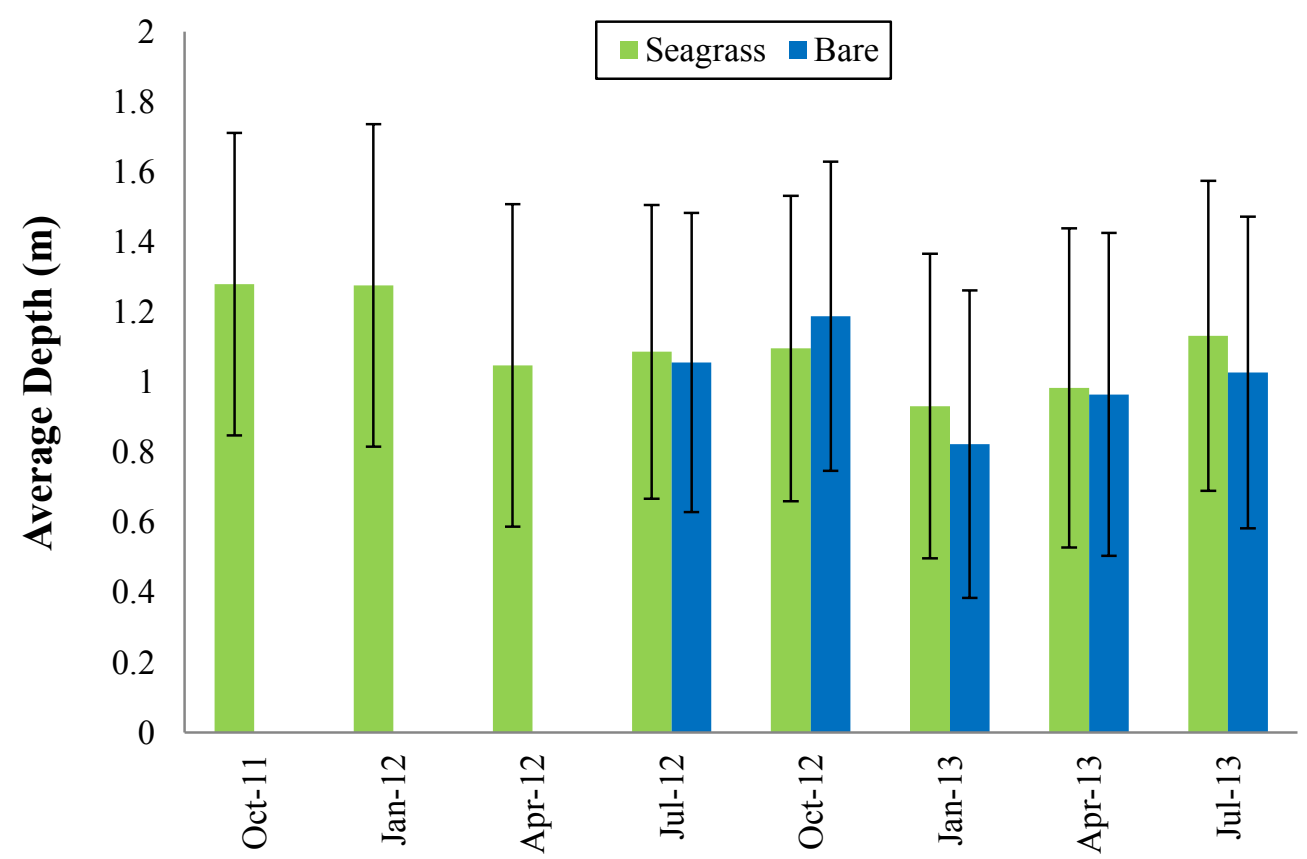

Figure 2.5: Water depth at the bare (blue) and center seagrass (green) sites averaged across each sampling period. Data were collected for periods ranging from 14 to 19 days. Error bars show \pm 1 SD. 
Seasonally averaged flow velocities ranged from $3.5 \mathrm{~cm} \mathrm{~s}^{-1}-7.1 \mathrm{~cm} \mathrm{~s}^{-1}$ at the seagrass site and $11.9 \mathrm{~cm} \mathrm{~s}^{-1}-25.9 \mathrm{~cm} \mathrm{~s}^{-1}$ at the bare site (Figure 2.6). All seasons with velocity records at both the seagrass and bare site showed significantly higher mean velocities at the bare site (ANOVA, $\mathrm{p}<0.01$ ). The longest seagrass blades in July 2013 had an average length of $53 \pm 8$ $\mathrm{cm}$, so velocities are reported at $70 \mathrm{~cm}$ above the sediment surface to avoid any interference with the seagrass canopy. Aquadopp data were not available for April 2013 and July 2013, therefore velocity data from a collocated Nortek Vector was used to determine the mean velocity. The Vectors recorded velocities at $10 \mathrm{~cm}$ above the bed, and the 'law of the wall' (Equation 1.5) was used to estimate the velocities at $70 \mathrm{~cm}$ above the bed to match the Aquadopp data. This may cause artificially low velocities at the seagrass site for these two seasons because the measurements were taken within the canopy where lower flow rates would be expected. The logarithmic velocity profile is assumed to shift upwards in regions with dense seagrass, such that the zero velocity point begins at the top of the seagrass canopy and the hydrodynamics within the canopy are governed by other forces. Therefore, velocities at $70 \mathrm{~cm}$ above the bed cannot necessarily be approximated from velocities within the canopy, as a smooth log profile is not expected between these points. However, due to the lack of other measurements, these shifted values were reported in Figure 2.6. 


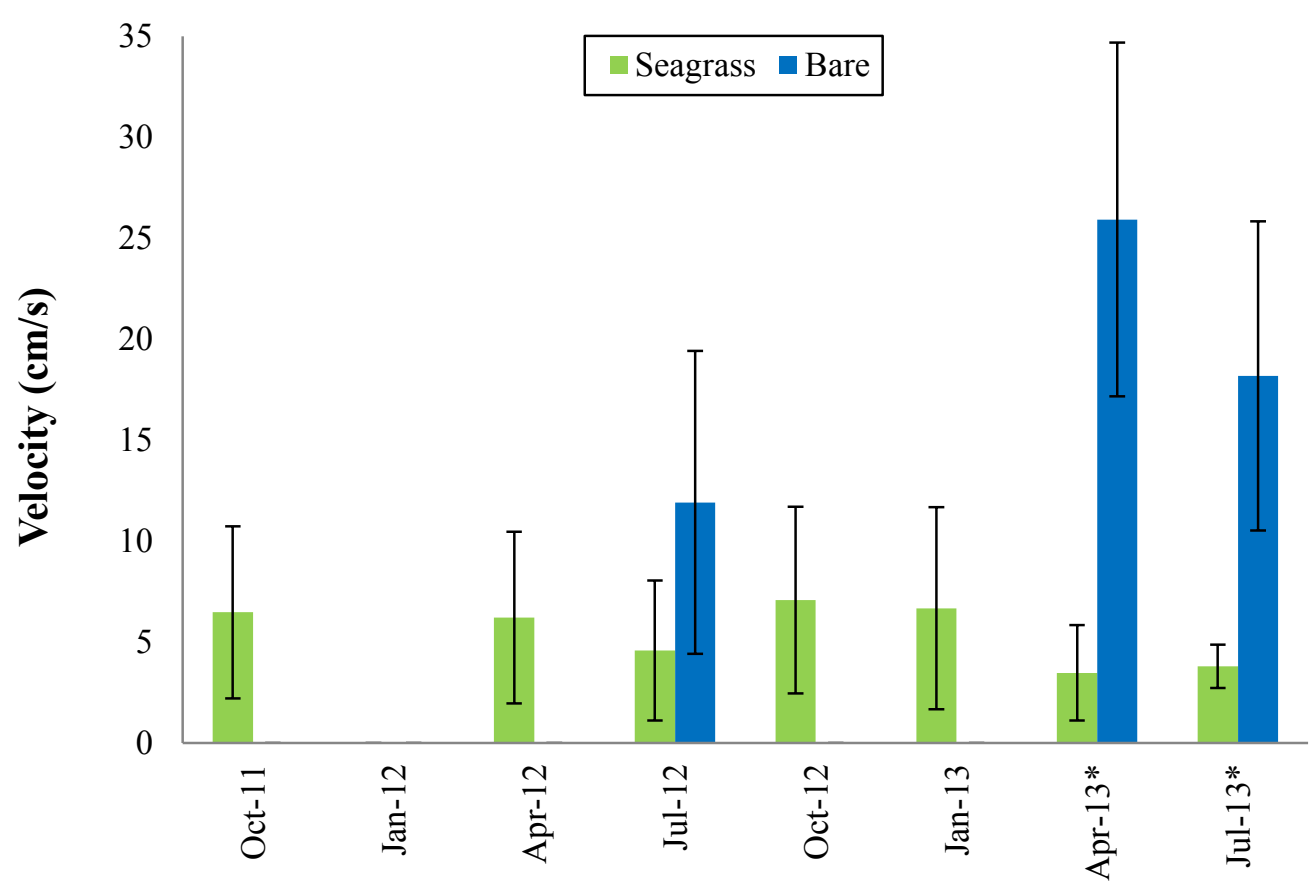

Figure 2.6: Seasonally averaged flow velocities across each sampling period at $70 \mathrm{~cm}$ above the bed, measured using a Nortek Aquadopp from October 2011 through January 2013. Velocities in April 2013 and July 2013 were recorded with a Nortek Vector positioned $10 \mathrm{~cm}$ above the bed, indicated by an asterisk (*). The $70 \mathrm{~cm}$ above-bed velocities were estimated using a logarithmic profile. Error bars show $\pm 1 \mathrm{SD}$.

\subsubsection{Wave Characteristics}

Waves in South Bay were primarily wind driven, with seasonally averaged significant wave heights ranging from $0.02 \mathrm{~m}$ to $0.09 \mathrm{~m}$ and seasonally averaged significant wave periods between $1.6 \mathrm{~s}$ and $2.4 \mathrm{~s}$ (Figure 2.7). The distribution of significant wave height was highly skewed, with intermittent, large waves occurring during storm events. Consequently, the maximum ten-minute significant wave heights for each season were much higher than the average value, with the largest $H_{s}$ across all deployments reaching $0.55 \mathrm{~m}$. In addition, significant wave height varied considerably as a function of wind direction, which altered fetch 
lengths. Time periods with significant wave heights less than $3 \mathrm{~cm}$ were removed from the data prior to averaging the wave period so that only wind generated waves, and not seiching of longperiod waves within the shallow bay or high frequency capillary waves, would be included. Average $H_{s}$ is statistically lower within the seagrass meadow compared to a bare site (ANOVA, $\mathrm{p}<0.01$ ). This reduction is larger during the spring, summer, and fall months when the meadow is established, but is also present during the winter when the canopy is sparse. Controls on significant wave height include; fetch length, which is constant between seasons as the site locations are fixed (Figure 2.3), wind speed, which was statistically similar across all sampling periods (Figure 2.4), water depth, which oscillates around MSL across all seasons (Figure 2.5), and attenuation, which could vary as a property of meadow structure. As predicted by the seasonal mean wind values from Figure 2.4, the high wind speeds in April 2013 and July 2013 correspond to the largest mean significant wave heights at the bare site, however the mean significant wave height at the vegetated site follows a trend more aligned with the seasonal density distribution, with maximum values in October 2011, January 2013, and April 2013 when densities were low. 
A

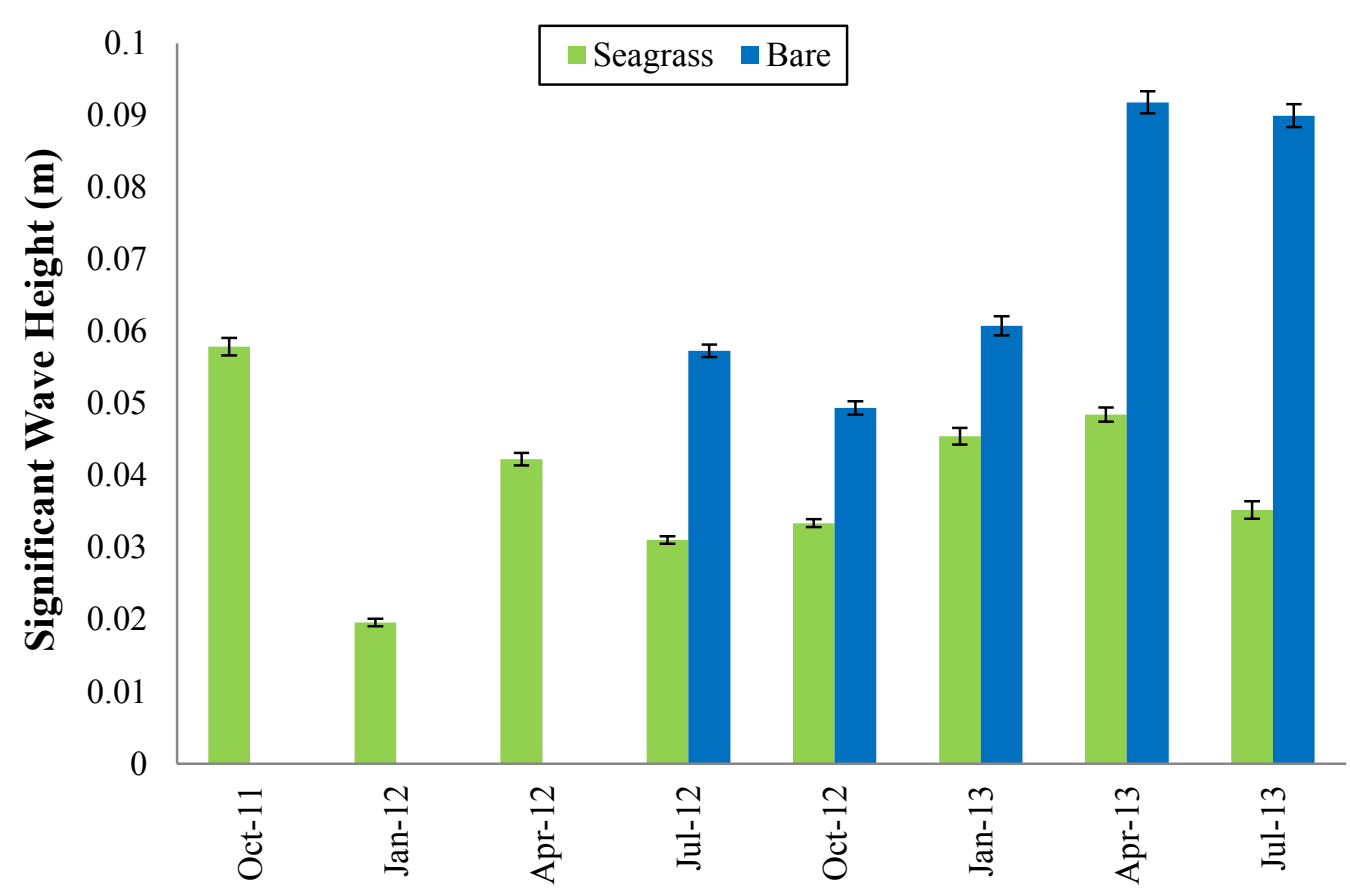

B

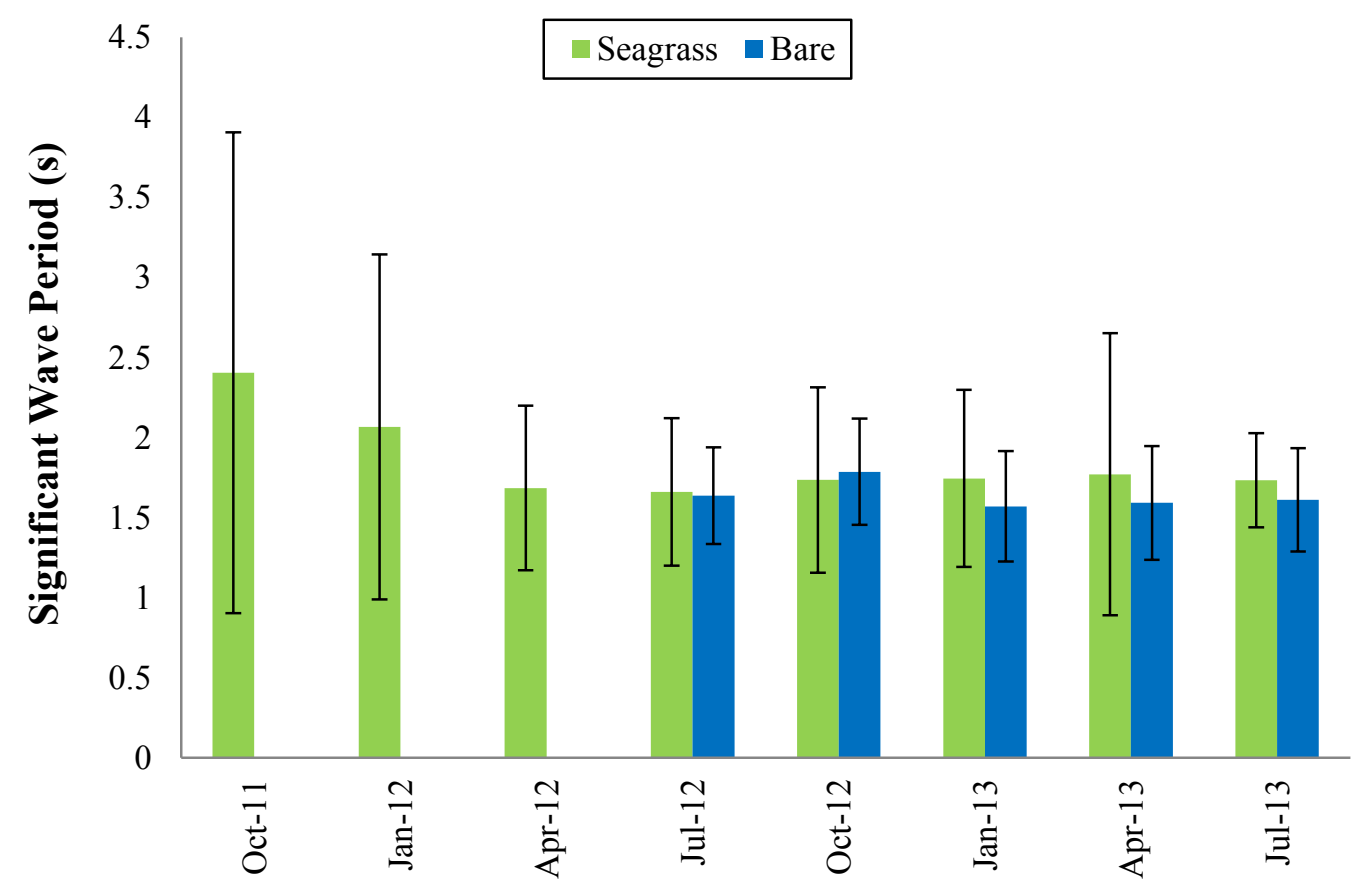

Figure 2.7: (A) Average significant wave height ( $\pm 1 \mathrm{SE}$ ) and (B) average significant wave period ( $\pm 1 \mathrm{SD})$ for the center vegetated site and nearby bare site, across 8 seasonal deployments (ranging from 14 to 19 days). Bare data is missing for October 2011 - April 2012 after establishing that the original bare site was vegetated following the April 2012 deployment. 
Average significant wave period was higher at the vegetated site across all seasons except during October 2012. This difference was within one standard deviation in all cases; no season exceeded a difference of 0.2 seconds between the mean center and mean bare significant wave period. Therefore, the waves impacting the seagrass site and bare site had a similar range of wave periods during each season.

\subsubsection{Wave Attenuation}

Wave heights recorded at the center vegetated and nearby bare site, separated by $0.5 \mathrm{~km}$ and considered to experience similar wave climates, are plotted against each other to graphically visualize the degree of attenuation from the Z. marina bed. Plots of significant wave height at the bare versus vegetated site are displayed across four consecutive seasons (Figure 2.8). Points that indicate attenuation fall below the 1:1 line, and the slope of the regression line represents the degree to which wave height is attenuated by the seagrass bed (adapted from Koch 2006). 


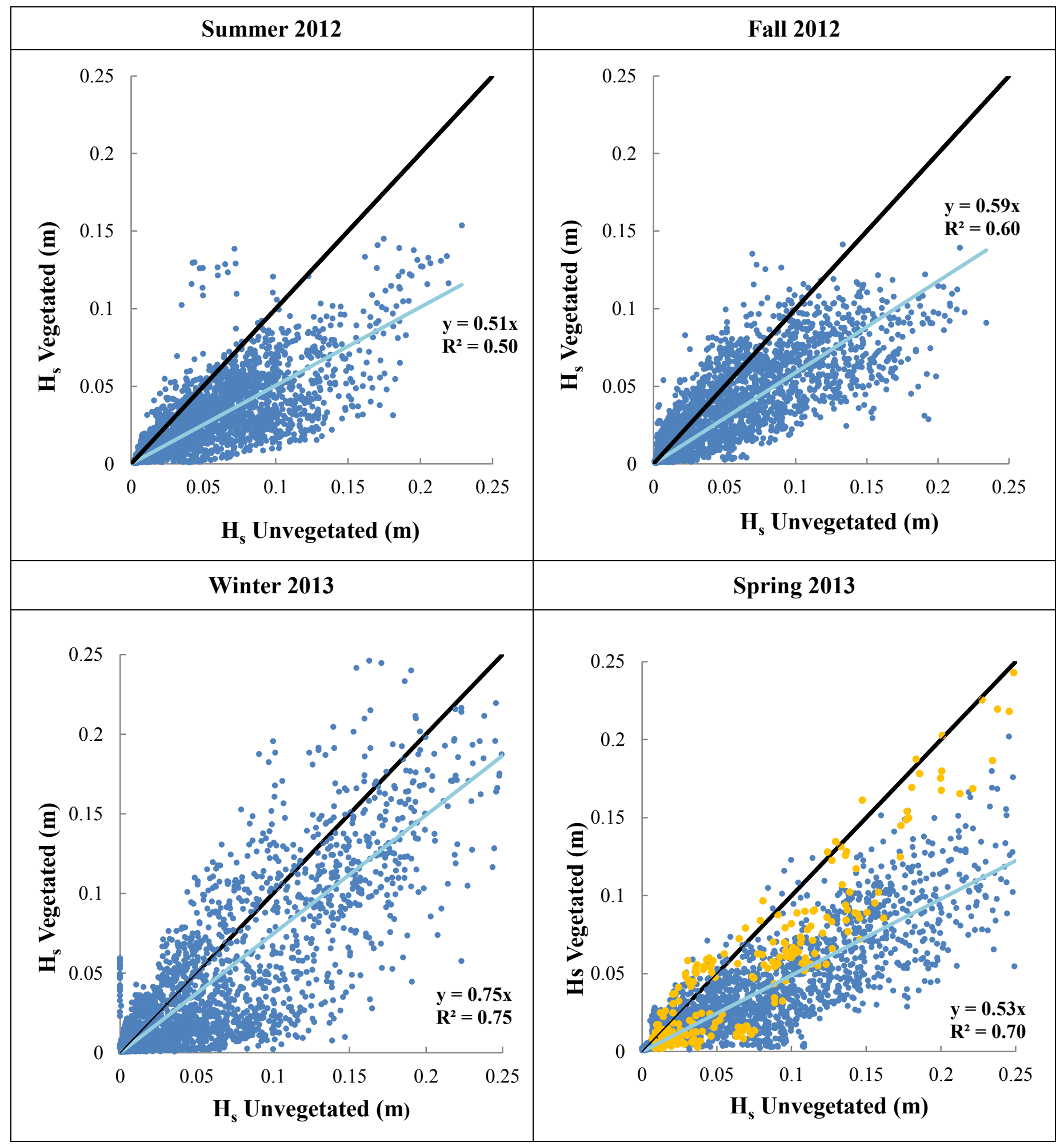

Figure 2.8: Significant wave height at the center vegetated site compared to significant wave height at the nearby bare site over four seasons. The slope of the regression line represents the degree of wave height attenuation 
between these two sites, with shallower slopes indicating greater attenuation. The regression line was fit to pass through the origin. Black line represents 1:1 slope line, indicating a case with no attenuation between the bare and vegetated sites. Orange points in spring 2013 are from the first two days of the deployment.

Overall, significant wave height at the seagrass site was $51 \%$ of significant wave height at the bare site in the summer, $59 \%$ in the fall, $75 \%$ in the winter, and $53 \%$ in the spring. Data from the summer and fall 2012 show greater variation and therefore lower $\mathrm{R}^{2}$ values $\left(\mathrm{R}^{2}=0.50\right.$ and 0.60 respectively), compared to winter and spring 2013. This may be a result of the changes in seagrass cover during the sampling period due to growth or senescence of the seagrass, or due to nonuniformity in bottom drag across the fetch distance created by the presence of seagrass. The direction of wave propagation varies with the wind direction in South Bay, which is shielded from ocean swell by a chain of barrier islands. When the meadow is established, waves from different directions traverse different lengths across vegetation prior to reaching the center site. If attenuation is a function of the distance of meadow traversed by a wave, a range of attenuation values would be expected when the meadow is established. Conversely, in the winter, the less dense meadow matches more uniformly with the surrounded unvegetated fetch, causing less scatter in the data, and a line of best fit that better matches the $1: 1$ line of no attenuation $\left(\mathrm{R}^{2}=\right.$ 0.75 , slope $=0.75)$

The spring 2013 deployment showed a cluster of points around the 1:1 line in addition to the scatter around the line of best fit, which may be due to changes in meadow morphometry during the course of data collection. Data from the first two days of the spring deployment (4/4 and 4/5/2013) are highlighted in orange on Figure 2.8, and show scatter near the 1:1 line similar to the winter deployment. Later data shows greater attenuation, such that combined the set has a slope of 0.53 , closer to the 0.51 slope from the summer data set. This may indicate that the 
meadow was growing and caused an increase in attenuation as the spring deployment progressed. However, similar to the greater scatter observed in summer 2012 and fall 2012, this variation may also be attributed to variation in fetch length caused by the change in wind direction instead of a morphological change in the meadow density. The wind angle varied over $200^{\circ}$ during the first two days of the deployment, from the SE to NW, and winds from these angles reoccurred later in the deployment and did not cause similarly low attenuation, suggesting that the low attenuation during this time was not solely a function of fetch.

\subsubsection{Comparison to Young and Verhagen Wave Height Model}

A modeling component was introduced to more accurately account for effect of changes in fetch length for different wind directions on wave attenuation. An empirical model developed by Young and Verhagen (1996) predicted significant wave height at a location as a function of

wind speed, water depth, and fetch length, and did not include bottom vegetation. The difference between the model output and the recorded significant wave height was considered to represent the wave height attenuation caused by seagrass compared to a theoretical bare site at the same physical location (Figure 2.9). This comparison showed wave height attenuation of up to $63.6 \%$ in the seagrass bed during summer months (Table 2.2). Model accuracy was verified by comparing model output values to the measured values at the bare site. The model both overand under- predicted wave heights at the bare site, although theoretically the attenuation at the bare site should be zero. Further rationale for this discrepancy is discussed below; however, this suggests that the attenuation values presented in Table 2.2 could be between $25 \%$ too high and $20 \%$ too low. 

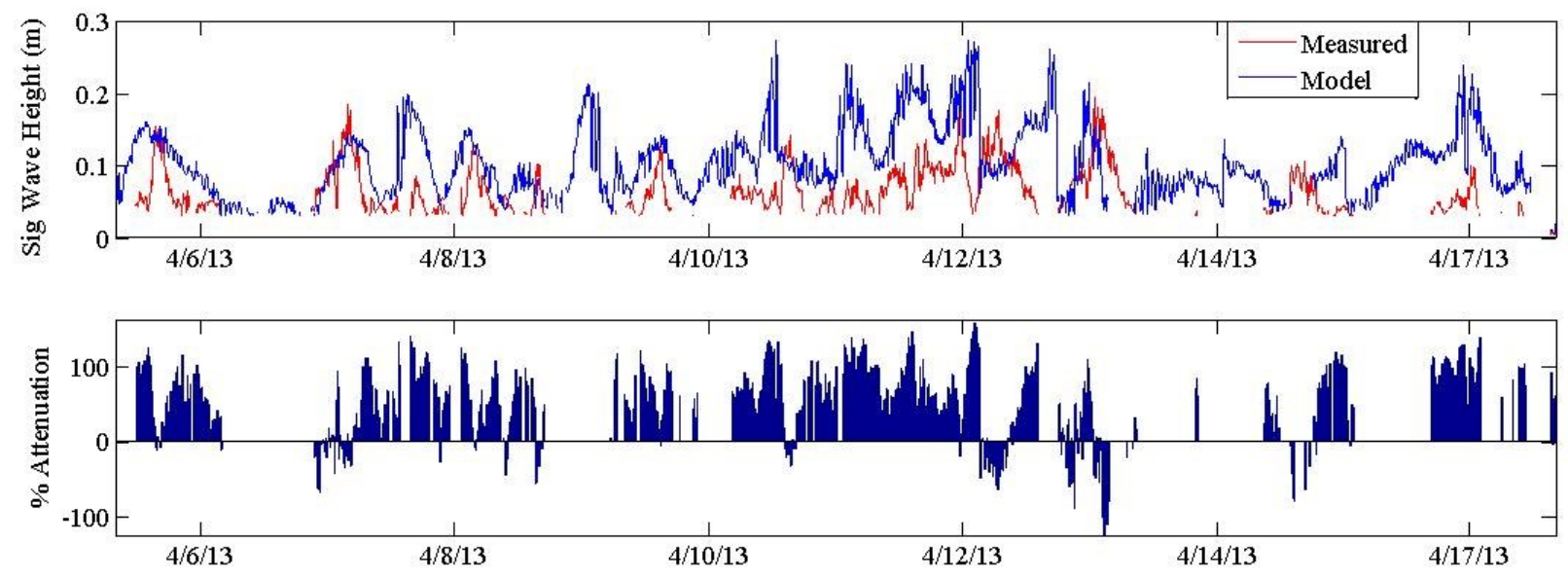

Figure 2.9: Wave height comparison between Young and Verhagen model output (blue) and measured values (red) at the center seagrass site during April 2013 (top). Time series of percent attenuation between measured and modeled wave height during April 2013 sampling period (bottom).

Table 2.2: Percent difference between observed significant wave heights and significant wave heights predicted by the Young and Verhagen (1996) model at each site, averaged across each sampling duration. Model calibrated for fine grained cohesive mud bottom surface. The greatest differences between the observed wave heights and the model predictions occur during the summer sampling periods (highlighted below).

\begin{tabular}{ccccc}
\hline & North Site (\%) & Center Site (\%) & South Site (\%) & Bare Site (\%) \\
\hline January 2012 & -9.8 & 14.9 & 19.2 & - \\
April 2012 & 21.5 & 34.3 & 25.9 & - \\
July 2012 & 49.2 & 46.4 & 37.7 & 17.7 \\
October 2012 & -9.6 & -18.9 & -9.9 & -14.9 \\
\hline January 2013 & -19.4 & 0.4 & -14.7 & -18.6 \\
April 2013 & 43.5 & 45.5 & 27.8 & -2.2 \\
July 2013 & 63.6 & 57.4 & 43.4 & 24.5 \\
\hline
\end{tabular}

The Young and Verhagen (1996) model predicted wave heights greater than those measured within the seagrass meadow during the spring and summer deployments. This 
indicates that actual wave heights were reduced compared to a model prediction of a bare South Bay. The model predicted wave heights lower than those measured in the field during the fall and winter deployments. Deviation from the modeled results was greatest during summer sampling periods, with a difference of $44.4 \%$ and $54.8 \%$ averaged across the three vegetated sites for summer 2012 and 2013 respectively, where densities reached $347 \pm 73$ and $411 \pm 33$ shoots $\mathrm{m}^{-2}$ in South Bay. Data from within the meadow during January 2013 were closest to the model results, with an average difference of $-11.2 \%$ across the three vegetated sites. This also corresponded with the lowest measured meadow density of $100 \pm 36$ shoots $\mathrm{m}^{-2}$.

The difference between the model results and the bare site field data ranged from $24.5 \%$ during July 2013 to $-18.6 \%$ in January 2013. Although the bare site itself was devoid of seagrass, portions of the fetch preceding the bare site measuring location did cross vegetated areas for some wind angles. Vegetation across the fetch length of the bare site during the growing season may contribute to higher attenuation values during the summer periods, and would explain why the less dense spring data better match the model prediction. The model under predicts wave heights for October 2012 and January 2013, which could be the result of multiple influences, including the coarseness of fetch distances input to the model and discrepancies between Wachapreague wind data and winds within South Bay.

Mariotti and Fagherazzi (2013) found that the Young and Verhagen model underpredicted wave heights in a study in Willapa Bay, Washington. They attributed this to an underestimation of fetch-limited wave growth to the smooth mud substrate in the bay, which they hypothesize induced less drag on the flow than the sediment used in the formulation of the Young and Verhagen model. They found that a low friction coefficient for the sediment was necessary to match the observed wave dynamics to a SWAN model prediction (Mariotti and 
Fagherazzi 2013). This both highlights the importance of drag on wave attenuation, as even small differences in sediment characteristics can have a measurable effect on wave height, and suggests that the Young and Verhagen model may not be a completely accurate prediction of wave heights for this South Bay study site. Table 2.2 shows that the model generally overpredicted wave heights at the bare location in South Bay, with the exception of October 2012 and January 2013. In addition to the vegetation non-uniformity discussed above contributing to attenuation at the bare site, this could also be dependent on the sediment characteristics and bottom topography. Young and Verhagen (1996) do not report a grain size for the sediment used to calibrate the model in Lake George, but describe the bottom as "relatively fine grained but cohesive mud" in which "the bed is not mobile and ripples do not develop". This description is seemingly consistent with the fine grained sediment in South Bay; however, the sediment in South Bay was not necessarily as cohesive, as it was easily resuspended. This discrepancy could result in higher bottom friction in South Bay as compared to Lake George, which would cause higher wave attenuation in South Bay compared to the smoother bed of Lake George, and would explain the model over-prediction. However, in comparing other fetch limited wave growth data sets to the data from Lake George, Young and Verhagen (1996) suggest that bottom friction may be less influential than the other variables present in depth limited conditions, and that the model should hold for most sediment types. Due to the complicating effects of seagrass these data are not appropriate to support a statement regarding the validity of the model, however, less dependence on sediment type would suggest that the attenuation observed at the bare site is a result of a partially vegetated fetch and not model error, and that the higher attenuation values from Table 2.2 are valid. 


\subsubsection{Wave Attenuation Coefficients}

Attenuation coefficients for South Bay averaged across seasonal deployments for varying seagrass densities varied from $\alpha_{\mathrm{w}}=0.19$ to 0.59 for a southerly wind direction and $\alpha_{\mathrm{w}}=0.03$ to 0.58 for a northerly wind direction, when calculated following Mazda et al. (1997) (Table 2.3).

Table 2.3: Seasonally averaged wave attenuation coefficients, separated by wind direction. Data were filtered to include $22.5^{\circ}$ to either side of the north to center site transect, and significant wave heights below $3 \mathrm{~cm}$ were removed. The number of data points included in the seasonal average after filtering is indicated by $\mathrm{n}$. Seasons with less than $\mathrm{n}=10$ data points were omitted.

\begin{tabular}{lcccc}
\hline & $\alpha_{\mathrm{w}}$ North Wind & $\mathrm{n}$ & $\alpha_{\mathrm{w}}$ South Wind & $\mathrm{n}$ \\
\hline October 2011 & 0.10 & 140 & 0.29 & 319 \\
\hline January 2012 & 0.25 & 50 & - & - \\
April 2012 & 0.03 & 285 & 0.48 & 138 \\
July 2012 & 0.10 & 164 & 0.41 & 206 \\
October 2012 & 0.58 & 37 & 0.59 & 146 \\
\hline January 2013 & 0.27 & 89 & 0.19 & 145 \\
April 2013 & 0.09 & 71 & 0.49 & 274 \\
July 2013 & - & - & 0.47 & 95 \\
\hline
\end{tabular}

The largest seasonally averaged wave attenuation coefficients for south winds occurred in October 2012 and April 2013 and 2012, while the smallest occurred in January 2013 when seagrass density was low, however there was no direct correlation with meadow density. High density summer vegetation may not induce as much drag on the flow as seagrass blades bend and create a skimming flow over top of the canopy (Nepf 1999). During the spring and fall when the bed was more sparse, flow moved through the canopy and interacted with individual shoots, 
creating wakes that dissipated energy in the flow. This process was found to increase near bed turbulence intensity in sparse vegetation, with decreasing turbulence as bed density increases and shields the bottom sediment (Nepf 1999). The method used to calculate wave attenuation here, from Mazda et al. (1997), is intended to approximate an integrated coefficient across the meadow, whereas the Nepf studies $(1997,1999)$ examined the interaction of individual shoots of vegetation with fluid flow. Changes in attenuation across the meadow can be explained by the mathematical formulations and analysis provided by Nepf (1999), because meadows are effectively an amalgamation of many individual shoots. What is not certain is if the drag created by an individual shoot can be scaled up to accurately predict meadow scale wave attenuation. Uncertainty arises from scale because only under sparsely vegetated conditions will significant flow move through the canopy and interact with individual blades. More typically, the skimming flow described by Nepf (1999) will cause the bulk of the flow to move over the top of the canopy, experiencing drag due to a rough carpet of combined seagrass blades instead of interactions with individual shoots. The fundamental differences in the derivation of these two methods would suggest that using a small scale model that accounts for vertical plant geometry would overestimate the amount of drag imparted onto a flow that only skims the top of the vegetation. This question will be addressed in the discussion of small scale flow in Chapter 3 .

The wave attenuation coefficient for north winds did not follow the same trend as the south winds, and instead the largest value occurred in October 2012 and the smallest in April 2012 and 2013. However, winds from the north did not all experience adequate fetch to fully develop wind waves prior to hitting the South Bay meadow. The $45^{\circ}$ window towards the north for the north to center site transect included fetch lengths that were limited to less than $2 \mathrm{~km}$ by the presence of Wreck Island. This was evident in the plots of $\alpha_{w}$ vs. wave frequency, significant 
wave height, and water depth for the north site, which also did not show the expected trends. As a result, the data from north winds were considered to be less accurate, and were removed from the remainder of the wave attenuation coefficient analysis.

Seasonally averaged attenuation coefficients provide a general comparison between seasons and can isolate the influence of meadow density on drag, but do not separate an adequately fine temporal scale to capture the variation in drag associated with different wave and depth conditions. Wave attenuation is dependent on these conditions, and while some parameters such as water depth have similar means across all seasons (Figure 2.5), considering the intraseasonal variation is helpful for understanding when high attenuation will occur (Figures $2.10,2.11$, and 2.13). 


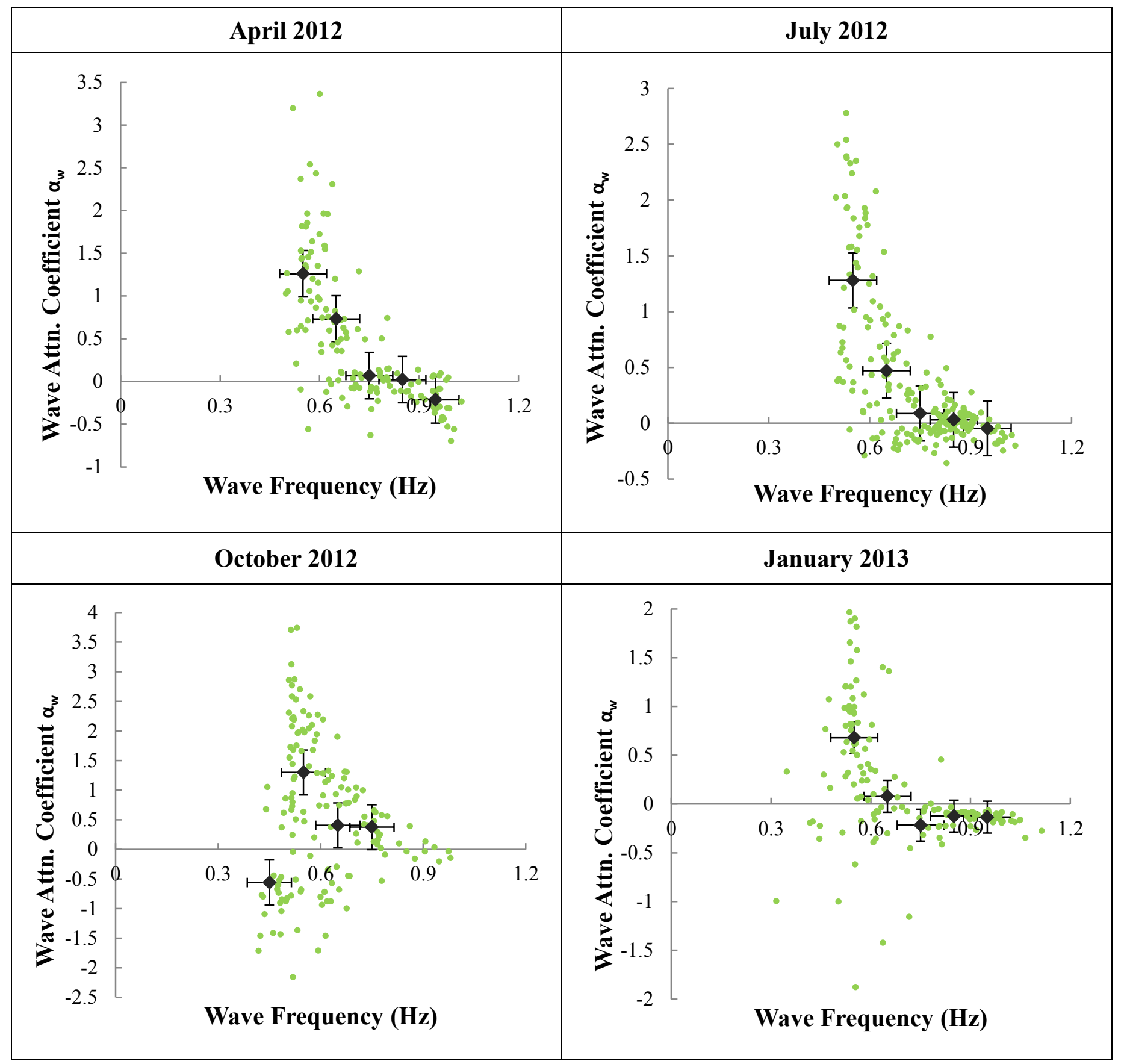

Figure 2.10: Wave frequency versus wave attenuation coefficient $\left(\alpha_{\mathrm{w}}\right)$ for south winds across four seasons. Raw data are presented in green points. Data were averaged in $0.1 \mathrm{~Hz}$ bins and averages were plotted along with the raw data as grey diamonds. Means that had fewer than 10 data points in a bin were excluded from the plots. Error bars on the averaged data show standard error. 
Plots of wave frequency vs. $\alpha_{\mathrm{w}}$ showed a trend of higher attenuation coefficients for lower frequency waves during each season (Figure 2.10). Some of the highest frequency values in the April, July, and January data had negative attenuation coefficients, which may be because these high frequency motions correspond to small waves whose oscillatory motion does not reach the seafloor or even the depth of the seagrass blades, and are therefore unaffected by the presence of the meadow. Linear wave theory suggests that waves will attenuate prior to reaching the sea floor when the wave frequency $(f)$ is greater than $\sqrt{g /(4 \pi h)}$ (Wiberg and Sherwood 2008). For the water depths typical in South Bay $(1-2 \mathrm{~m})$, this relationship suggests that waves with a frequency greater than $0.88-0.63 \mathrm{~s}^{-1}$, depending on the tidal conditions, will not interact with the sediment. This is consistent with the decrease in attenuation coefficients observed as wave frequencies increase, approaching $\alpha_{\mathrm{w}}=0$ as frequencies surpass $0.75 \mathrm{~s}^{-1}$ (Figure 2.10).

Negative attenuation values occur for three of the averaged data points during the winter and only one of the averaged points for both spring and summer (Figure 2.10). The distance to the top of the seagrass bed, where waves will begin to feel drag, decreases in the summer when the canopy is established with longer blades. Smaller waves may interact with the vegetation above the bed in these cases, and experience drag even when the wave motions are too small to reach the sea floor. In the winter, short, sparse blades make it less likely that a wave will be attenuated if it is not of adequate wavelength for the orbital motions to interact with the bottom. Assuming a maximum summer seagrass blade length of $0.5 \mathrm{~m}$ (and assuming these blades extend vertically), waves with a frequency less than $1.25-0.72 \mathrm{~s}^{-1}$ will interact with the seagrass canopy during the summer. This covers the extent of the frequency range measured (Figure 2.10).

The October 2012 data also show one negative mean, however this occurs at the data point with the longest period. Data for the other seasons do not include waves as small as 0.45 
$\mathrm{Hz}$, reflecting a tendency for waves of a period around $2.2 \mathrm{sec}$ not to be attenuated by seagrass. Bradley and Houser (2009) identify a low point in their plot of frequency versus $C_{D}$ at approximately $0.38 \mathrm{~Hz}$ that they suggest may have been related to blade oscillation. However, due to the lack of data including waves of small frequencies, I cannot speculate if this trend is related or simply an erroneous data point.

From the above plots, the maximum $\alpha_{\mathrm{w}}$ value occurs at a frequency of approximately $0.55 \mathrm{~Hz}$ for every season, corresponding to a wave period of $1.8 \mathrm{sec}$. The averaged $\alpha_{\mathrm{w}}$ value for this wave period is as high as 1.3 during April, July, and October, and drops to 0.7 during January 2013. 


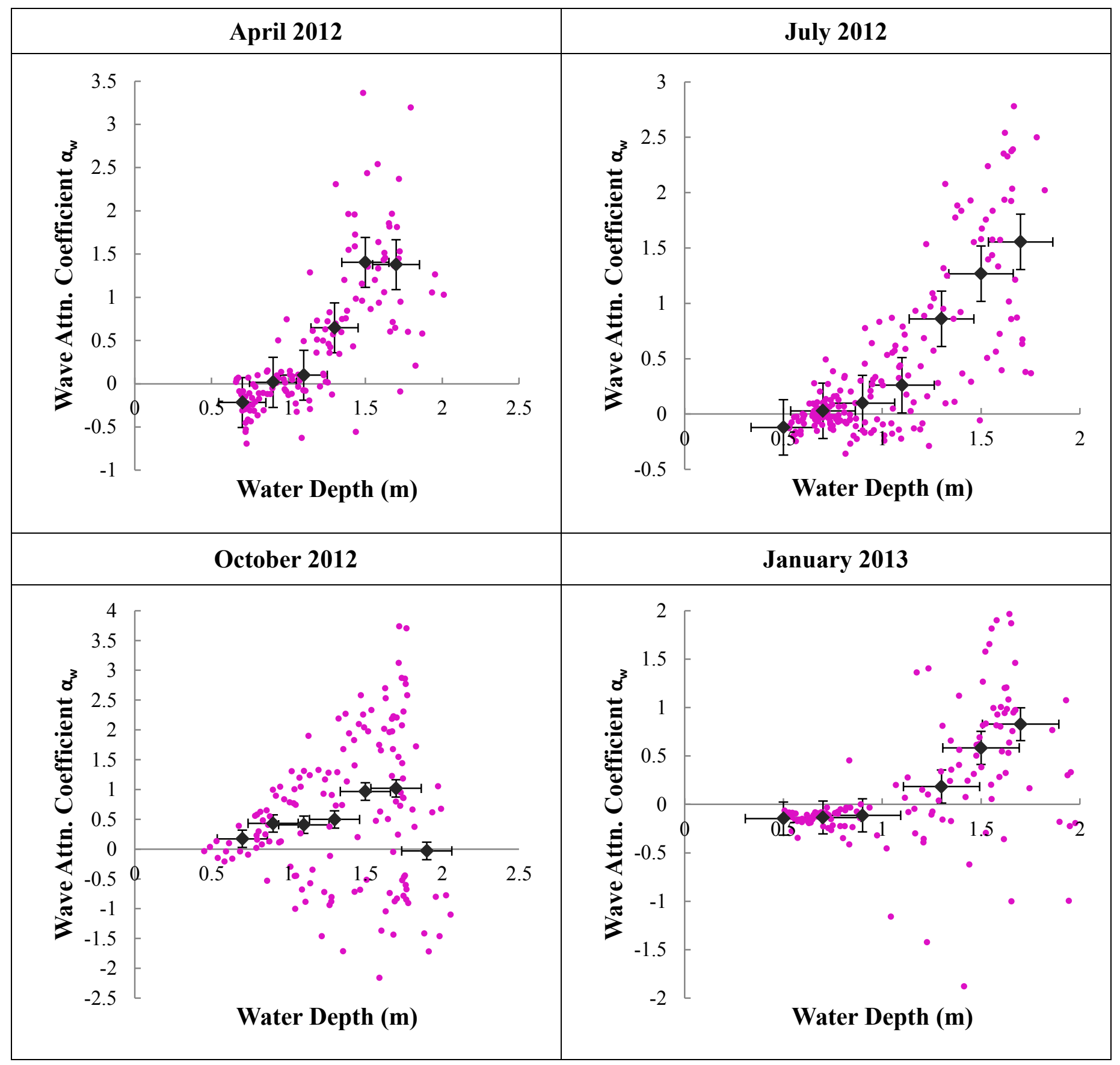

Figure 2.11: Water depth versus wave attenuation coefficient $\left(\alpha_{\mathrm{w}}\right)$ for south winds across four seasons. Raw data are presented as purple points. Depth data were averaged in $0.01 \mathrm{~m}$ bins and plotted along with the raw data as grey diamonds. Bins that had fewer than 10 data points were excluded. Error bars on the averaged data show standard error. 
Although the relationship between water depth versus wave attenuation coefficient first appears counterintuitive, showing an increase in $\alpha_{\mathrm{w}}$ at greater depths (Figure 2.11), waves in South Bay are locally generated wind waves and therefore are formed in the same conditions in which they are being attenuated. Wave development in fetch limited conditions is controlled by water depth, wind speed, and fetch length (Young and Verhagen 1996). In shallow water, wave frequency and wave height are affected by the water depth, causing lower wave heights and shorter wave periods in shallow water (CERC 1984, Figure 2.12). This is because bottom friction attenuates wave orbitals that are larger than the depth of the water column. Low wave frequencies cause greater attenuation coefficients (Figure 2.10), because high wave frequencies will be attenuated before they interact with the sea floor. If wave frequency is limited by depth conditions, it is reasonable that depth will have a similar relationship with $\alpha_{w}$ as frequency, although wave attenuation would ultimately be controlled by when wave motion is interacting with the canopy, which is a function of both water depth and wave frequency.

At greater depths, wave formation is still dependent on the wind energy imparted to the water surface, so a high tide with low wind speeds may result in a small or negative attenuation coefficient if the waves are not large enough to interact with the sea floor. This may explain the scatter within in the data, especially in October 2012 and January 2013, for deep water conditions. Overall, $\alpha_{\mathrm{w}}$ was shown to depend on wave frequency, significant wave height, and water depth, although the fundamental consideration was when waves were able to impact the sea floor. 

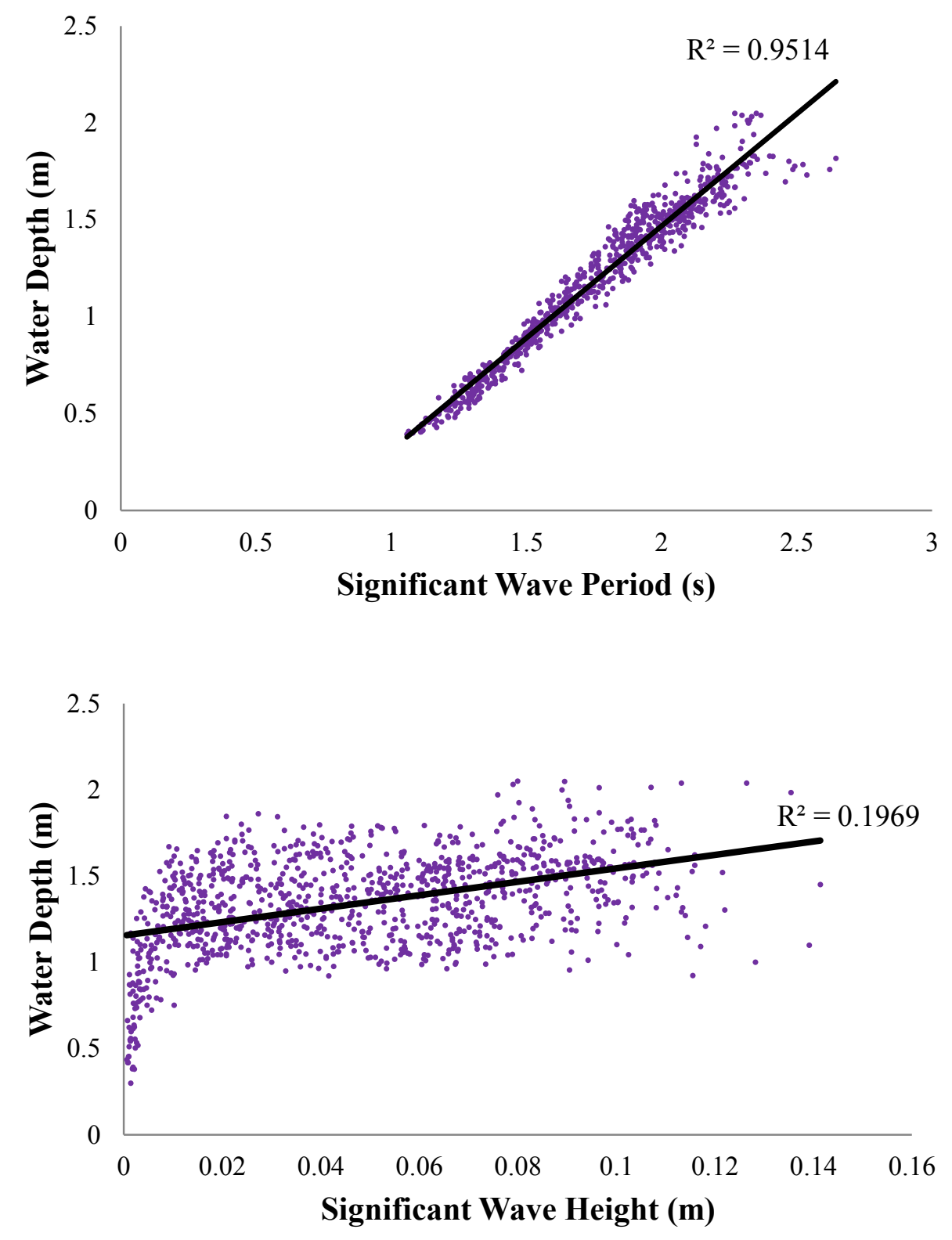

Figure 2.12: Significant wave period (s) versus water depth (m) and significant wave height (m) versus water depth (m) for October 2012 data recorded at the Center site, for waves with significant wave height greater than $5 \mathrm{~cm}$ and significant wave period less than $5 \mathrm{sec}$. 


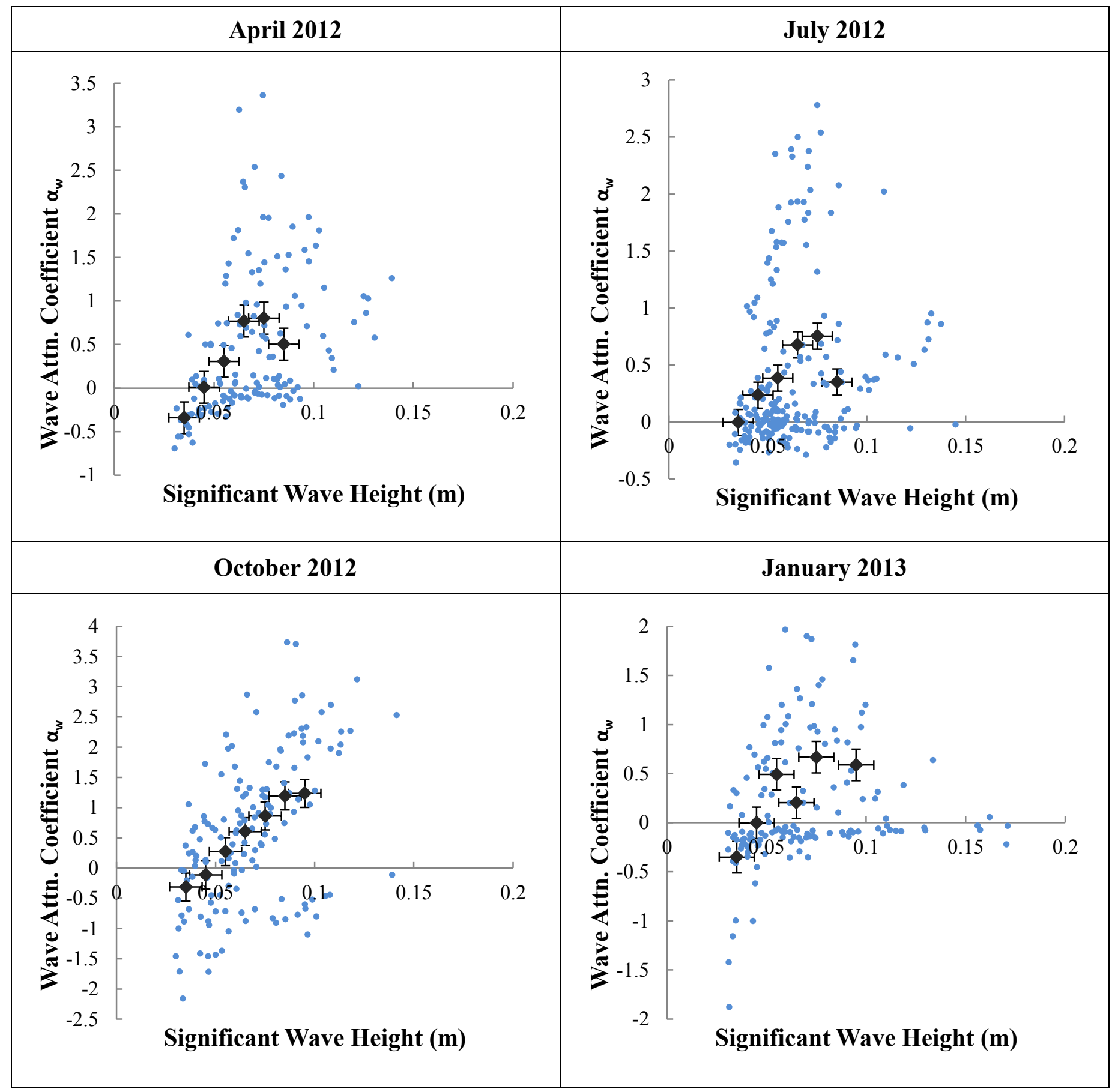

Figure 2.13: Significant wave height $\left(H_{s}\right)$ versus wave attenuation coefficient $\left(\alpha_{w}\right)$ for south winds across four seasons. Raw data are presented in blue points. Wave height data were averaged in $0.01 \mathrm{~m}$ bins and plotted along with the raw data as grey diamonds. Bins that had fewer than 10 data points were excluded. Error bars on the averaged data show standard error. 
Higher significant wave heights generally resulted in larger wave attenuation coefficients, however the scatter in these data were greater than those of wave frequency versus $\alpha_{\mathrm{w}}$ (Figure 2.10). The largest average attenuation coefficient, $\alpha_{\mathrm{w}}=1.2$, occurred at the highest wave height $(\mathrm{Hs}=0.1 \mathrm{~m})$ in October 2012. Unlike wavelength, which describes the size of a wave and results in a clear relationship for when waves will interact with the sea floor (depth $<\lambda / 2)$, there is no theoretical relationship between wave height, which describes the energy in a wave ( $\mathrm{E} \alpha$ $\mathrm{H}_{\mathrm{s}}{ }^{2}$ ), and when a wave of a certain height will experience bottom drag. However, when the wavelength is long enough for a wave to interact with the sea floor, greater wave heights will cause more energy to interact with the canopy. Larger waves create higher orbital velocities at any given depth, thereby increasing the overall drag force acting on the canopy $\left(F_{D} \alpha u^{2}\right)$. Greater interaction allows for potentially more attenuation of wave height, and therefore a larger $\alpha_{\mathrm{w}}$.

Negative $\alpha_{\mathrm{w}}$ values for small wave heights, similar to described above for small frequency waves, are likely not interacting with the bottom, and therefore represent waves that are still growing due to wind energy input instead of waves that are being attenuated by bottom friction. This occurs for the smallest average $\mathrm{H}_{\mathrm{s}}$ bin for each season (Figure 2.13), although there are also negative values throughout the data set that may be a result of tidal conditions. As water depth increases with rising tide, waves that may have interacted with the seafloor at low tide no longer feel frictional effects (Koch 2006).

\subsubsection{Seasonal Grain Size}

Submerged macrophytes have been observed to increase sedimentation rates by reducing wave energy and slowing current velocities (Fonseca and Cahalan 1992; Koch 1999), which 
causes suspended load in the water column to deposit and reduces sediment resuspension by lowering the effective bed shear stress (Almasi et. al 1987; Fonseca 1996; Gacia et. al 1999). A seasonal analysis of the grain size distribution within a temperate seagrass meadow was designed to look at variation in particle deposition with changing meadow density.

Flow velocities were lower in the meadow than at the bare site (Figure 2.6) and wave heights were attenuated within the meadow in all seasons (Figure 2.7). Given these less energetic conditions, it is expected that particles in the same range of diameters will settle within the seagrass meadow while they would remain suspended in the flow across the bare site. Comparing the percent of fine sediments at the two sites, the vegetated site consistently had a greater mean percent fine sediment than the bare site (Figure 2.14); however, these differences were not statistically significant (ANOVA, $p>0.05$ ). Variation in percent fine sediment seasonally within the seagrass meadow was also not statistically significant (ANOVA, $p>0.05$ ), which does not agree with predictions of seasonal grain size variation based on the hydrodynamic data. This may be due in part to the small sample size. Variation in $\mathrm{D}_{84}$ at the vegetated site was also uncorrelated with seasonal meadow density, with the smallest average grain size of $151 \pm 1 \mu \mathrm{m}$ occurring with the lowest bed density in January 2013, and the largest average grain size of $158 \pm 3 \mu \mathrm{m}$ occurring with a mid-range bed density in April 2012 (Table 2.4). Larger average $D_{84}$ values were generally observed at the unvegetated site, with the exception of the October 2012 data (Table 2.4). 


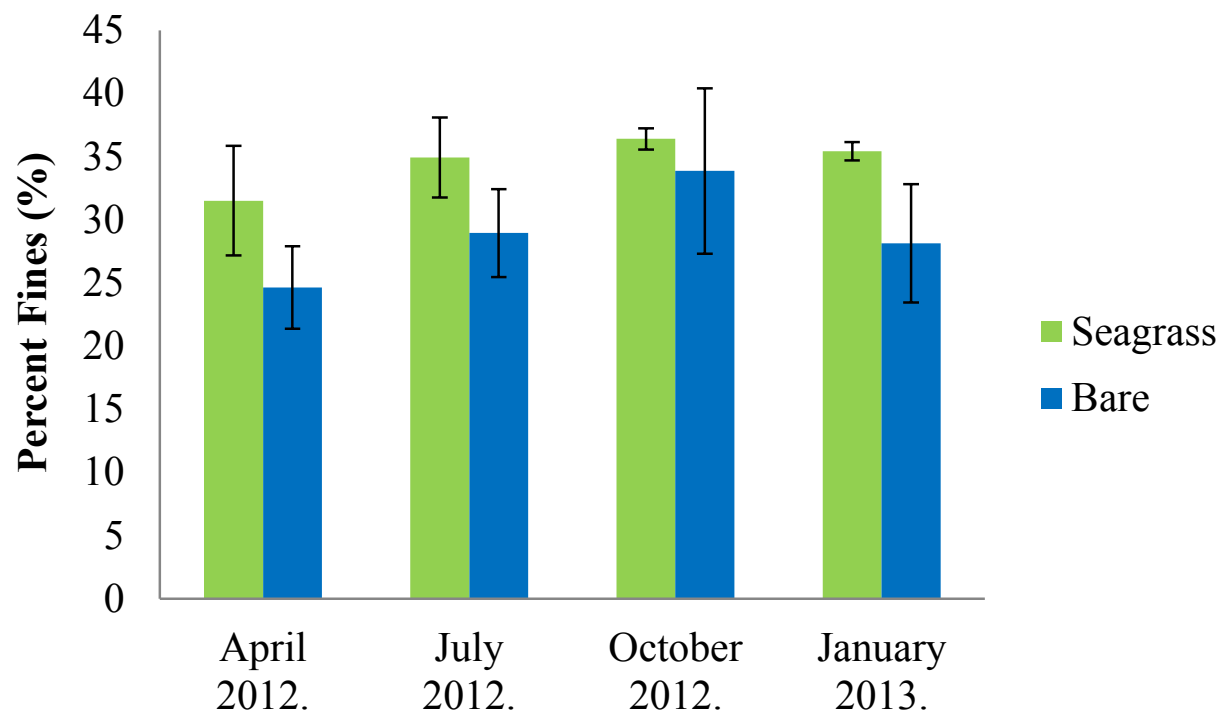

Figure 2.14: Percentage of fine sediment (silts and clays with diameter $<74 \mu \mathrm{m}$ ) within the seagrass meadow and at a bare site, compared seasonally from April 2012 through January 2013. Error bars show one standard deviation.

Table 2.4: Sediment grain size in South Bay, sampled seasonally over one year at one vegetated and one bare location. $\mathrm{n}_{\text {cores }}$ represents The number of cores that were sampled at each site. Every core was subsampled three times when run through the particle size analyzer, and statistics were calculated using the mean value from each core. Data for each season are reported as $\mathrm{D}_{84} \pm$ one standard deviation.

\begin{tabular}{ccccc}
\hline & Vegetated $\mathrm{D}_{84}(\mu \mathrm{m})$ & $\mathrm{n}_{\text {cores }}$ & $\begin{array}{c}\text { Bare } \mathrm{D}_{84} \\
(\mu \mathrm{m})\end{array}$ & $\mathrm{n}_{\text {cores }}$ \\
\hline April 2012 & $158 \pm 3$ & 3 & $162 \pm 2$ & 3 \\
July 2012 & $154 \pm 2$ & 2 & $158 \pm 3$ & 3 \\
October 2012 & $156 \pm 2$ & 3 & $152 \pm 4$ & 3 \\
January 2013 & $151 \pm 1$ & 3 & $159 \pm 3$ & 3 \\
\hline
\end{tabular}


Hansen and Reidenbach (2012) found significantly different $\mathrm{D}_{84}$ values of $157 \pm 7 \mu \mathrm{m}$ at a bare site and $130 \pm 17 \mu \mathrm{m}$ at a vegetated site in South Bay during the summer of 2010. Data from July 2012 were similar at the bare location (which was a different bare location than that used by Hansen and Reidenbach) with a $\mathrm{D}_{84}$ of $158 \pm 3 \mu \mathrm{m}$, however the site within the meadow had a grain size of $154 \pm 2 \mu \mathrm{m}$, which was greater than that found by Hansen and Reidenbach (2012), and not significantly different from the grain size at the bare site. Differences may have arisen due to a variation in sample collection techniques. In this study, $10 \mathrm{~cm}^{3}$ sediment cores extending approximately $1.75 \mathrm{~cm}$ in depth were analyzed, whereas Hansen and Reidenbach (2012) used grab bag samples from the sediment surface. Cores may provide an integrated look at long term sediment characteristics across several seasons, whereas grab samples might emphasize short term changes.

As Gacia et al. (1999) suggests, this discrepancy may also be because particle deposition is more sensitive to antecedent hydrological conditions such as recent storms than gradual changes in physical meadow characteristics such as seagrass density and average velocities, even though the meadow modifies local hydrodynamics. Storms have been shown to scour fine sediment from bare sites across a short time period. However, within a seagrass meadow, the meadow could either experience scouring of fine particles and an increase in grain size following a storm, or the slower current velocities may result in a fining of the sediment as large amounts of suspended load in the water column are advected into the seagrass meadow. Finer grained particles could then settle under these calmer conditions. Meadow density may play a role in which of these effects occur, as sparse conditions generally create more stem-wake interaction and intensify scouring around individual shoots, while dense meadows collapse and provide a sheltering effect for the underlying sediment (Nepf 1999). Sampling grain size before and after a 
storm within a seagrass bed may better elucidate the effect of these single events, as well as collecting more surficial samples. 


\subsection{Summary}

This chapter presents several estimations of the wave attenuation induced by a temperate Z. marina meadow across all seasons and consequently a range of density variations. Wave height attenuation, both comparing a vegetated site to a bare site and comparing measured values to model predictions, showed the largest reduction during the summer when the meadow was most dense, and the lowest reduction during the winter when the meadow was least dense (Table 2.5). The wave attenuation coefficient was largest during the spring, but this exceeded the summer and fall attenuation coefficients by only $11 \%$.

Table 2.5: Summary of average attenuation statistics calculated using three methods. Multiple seasons were sampled, however values from different years are averaged together to determine representative seasonal statistics. These values are presented only for purposes of general seasonal comparison.

\begin{tabular}{lccc}
\hline & $\begin{array}{c}\text { Percent } \mathrm{H}_{\mathrm{s}} \text { Reduction } \\
\text { Compared to Bare Site }\end{array}$ & $\begin{array}{c}\text { Percent } \mathrm{H}_{\mathrm{s}} \text { Reduction } \\
\text { Compared to Model }\end{array}$ & Average $\alpha_{\mathrm{w}}$ \\
\hline Spring & $47 \%$ & $33 \%$ & 0.49 \\
Summer & $49 \%$ & $50 \%$ & 0.44 \\
Fall & $41 \%$ & $-13 \%$ & 0.44 \\
Winter & $25 \%$ & $-2 \%$ & 0.19 \\
\hline
\end{tabular}

Hansen and Reidenbach (2012) found a $45-70 \%$ reduction in wave height between a seagrass meadow and an unvegetated region during May and June of 2010, with sites ranging from a seagrass density ranging from $150 \pm 80$ shoots $\mathrm{m}^{-2}-570 \pm 70$ shoots $\mathrm{m}^{-2}$. The average summer reduction in wave height comparing a vegetated site to a bare site of $49 \%$ for this research falls into the lower end of this range, with summer densities of $347 \pm 73$ and $411 \pm 33$ shoots $\mathrm{m}^{-2}$, near the middle of the density range of Hansen and Reidenbach (2012). Differences 
in both density and bathymetry may have modified these results; however, overall they are consistent.

The attenuation predicted by the Young and Verhagen (1996) model followed a similar trends as the comparison with the bare site, with the largest magnitude of attenuation in the summer and lower attenuation in the spring; however, observed wave heights were greater than modeled wave heights during the fall and winter, resulting in negative percent attenuation values. The Young and Verhagen (1996) model assumes the entire fetch is unvegetated, which explains the larger wave attenuation values for spring and summer when meadow density is high. In the winter when meadow density is low, the percent difference between the observed and modeled values is negligible, as expected.

Sediment was typically finer within the seagrass meadow compared to the bare site; however, the trends in particle size did not match density variations. Gacia et al. (1999) suggested that extreme events drive suspension dynamics more than gradual changes in density or seasonally averaged velocities, which may explain why the expected variation was not seen in this data. Additionally, the amount of seasonal sediment deposition and suspension could be much smaller than the total volume of the $10 \mathrm{~cm}^{3}$ sediment cores, so a different technique such as the deposition plates used by Gacia et al (1999) might capture these short term changes more accurately.

Overall, this research shows that seasonal morphometric variations within a seagrass meadow affect large scale wave attenuation. The highest attenuation was shown to occur in the summer when the density was highest; however, the largest wave attenuation coefficient occurred in the spring, which may be due to flow progressing through the more sparse canopy in the spring, but being displaced over the top of the canopy in the summer. Seasonal variations did 
not show a significant effect on sediment grain size, which may indicate the importance of strong events over changes in seasonal morphometry, or could be a result of our sampling techniques.

Chapter 3 will continue to address flow modification by Z. marina seagrass, exploring the small-scale fluid mechanics which drive the large scale attenuation discussed here. 


\section{CHAPTER 3:}

\section{Dynamics of the Wave-Current Boundary Layer}

Bottom boundary layers were compared between a vegetated and bare site for calm and wavy flow conditions in South Bay, Virginia. Two logarithmic layers were found in near bed velocity profiles where waves are expected to interact with the bed. Wave boundary layer depth was found to range between 0.83 and $1.21 \mathrm{~cm}$, however this exceeded theoretical boundary layer thickness calculations by an order of magnitude. On average, greater shear velocity was found at the bare site and in wavy conditions; however, when nearly identical wave climates were compared similar values of shear velocity were observed at both the vegetated and bare sites. Greater turbulent kinetic energy and bed shear stress were observed in high wave conditions and at the bare site. A greater percentage of fluid motion at the seagrass site was due to turbulence, similar to the low wave conditions at the bare site. These near bed measurements do not show the expected characteristics of the wave boundary layer, but do confirm that greater turbulent kinetic energy and bed shear stress occur in near bed flows at a bare site compared to a vegetated site. 


\subsection{Introduction}

Bottom boundary layers control mass transport, nutrient fluxes, mixing, and diffusion from the sea floor into the water column and define the stresses experienced by sediment grains on the ocean floor. In shallow coastal environments, the combined forcing of waves and tidal currents creates complicated boundary layer structure in a thin layer above the sediment. In this near bed region, the boundary layers created by waves and currents interact in a nonlinear fashion to form the turbulence and stress climate controlling the fate of mass transport from the bed to the overlying flow. Wave motion can create shear stresses much greater than current motion alone due to the short impulse and change in direction caused by wave orbital motion (Grant and Madsen, 1979). While waves are essential in suspending sediment, currents are the driving transport force, and coupled together, waves and currents define the dynamics of sediment transport in a given area. Correlations between increased wave height and sediment suspension have been identified previously (Granata et al. 2001; Lawson et al. 2007); however, the underlying cause of this relationship lies in the small scale interactions within the wavecurrent boundary layer.

\subsubsection{Wave-Current Boundary Layers}

As discussed in Section 1.3, Grant and Madsen (1979) described wave-current flow as a combination of two logarithmic layers, a thin wave boundary layer closest to the sediment superimposed on a thicker current boundary layer that extends to the free stream velocity further above in the water column (Equations 1.6 and 1.7). Due to the small size of the WBL, it has historically been difficult to observe in situ; however, various laboratory studies have been performed. Sleath (1987) measured boundary layer turbulence within a purely oscillatory flow 
water tunnel, and found that turbulence intensities varied across a wave cycle, with maximum turbulence occurring as the flow decelerated. Hay et al. (2012a and 2012b) also recorded laboratory measurements of the velocity, turbulence, and stress within a wave boundary layer. They focused on the temporal characteristics of turbulent oscillatory boundary layers, and observed a magnitude overshoot and phase lead similar to Sleath (1987). Again similar to Sleath (1987), Hay et al. (2012b) observed peak TKE and Reynolds stress near the bed prior to the maximum phase averaged flow velocity, which diffused upwards.

While the lack of robust instrumentation has made boundary layers historically difficult to study in the field, the recent development of in situ sensors that can accurately measure velocities at millimeter distances from the seafloor has led to several experiments. Foster et al. (2000) measured wave boundary layer flows with a series of hot film anemometers in the Outer Banks, NC, but had difficulties due to mobilized bedload. They measured a bed shear stress and phase shift in the boundary layer smaller than predicted by an eddy viscosity model, but were limited by the physical placement of the hot film anemometers. Hackett et al. (2011) recorded velocity profiles using particle image velocimetry (PIV) at the WBL-CBL interface in water approximately $20 \mathrm{~m}$ deep off the coast of New Jersey. They found a logarithmic layer of flow in the average velocity profile above what was assumed to be the top of the wave boundary layer followed by a velocity inflection point, associated with high turbulence intensities. They did not observe a second logarithmic layer beyond the inflection point, as predicted by Grant and Madsen (1979), but attributed this to a lack of data available beyond the observed inflection. The expected interaction between the overlying current boundary layer and wave boundary layer was described by Sleath (1987) as a wave velocity phase lag at the top of the WBL, however this develops into a phase lead in the lower part of the WBL. Hackett et al. (2011) observe a phase 
lag at the base of their profiles, which they attribute to the top of the transition zone between the CBL and WBL.

Boundary layer properties such as the thickness of the layer and the turbulence intensity within the layer control mixing and transport of sediment and nutrients from the sea floor into the water column, and are important to understand in mass transport models. Wave boundary layer thickness is determined by the wave period and shear velocity, which limits the amount of time the boundary layer has to form, so higher frequency waves are hypothesized to create thinner wave boundary layers, whereas lower frequency waves will allow the boundary layer to develop further into a thicker layer. The wave frequency is also correlated to the bed shear stress experienced by the underlying sediment, and therefore the amount of suspended sediment mobilized into the water column. A faster forming layer will exert greater bed shear stress on the sediment, and is therefore more likely to exceed the critical shear stress required for resuspension in comparison to a slower forming layer with lower bed shear. It is also of interest to determine how much stress is caused by wave motions versus turbulent motions. This is distinguishable through the process of wave-turbulence decomposition (Section 3.2.4), which converts a wave signal into frequency space to determine which energy is due to waves versus turbulence, and from this can determine the relative stress contributions.

\subsubsection{Flow within Seagrass Beds}

Submerged macrophytes can significantly alter the hydrodynamic characteristics of near bed flow. In shallow wave dominated environments, seagrasses are often cited as attenuating wave heights and thereby lowering the concentration of suspended sediment in the water column (Granata et al. 2001). However, the mechanisms behind these macro scale turbidity effects occur 
as a result of flow modification within the seagrass canopy and the resulting effects on the bottom boundary layer. Changes in velocity structure, turbulence generation, and wave attenuation with depth within a seagrass canopy have been documented in several studies, however detailed near bed flow structure has not been thoroughly examined within a seagrass bed.

Velocities within a seagrass canopy are lower than the overlying flow as a result of the skin friction and form drag from the physical structure of the vegetation that dissipates momentum from the flow through turbulence generation (Fonseca and Fischer 1986, Koch and Gust 1999). In a pure current environment, velocities within a bed of Zostera marina were found to be $40-70 \%$ of the overlying flow, and with greater velocity reduction at higher vegetation densities (Lacy and Wylie-Echeverria 2011). Hansen and Reidenbach (2012) found a velocity reduction of $70-90 \%$ when comparing near bed mean flow within a bed of $Z$. marina and an adjacent bare site. Flow intensification near the bed has been observed within seagrass meadows as a result of vertical biomass distribution of a Z. marina plant. Seagrass structurally consists of a single stem (or sheath) extending upwards from the sediment, from which multiple leaves emerge (Figure 3.1). This morphology results in a region of lower vegetation density near the bed, which is less effective at removing momentum from the flow compared to the portion of the seagrass canopy occupied by the higher density blades (Ackerman and Okubo 1993). 


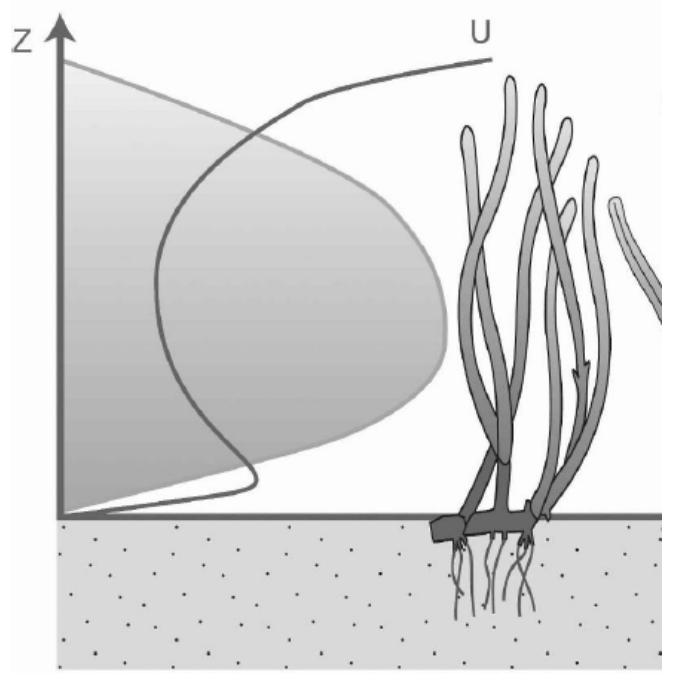

Figure 3.1: Flow intensification near the bed as a result of biomass distribution. Shaded area represents seagrass biomass distribution, curve shows flow velocities from Ackerman and Okubo (1993), and the plant to the right shows the morphology of Zostera marina. Figure modified from Koch et al. (2006).

Turbulence intensity is also an important parameter to quantify in understanding the mixing of sediment, as well as other dissolved and particulate mass, from the sea floor to the above water column, especially in comparing a bare site to a vegetated site. The turbulence experienced within a vegetated canopy can vary greatly depending on the density of vegetation. When density is high, mean flow will be displaced over the canopy, creating a region of relatively quiescent flow within the vegetation with lower mean flow and therefore reduced turbulence intensity. At medium to low densities, however, stem-wake interactions within the canopy can create turbulent eddies that are formed from flow across each individual plant shoot. This, coupled with an increase in flow, can result in much higher within canopy turbulence compared to the relatively unobstructed mean flow in an unvegetated environment.

Blade density has been found to influence turbulence generation within a canopy of emergent vegetation, with high density beds producing less turbulence than low density beds 
(Nepf et al. 1997). As current velocities increase in high density beds, seagrass blades bend and create a skimming flow that deflects flow momentum upward and protects the sea floor. In sparse beds, individual shoots each create wakes that enhance turbulent mixing and bed shear locally (Nepf 1999) and may modify or obscure the boundary layer structure. The dominant turbulent length scale is also modified by vegetation, shifting to a smaller eddy scale, likely due to seagrass stems breaking apart larger eddies (Nepf et al. 1997). In a small region near the bed (z/h $<0.1)$, Nepf et al. (1997) found that bed shear processes control turbulence production; however, higher in the water column turbulence production was dominated by stem-wake interaction.

Lowe et al. (2007) showed that the rate of wave energy dissipation was governed by in canopy flow structure, linking large scale attenuation to small scale flows. More wave energy attenuation occurred when the flow had a higher initial velocity and a larger wave period. Specifically, Lowe et al. (2005) found that attenuation was a function of canopy element spacing and wave orbital excursion length, with greater attenuation occurring for larger ratios of element spacing/element diameter and larger orbitals. Waves with very small orbital excursion lengths are attenuated by inertial forces, and therefore the least attenuated, while waves with very large orbital excursion lengths are quasi-unidirectional and experience the maximum attenuation. In the middle range of wave orbital excursion lengths, canopy shear, inertial forces, and drag interact to cause wave attenuation.

High frequency wave motions have been shown to be attenuated within a canopy due to the drag forces imparted on the flow by the vegetation; however, low frequency motions have been shown to penetrate the canopy. Hansen and Reidenbach (2012) found that a seagrass meadow acts as a low pass filter, reducing current velocities and high frequency waves, but 
allowing longer low frequency waves to penetrate the canopy. These low frequency (long period) waves that penetrate the canopy are what Lowe et al. (2007) found to be the most attenuated. This suggests that combined wave-current interaction is present at the sea floor within a seagrass canopy, and may be useful to explain the reduction in suspended sediment often observed within a seagrass meadow. Boundary layer structure within a seagrass canopy is of interest to examine to understand if adequate wave energy passes through the canopy to cause wave driven sediment suspension events, or if suspension is primarily driven by turbulence derived from vegetative drag. Again using wave-turbulence decomposition, the relative contribution of waves and turbulence to the stresses within the canopy can be compared, and can determine if wave motions impact sediment resuspension within a bed by generating turbulence within the wave boundary layer. If the meadow is considered as a low pass filter, than I would expect a thicker wave boundary layer, similar to the bare case with longer period waves. However, high turbulence intensities created by stem-wake interaction could also obscure the wave boundary layer in a seagrass bed altogether, especially as lower frequency waves in a shallow coastal bay are more rare, and may not create a strong boundary layer to begin with.

\subsubsection{Objectives}

The objective of this chapter is to analyze and compare near-bed flows in multiple wave conditions at a vegetated and unvegetated (bare) site. Boundary layer characteristics will first be quantified at a bare site, comparing a day with relatively wavy flow to a day with few waves. Mean velocity structure will be quantified for both wave conditions, and boundary layer thickness determined using a transition in the log profile between the WBL and the overlying layer. The region of contaminated flow measurements near the bed due to backscatter effects 
from the acoustic Doppler velocimeter (ADV) will be identified and removed from analysis. Stress profiles, divided into wave and turbulent components, as well as the distribution of turbulent kinetic energy (TKE) will be compared for these two flow conditions. Bed shear stress will be quantified using several different methods.

A similar analysis will occur for flow within a vegetated seagrass bed comparing low wave and high wave data sets. Again, log profiles will be used to determine if a wave boundary layer is visible within the turbulent flow, and stress and TKE profiles will be compared between these two conditions. Seagrass densities at our site are within the moderate to low range (Table 2.1), so we expect significant turbulence generation from stem-wake interaction. Finally, bed shear stress will be computed for both flow conditions and compared to measured suspended sediment concentrations. Comparing bare and vegetated flow, we will draw conclusions on the effect of medium to low density vegetation on the formation of a wave boundary layer, and the consequences of these differences in flow for mass transport within a vegetated canopy. 


\subsection{Methods}

\subsubsection{Data Collection}

Research was conducted in South Bay, a shallow coastal lagoon located within the Virginia Coast Reserve Long Term Ecological Research site (VCR LTER) on the Delmarva Peninsula, Virginia (Figure 2.1). A full description of South Bay can be found in the methods section of Chapter 2. In addition to the seasonal data described in Chapter 2, high resolution velocity profiles were recorded at three sites in the VCR LTER in ten min increments using a Nortek Vectrino II acoustic Doppler profiler (Figure 3.2). Data were collected during July 2012 and July 2013 at the center seagrass site, during July 2012, October 2012, and July 2013 at the bare (unvegetated) site, and at a second bare site (denoted sbare) during October 2012 and July 2013. Additionally, current profilers (Nortek Aquadopp) with attached optical backscatter sensors (OBS) to detect water column turbidity were deployed at the center and bare sites during July 2012 and July 2013, when the majority of Vectrino II profiles were recorded, to provide velocity measurements higher in the water column and turbidity data.

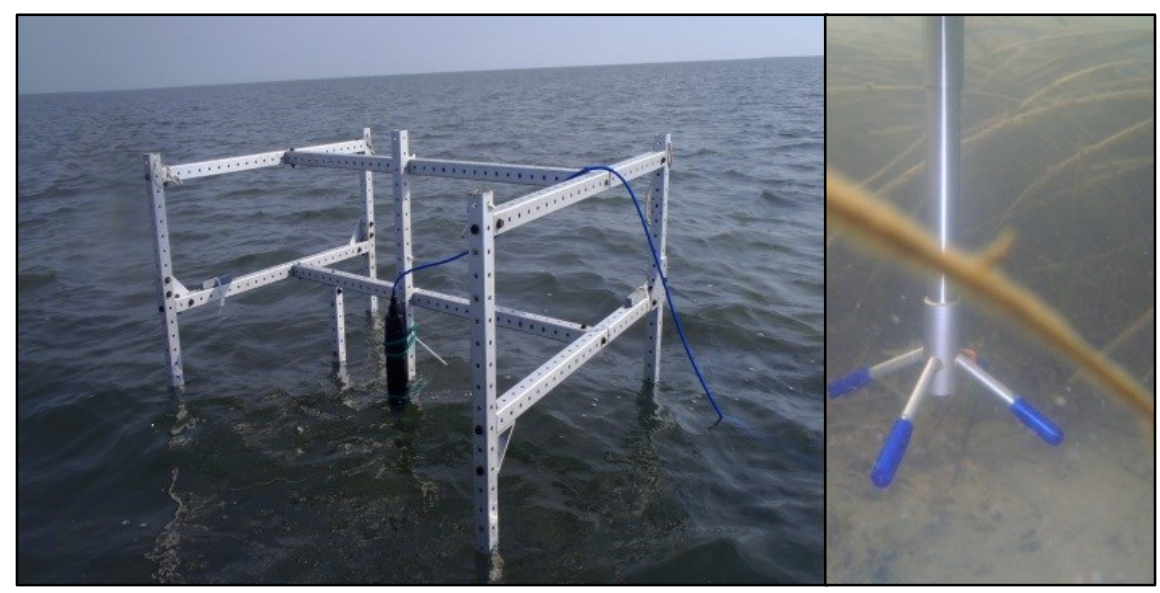

Figure 3.2: Nortek Vectrino II (Acoustic Doppler Profiler) deployed in South Bay 
The Vectrino II recorded velocity data over a $30 \mathrm{~mm}$ profile at $1 \mathrm{~mm}$ resolution at a rate of $20 \mathrm{~Hz}$. Doppler pulses are emitted from a center transmitter and received by four passive transducers angled $30^{\circ}$ towards the center, resulting in a sample volume $40-70 \mathrm{~mm}$ from the center transmitter. This high spatial and temporal resolution allowed for the resolution of turbulence motions at our site. The Vectrino II was positioned to record velocity measurements directly adjacent to the sediment-water interface to capture motions potentially associated with wave-current boundary layer development. To ensure the measurements closest to the sediment were included in the data set, several bins were positioned below the interface, indicating the location of the bottom. As a result, some profiles contain fewer than 30 velocity measurements. Seagrass was removed from beneath the probe at the vegetated site to prevent blade interference, and no notable bedforms were observed at either the seagrass or bare site.

\subsubsection{Data Processing}

Vectrino II data were validated using signal to noise ratio (SNR) and percent correlation between beams. Similar to any ADV, the Vectrino II requires sufficient particle concentrations in the water column to provide a Doppler signal, which was defined for this study as SNR $>20$ dB. Percent correlation greater than $80 \%$ was considered adequate for average velocity profiles; however, to decompose turbulence it was necessary for correlation greater than $95 \%$ to avoid interference from background instrument noise. In addition, the instrument is limited by acoustic backscatter from solid boundaries, which has been shown to contaminate data within $5 \mathrm{~mm}$ of a surface (Hay et al. 2012a).

Velocity profiles collected by the Vectrino II were first rotated into the direction of the mean flow, using an average of the rotation required for the top three points. Motion lower in 
the profile may be obscured by wave induced oscillations, and was not always representative of the dominant flow direction. Each raw data record was then analyzed to see if the SNR and percent correlation averaged across the 10 minute record exceeded $20 \mathrm{~dB}$ and $80 \%$ respectively, the recommended limits for velocity measurements. If these conditions were met, the raw data were used to calculate an average velocity profile. Due to the uncertain nature of collecting field data, several records showed evidence of fouling, and these periods of low SNR and percent correlation lowered the averages beyond those considered acceptable for analysis. Fouling occurred as a result of floating vegetation that became ensnared on the profiler head, primarily uprooted seagrass at the vegetated site and sea lettuce at the bare site. The vegetation was removed from the sensor head as soon as it was detected during data collection, however to preserve as much data as possible, the affected 10 minute records were filtered to remove the time periods during which interference occurred. This was achieved using a MATLAB filter that checked each data point individually for an SNR greater than $20 \mathrm{~dB}$ and a percent correlation greater than 80 , and removed any data where these conditions were not met. If fewer than three continuous minutes of data remained after the filter then the entire block was discarded, as approximately 3 min of data are considered necessary for good statistical averages.

Extended velocity profiles from Aquadopp profiler data were also filtered using the same criteria as the Vectrino II for average velocity profiles. Points with a correlation of less than $80 \%$ were removed from the Aquadopp data, which also removed data for which the top of the profile was out of the water during low tide. Figure 3.3 shows typical percent correlation data for an Aquadopp deployment. Poor correlation at low tide is expected when the profiling range surpasses the water depth, but this low correlation extends beyond just the region that is no longer under water. This may be due to interference or backscatter from the water surface. 


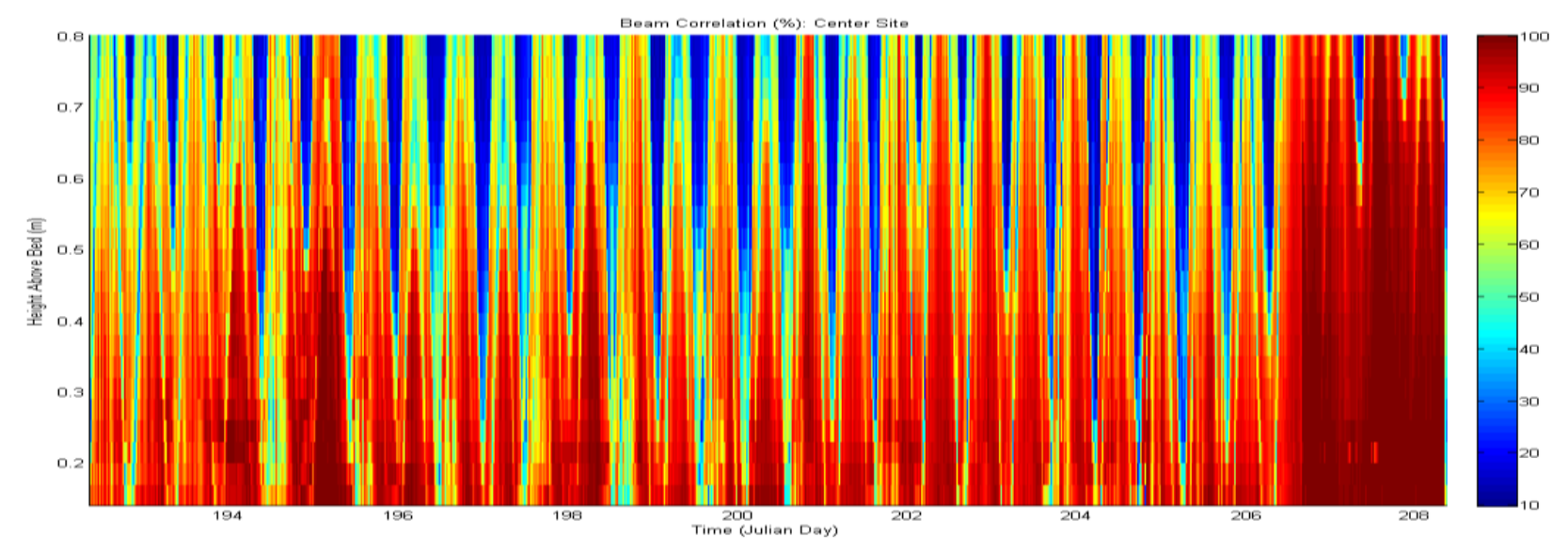

Figure 3.3: Aquadopp profiler percent correlation data for the July 2012 deployment at the seagrass site, but typical of Aquadopp data from other deployments. The break in the correlation pattern following Julian day 206 (July 25, 2012) was a result of the profiler flipping over, likely as a result of a storm that occurred on July 25, 2012. Data with percent correlation between 80 and $100 \%$ is considered valid.

\subsubsection{Boundary Layer Depth}

Velocity profiles were obtained for each 10 minute deployment record collected by the Vectrino II and profiles of the maximum velocities across each wave period were analyzed to determine if two significantly different logarithmic layers were present in the data. Logarithmic velocity layers are expected to form both within a combined wave-current boundary layer and within a current boundary layer as a result of the no slip condition. The presence of two distinct $\log$ layers was used to indicate the formation of a wave boundary layer in the flow adjacent to the sediment. If two log layers were observed, the lower layer was predicted to correspond to the combined wave-current boundary layer, and the upper layer to the overlying current boundary layer. The data included in each $\log$ layer was manipulated to achieve the best possible $\mathrm{R}^{2}$ value for the lower layer. $\mathrm{R}^{2}$ values for either profile below 0.9940 caused the profile to be discarded, as greater uncertainty would result in excessively large error (Grant et al. 1984, Grant and 
Madsen 1986, Drake et al. 1992). If no obvious split was observed, the data were simply divided into two equal sets and analyzed for a statistical difference. Shear velocity values were calculated using a best fit line calculated for the lower profile $\left(u_{c w}^{*}\right)$, then a $95 \%$ confidence interval was calculated for $u_{c w}^{*}$ values using the method of Grant et. al (1984) where the margin of error $(e)$ on $u^{*}$ is given by:

$$
e=\left(t_{\frac{\alpha}{2}, n-2}\right)\left[\frac{1}{n-2}\left(\frac{1-R^{2}}{R^{2}}\right)\right]^{1 / 2}
$$

where $\frac{t \alpha}{2}, n-2$ is the value of the Student's $t$ distribution for a $95 \%$ CI with $n-2$ degrees of freedom, $n$ is the number of data points, and $R^{2}$ is the coefficient of determination for the logarithmic regression used to determine the value of shear velocity. If these two confidence ranges did not overlap, the $u^{*}$ values obtained for the top and bottom profiles were determined to be statistically different, and therefore represented two distinct layers of logarithmic flow. This analysis was repeated for each 10 minute profile. The depth at which the split between logarithmic profiles occurred was recorded as the depth of the wave-current boundary layer $\left(\delta_{c w}\right)$

Wave-current boundary layer thickness determined from velocity profiles in situ was compared to two theoretical boundary layer depth formulations, and the predicted thicknesses were compared between the theoretical methods. First, using a relationship from Fredsoe and Deigaard (1992), the thickness of the turbulent wave boundary layer $\left(\delta_{w}\right)$ was calculated as:

$$
\delta_{w}=0.09 k_{s}\left(\frac{A}{k_{s}}\right)^{0.82}
$$

where $k_{s}$ is a measure of bed roughness, $A=\frac{u_{1 m} T}{2 \pi}$ is the free stream amplitude, $u_{1 m}$ is the velocity one meter above the bed, and $T$ is the wave period. Boundary layer thickness was also 
calculated using the shear velocities obtained from the logarithmic profiles determined to be within the wave-current boundary layer following Grant and Madsen (1986):

$$
\delta_{c w}=\frac{\kappa u_{c w}^{*}}{\omega}
$$

where $\kappa$ is von karman's constant, and $\omega$ is the wave frequency in radians.

\subsubsection{Wave-Turbulence Decomposition}

Variations in turbulence characteristics between the overlying flow and the wave boundary layer are of particular interest, as these control the extent of near bed mixing and influence sediment suspension. In wave dominated environments, turbulence cannot be calculated through the traditional approach of quantifying variation from a mean, as wave motion also contributes to these variations. Therefore, the phase method of wave-turbulence decomposition (Bricker and Monismith 2007) was employed.

Waves and turbulence can both modify sediment dynamics in shallow water environments (de Boer 2007), however turbulent movements are often masked by larger amplitude variations caused by waves (Trowbridge 1998). Separating these components is important to accurately quantify turbulent mixing and the bed shear stresses that initiate sediment motion. To independently assess the effect of each of these mechanisms, the instantaneous horizontal and vertical velocity components can be separated in to the sum of the mean velocity, turbulent velocity, and wave induced orbital velocity (Equation 1.1). Each component can be individually determined using a method of spectral wave-turbulence decomposition.

Many methods of wave-turbulence decomposition require multiple instruments (Trowbridge 1998; Benliov \& Filyushkin 1970), however the Phase method formulated by Bricker and Monismith (2007) and employed in this research uses a single point velocity 
measurement to determine the phase lag between the $u$ and $w$ components of surface waves and calculate wave and turbulent components. Natural waves consist of oscillations at many frequencies superimposed to form the observed motions. Turbulent motions occur at much smaller frequencies that are often masked within a wave form; however, can be visualized using a Fourier transform which converts the raw velocity data into a sum of sine and cosine functions. Plotting the frequencies of these sinusoidal functions as a power spectrum, the wave peak can be identified as a region of higher energy and separated from turbulence (Figure 3.4).

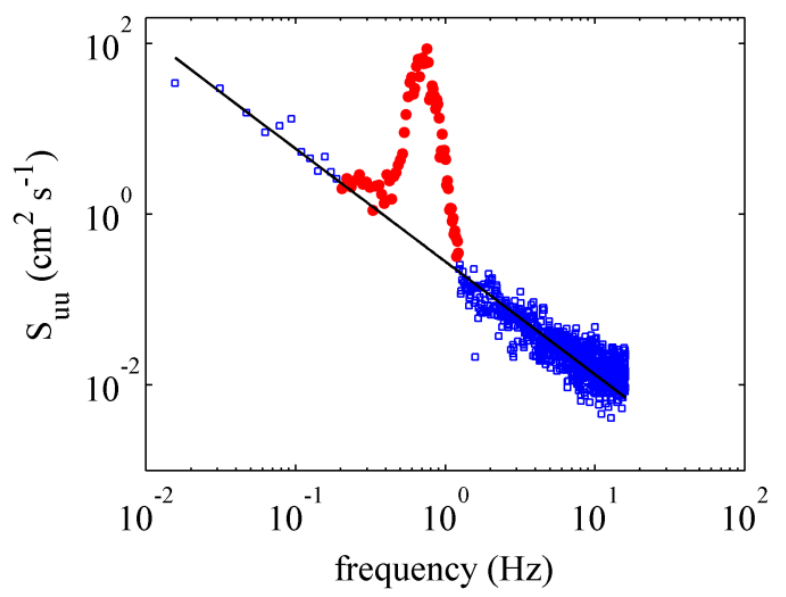

Figure 3.4: PSD of the horizontal velocity. Black line is best fit to data outside the wave peak, used to estimate the peak area. Red points correspond to the estimated wave peak, while blue points represent turbulent scatter. From Hansen and Reidenbach (2012).

The turbulence spectrum can be determined by subtracting the raw velocity spectrum $\left(S_{u w}(\omega)\right)$ from the wave induced orbital velocity spectrum $\left(S_{\widetilde{u} \widetilde{w}}(\omega)\right)$ :

$$
S_{u^{\prime} w^{\prime}}(\omega)=S_{u w}(\omega)-S_{\widetilde{u} \widetilde{w}}(\omega)
$$

Integrating the spectra on the right side of Equation 3.3, we obtain equations for the total and wave Reynolds stress, which are visually represented as the total area under the curve in Figure 
3.3 and the area beneath the red portion of the curve respectively. Wave stresses are calculated through a spectral sum, as shown in Equation 3.4 below.

$$
\overline{\tilde{u} \widetilde{w}}=\int_{-\omega_{N y q u i s t}}^{\omega_{N y q u i s t}} S_{\widetilde{u} \widetilde{w}}(\omega) d \omega
$$

where $S_{\widetilde{u} \widetilde{w}}$ is the two-sided cross-spectral density (CSD) of the wave-induced orbital velocities, $\omega$ is frequency, and $\omega_{\text {Nyquist }}$ is the Nyquist sampling frequency, equal to half the frequency of the discrete signal. With a finite data set, the equation for wave stress is converted to summation notation:

$$
\overline{\tilde{u} \widetilde{W}}=\sum_{-N / 2}^{N / 2} \widetilde{U}_{j} * \widetilde{W}_{j}
$$

where $U_{j}$ and $W_{j}$ are the Fourier transforms of $u(t)$ and $w(t)$ at frequency $\omega$, and $N$ is the number of data points used in the Fourier transform. $\widetilde{U}_{j}$ and $\widetilde{W}_{j}$ are calculated from the difference of raw $U_{j}$ and $W_{j}$ and the turbulent $U_{j}^{\prime}$ and $W_{j}^{\prime}$. A CSD includes both positive and negative values, so prior to summation the wave stresses should be converted to autospectral density (PSD), which only includes positive real values. Rewriting the Fourier coefficients in phasor notation, the wave stress can be expressed as shown in equation 3.4:

$$
\overline{\tilde{u} \widetilde{w}}=\sum_{j=\text { wave peak }}\left|\widetilde{U}_{j}\right|\left|\widetilde{W}_{j}\right| \cos \left(\angle W_{j}-\angle U_{j}\right)
$$

Total Reynolds stress can be calculated in a similar fashion, following equations 3.2 through 3.4, but instead summing over the entire curve instead of just the wave peak. The calculated values of $\overline{\tilde{u} \widetilde{w}}$ and $\overline{u w}$ are then substituted into equation 3.5 to calculate the turbulent Reynolds stress $\left(\overline{u^{\prime} w^{\prime}}\right)$.

$$
\overline{u^{\prime} w^{\prime}}=\overline{u w}-\overline{\tilde{u} \widetilde{w}}
$$


Wave frequency $(f)$ was determined using spectral analysis internally within the wave gauge (Ruskin RBR) software, and wavelength was calculated via wave number from wave period (1/f) and water depth, following Soulsby (2006). Analysis of turbulent kinetic energy (TKE) was also possible following the isolation of the wave and turbulent components of the flow, as TKE can be greatly overestimated in wavy flows if all deviations from the mean are included as turbulent motion. Considering only the turbulent variations in the streamwise $(u$ ') transverse $\left(v^{\prime}\right)$ and vertical $\left(w^{\prime}\right)$ directions, TKE was calculated as:

$$
T K E=\frac{1}{2}\left(\overline{u^{\prime 2}}+\overline{v^{\prime 2}}+\overline{w^{\prime 2}}\right)
$$

\subsubsection{Sediment Suspension}

Water column turbidity was measured as a voltage using a turbidity sensor (OBS), which recorded data for one of every 10 minutes. Voltages were converted to TSS concentrations in $\mathrm{mg} \mathrm{L}{ }^{-1}$ through calibration curves derived using sediment from South Bay. Negative concentrations and unreasonably high values $(>10,000 \mathrm{mV})$ were filtered from the data set, then the data was smoothed by averaging the recorded values over $60 \mathrm{sec}$ increments.

Physical mechanisms hypothesized to control water column turbidity were explored using Vectrino II velocity measurements to calculate turbulence at different heights above the sea floor. Using spectral analysis, the wave peak was isolated and removed from the spectrum and the remaining energy summed to determine the turbulent component. Wave orbital velocity at incremental heights above the bed was also considered an influential factor on sediment suspension, and was calculated as follows using wave-turbulence decomposition (Wiberg and Sherwood 2008): 


$$
u_{o r b, R M S}^{2}=2\left[\sum_{j} S_{\widetilde{u} \widetilde{u}_{j}} \Delta f_{j}+\sum_{j} S_{\tilde{v} \widetilde{v_{j}}} \Delta f_{j}\right]
$$

where $\mathrm{u}_{\mathrm{orb}, \mathrm{RMS}}$ is the root mean squared (rms) orbital velocity. By summing only the wave spectra, this method excludes contamination from mean current and turbulence motion. Wave orbital velocity can also be approximated using linear wave theory for small amplitude monochromatic waves (Dean and Dalrymple 1991):

$$
u_{o m}=\frac{\pi H_{s} \cosh (k z)}{T \sinh (k h)}
$$

where $u_{o m}$ is the horizontal component of the orbital velocity, $k=\frac{2 \pi}{L}$ is the wavenumber, $L$ is the wavelength, $z$ is the height above the bed, and $h$ is the depth of the water column.

Total bed shear stress was calculated to determine if the bed shear experienced was greater than the critical shear stress following several methods. First, Wiberg and Sherwood (2008) calculated total bed shear stress as the root of the sum of the squared values of the wave and current contributions to the shear stress (Equation 1.9), where the individual wave $\left(\tau_{\text {wave }}\right)$ and current $\left(\tau_{\text {currrent }}\right)$ component are calculated as:

$$
\begin{gathered}
\tau_{\text {wave }}=\frac{1}{2} f_{w} \rho u_{b}^{2} \quad f_{w}=0.04\left[\frac{u_{b} T}{2 \pi k_{b}}\right]^{-0.25} \\
\tau_{\text {current }}=\rho u_{* \text { current }}^{2}
\end{gathered}
$$

where $f_{w}$ is the wave friction factor, $\rho$ is the fluid density, $u_{b}$ is the bottom orbital velocity, and $k_{b}$ is the characteristic roughness length (Fagharazzi and Wiberg 2009). Lawson et al. (2007) estimates $k_{b}$ as $3 \mathrm{D}_{84}$, where $\mathrm{D}_{84}$ is the sediment grain diameter $\left(\mathrm{D}_{\mathrm{x}}\right)$ at which $84 \%$ of the sample is finer than $D_{x}$.

Salehi and Strom (2012) compared multiple methods of calculating bed shear stress, and determined that a logarithmic profile method (Grant and Madsen 1986, Kim et al. 2000, 
Anderson at al. 2007) was most accurate for current dominated regions while a modified TKE method (Anderson et al. 2007) was most accurate for wave dominated flows. Both methods were considered and compared for South Bay data. The log profile method uses a velocity profile of near bed flow to fit a value of $u^{*}$ for combined wave-current boundary layer flow in the following form:

$$
\frac{u}{u_{*}}=\frac{1}{\kappa} \ln \left(\frac{z u_{*}}{v}\right)+B
$$

where $\mathrm{B}$ is a function of the bed roughness, set equal to 5.5 for hydraulically smooth beds. Shear stress was then calculated from the $u^{*}$ determined by the log profile as (Grant et al. 1984):

$$
\tau_{b}=\rho u_{*}^{2}
$$

where $\rho$ is the fluid density.

The modified TKE method calculates bed shear stress using only the vertical turbulent fluctuations $\left(\overline{w^{\prime}}\right)$ to minimize the influence of wave orbital motion on the velocities.

$$
\tau_{b}=0.9 \rho \overline{w^{\prime 2}}
$$

Near the bed, vertical velocity fluctuations are less susceptible to wave orbital motion and therefore more accurately characterize the turbulent fluctuations inducing bed shear (Salehi and Strom 2012). Instrument noise errors from vertical velocity measurements are also smaller than those from horizontal measurements by an order of magnitude (Kim et al. 2000). 


\subsection{Results and Discussion}

Near bed velocity profiles were collected over a range of wave conditions in nine separate deployments from July 2012 through July 2013, each lasting between one and two hours. Data was collected at the center seagrass site only during summer months when the meadow was near peak biomass. Densities were documented as $347 \pm 73$ shoots $/ \mathrm{m}^{2}$ and $411 \pm$ 33 shoots $/ \mathrm{m}^{2}$ in July 2012 and July 2013 respectively. Significant wave height averages at the bare site ranged from $0.006 \mathrm{~m}$ on October 14, 2012 through $0.114 \mathrm{~m}$ on July 1, 2013, and average vegetated site $H_{s}$ values between $0.001 \mathrm{~m}$ on July 13, 2012 and $0.077 \mathrm{~m}$ on July 24, 2012 (Table 3.1). These wave heights were relatively small, but encompassed the average $\mathrm{H}_{\mathrm{s}}$ range of 0.02 to $0.09 \mathrm{~m}$ observed during seasonal deployments in South Bay. Peak wave heights that occurred during storm events were impossible to record due to logistical issues, as the Vectrino II could not be remotely deployed, so collection was limited to times deemed safe for boat travel. As a result, these near bed profiles represent conditions with wave heights only up to $35 \%$ of the largest waves observed at the bare site over all seasonal deployments (overall bare site $\mathrm{H}_{\mathrm{s} \max }=0.55 \mathrm{~m}$ ) and $67 \%$ of the largest wave height observed at the seagrass site in July $2012\left(\mathrm{H}_{\mathrm{s} \max }=0.15 \mathrm{~m}\right)$, but do include the largest wave heights observed at the seagrass site during July $2013\left(\mathrm{RBR} \mathrm{H}_{\mathrm{s} \max }=0.19 \mathrm{~m}\right)$. To determine the effects of wave motion on near bed boundary layer flows, the runs with greatest (7/1/2013 and 7/24/2012) and least (10/14/2012 and 7/13/2012) significant wave height were selected from both the bare and vegetated site for further analysis. 
Table 3.1: Wave properties and environmental conditions for each Vectrino II run, averaged over the sampling duration. Temperature, depth, $\mathrm{H}_{\mathrm{s}}, \mathrm{H}_{\max }$, and $\mathrm{T}_{\mathrm{s}}$ data were obtained from collocated wave gages. Wind speed and direction were recorded from the Hog Island met station. Asterisk indicates data was recorded at sbare, a bare site further south of the meadow with different current conditions. Bolded dates were selected for further analysis.

\begin{tabular}{|c|c|c|c|c|c|c|c|c|}
\hline & $\begin{array}{c}\text { Temp } \\
\text { (C) }\end{array}$ & $\begin{array}{l}\text { Depth } \\
(\mathrm{m})\end{array}$ & $\mathrm{H}_{\mathrm{s}}(\mathrm{m})$ & $\begin{array}{c}\mathrm{H}_{\max } \\
(\mathrm{m})\end{array}$ & $\mathrm{T}_{\mathrm{s}}(\mathrm{s})$ & $\lambda(\mathrm{m})$ & $\begin{array}{c}\text { Wind Speed } \\
\left(\mathrm{m} \mathrm{s}^{-1}\right)\end{array}$ & $\begin{array}{c}\text { Wind } \\
\text { Direction }\end{array}$ \\
\hline & \multicolumn{8}{|c|}{ Bare } \\
\hline 07_25_2012 & 26.7 & 1.05 & 0.030 & 0.056 & 1.62 & - & 3.0 & $\mathrm{~N}$ \\
\hline $07 \_26 \_2012 *$ & 26.4 & 0.90 & 0.084 & 0.127 & 1.86 & - & 3.2 & SW \\
\hline 10_14_2012* & 17.1 & 0.93 & 0.006 & 0.015 & 1.65 & 2.97 & 2.9 & SW \\
\hline \multirow[t]{2}{*}{ 07_01_2013 } & 24.9 & 0.61 & 0.114 & 0.191 & 1.48 & 2.51 & 3.4 & $\mathbf{S}$ \\
\hline & \multicolumn{8}{|c|}{ Vegetated } \\
\hline 07_12_2012 & 24.8 & 0.81 & 0.018 & 0.036 & 1.39 & - & 2.0 & $\mathrm{E}$ \\
\hline 07_13_2012 & 26.3 & 0.71 & 0.001 & 0.002 & 2.18 & 2.83 & 1.1 & $\mathbf{E}$ \\
\hline 07_24_2012 & 29.1 & 0.85 & 0.077 & 0.149 & 1.50 & 3.63 & 2.5 & $\mathbf{W}$ \\
\hline 07_26_2012 & 25.9 & 0.41 & 0.041 & 0.085 & 1.52 & - & 3.1 & SW \\
\hline 07_02_2013 & 23.1 & 0.60 & 0.003 & 0.009 & 1.36 & - & 2.6 & $\mathrm{~S}$ \\
\hline
\end{tabular}

\subsubsection{Flow Conditions}

Bottom boundary layer flows primarily depend on the water depth, near bed current velocities, wave orbital velocities, and bottom roughness. Of these variables, bottom roughness was assumed to be constant through an hour long deployment. The remaining three variables will be considered across hour long records for each of the four deployments below.

\subsubsection{Water Depth}

Water depths in South Bay ranged from around $30 \mathrm{~cm}$ through $200 \mathrm{~cm}$. At shallower depths, less wave motion will be attenuated through the water column leaving more energy to interact with the sea floor; however, waves generated in shallow water will also be smaller and 
less energetic. Vectrino II data was recorded primarily at low to mid tide to capture data in which it was possible for wave velocities to interact with the sea floor. July 1, 2013 and July 13, 2012 were collected on rising tides, while October 14, 2012 and July 24, 2012 were collected on falling tides. Flows in South Bay have been previously found to be asymmetric, with higher velocities recorded during ebbing tides than flooding tides (Hansen and Reidenbach 2012). This is consistent with the average velocity data presented in Table 3.2. Tidal current velocities are also expected to be greater closer to mid tide as the majority of water is passing through the bay, and lower at high and low tide.

\subsubsection{Near Bed Current Velocities}

Velocity profiles were recorded at $20 \mathrm{~Hz}$ and therefore included both turbulence and wave oscillations. Hourly averages smoothed wave and turbulent fluctuations, and were reported as the mean current velocities at $5 \mathrm{~mm}$ and $25 \mathrm{~mm}$ above the bed (Table 3.2). Mean velocity ranged from a low of $0.4 \mathrm{~cm} \mathrm{~s}^{-1}$ at $5 \mathrm{~mm}$ above the bed on July 13, 2012 to a high of $4.7 \mathrm{~cm} \mathrm{~s}^{-1}$ at $25 \mathrm{~mm}$ above the bed on October 14, 2012. Mean velocities were larger higher in the water column for all four deployments presented below, which is consistent with a logarithmic velocity profile near the bed.

Mean velocity across the one hour deployment at the bare site on October 14, 2012 was $3.1 \mathrm{~cm} \mathrm{~s}^{-1}$ at $5 \mathrm{~mm}$ above the bed and $4.7 \mathrm{~cm} \mathrm{~s}^{-1}$ at $25 \mathrm{~mm}$ above the bed, and $2.8 \mathrm{~cm} \mathrm{~s}^{-1}$ and 3.8 $\mathrm{cm} \mathrm{s}^{-1}$ on July 1, 2013 at $5 \mathrm{~mm}$ and $25 \mathrm{~mm}$ respectively (Table 3.2). Frictional boundary effects on mean flow velocity are apparent, as the difference between the velocities at $5 \mathrm{~mm}$ and $25 \mathrm{~mm}$ above the bed was $1.6 \mathrm{~cm} \mathrm{~s}^{-1}$ on October 14, 2012 and $1 \mathrm{~cm} \mathrm{~s}^{-1}$ on July 1, 2013 (Figures 3.5 and 3.6 respectively). The steeper gradient on October 14, 2012 is likely caused by the larger free 
stream velocity. Less attenuation occurred with depth during the high wave conditions on July 1 , 2013 compared to the low wave conditions on October 14, 2012, meaning that the velocities at 5 $\mathrm{mm}$ and $25 \mathrm{~mm}$ were more uniform. This may be due to the higher wave energy present on July 1, 2013, which may dissipate little orbital motion over the shallow depth of $0.57 \mathrm{~m}$. Greater mean flow magnitude during the low wave deployment on October 14, 2012 may also be a result of eliminating the negative flows induced by wave orbital motion from the average, which would be included for the high wave case on July 1, 2013.

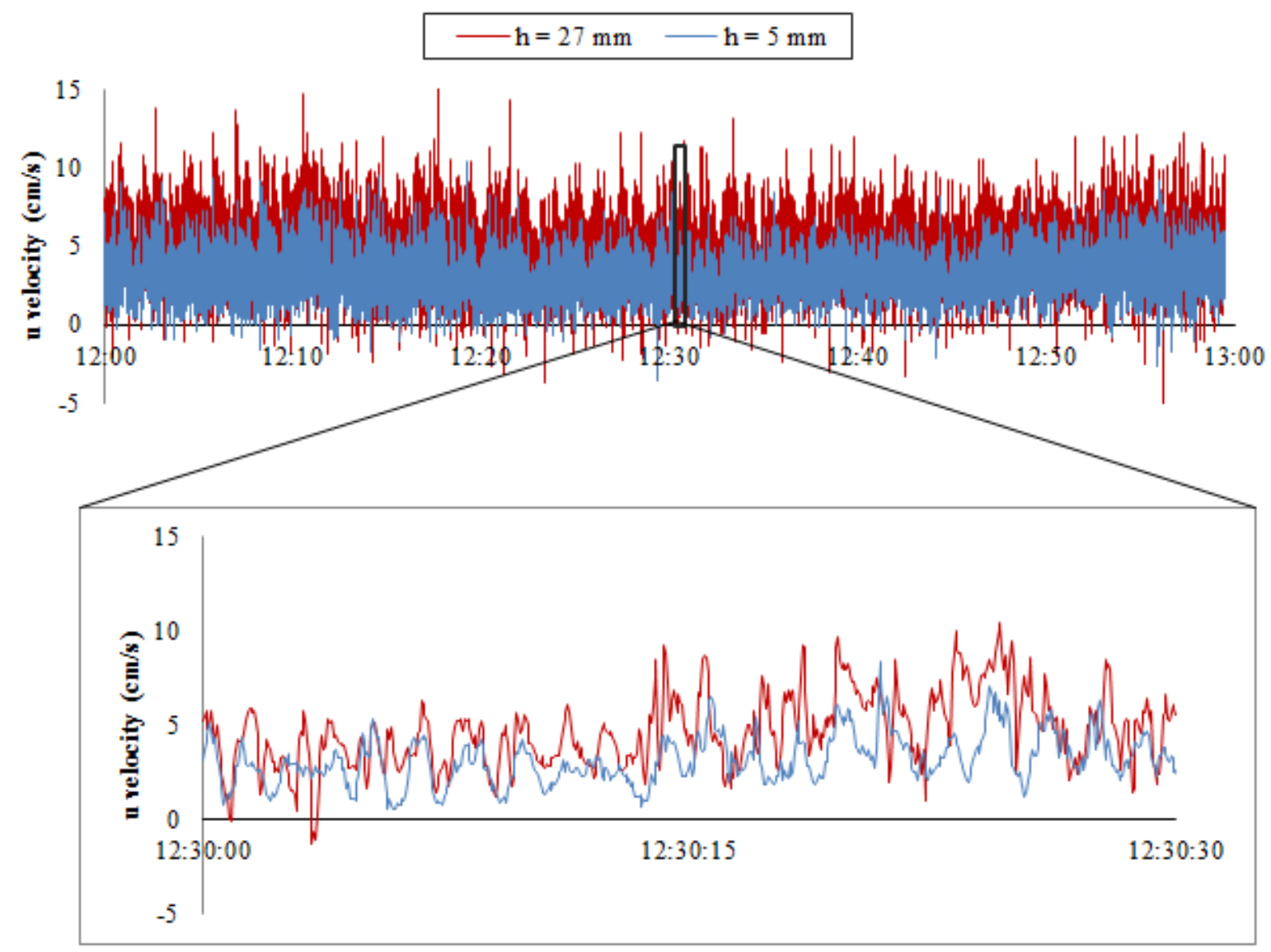

Figure 3.5: Velocity in the direction of mean flow recorded on October 14, 2012 from 12:00 through 13:00 at $5 \mathrm{~mm}$ (blue line) and $27 \mathrm{~mm}$ (red line) above the sea floor. Thirty seconds of data from 12:30:00 through 12:30:30, indicated by the black box in the top plot, are magnified in the bottom plot. 


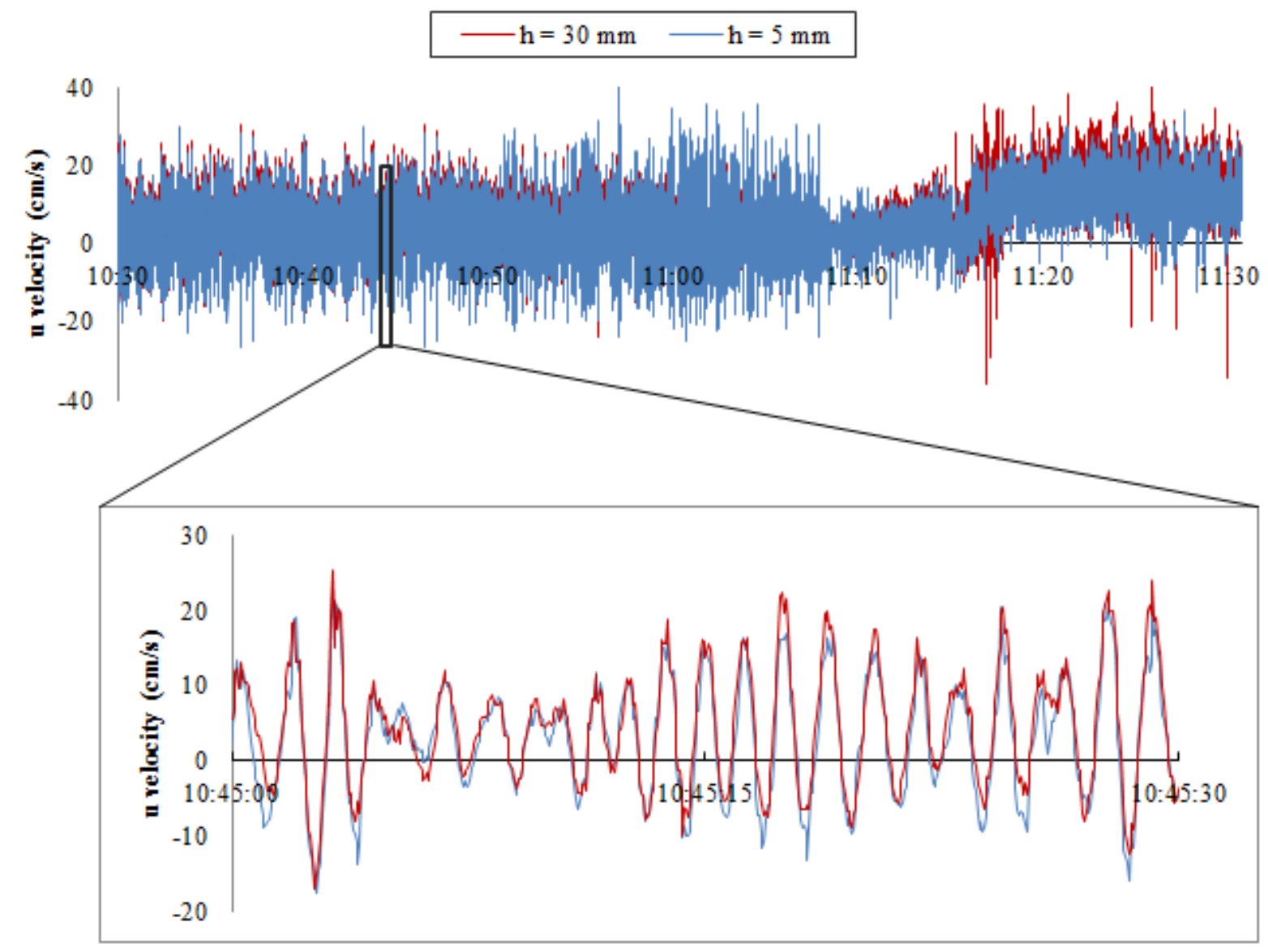

Figure 3.6: Velocity in the direction of mean flow recorded on July 1, 2013 from 10:30 through 11:30 at $5 \mathrm{~mm}$ (blue line) and $30 \mathrm{~mm}$ (red line) above the sea floor. Reduction of flow velocities near 11:10 indicates fouling by floating vegetation, spike in $30 \mathrm{~mm}$ data prior to 11:20 occurs as instrument is cleared of vegetation, and recording continues thereafter. Thirty seconds of data from 10:45:00 through 10:45:30, indicated by the black box in the top plot, are magnified in the bottom plot.

July 13, 2012 at the seagrass site showed the lowest total flow velocity of all four data sets, never exceeding $5 \mathrm{~cm} \mathrm{~s}^{-1}$, with a mean velocity of $0.4 \mathrm{~cm} \mathrm{~s}^{-1}$ at $5 \mathrm{~mm}$ and a mean velocity of $0.6 \mathrm{~cm} \mathrm{~s}^{-1}$ at $25 \mathrm{~mm}$ (Table 3.2). These low flow velocities may be a result of current attenuation within the seagrass bed, which was combined in this case with a lack of wave orbital motion to 
create particularly small mean velocities. July 24,2012 at the seagrass site was similar to the high wave condition at the bare site on July 1,2012; data at $5 \mathrm{~mm}$ above the bed and $25 \mathrm{~mm}$ above the bed have comparable average velocities $\left(3.0 \mathrm{~cm} \mathrm{~s}^{-1}\right.$ and $4.0 \mathrm{~cm} \mathrm{~s}^{-1}$ respectively, Table $3.2)$.

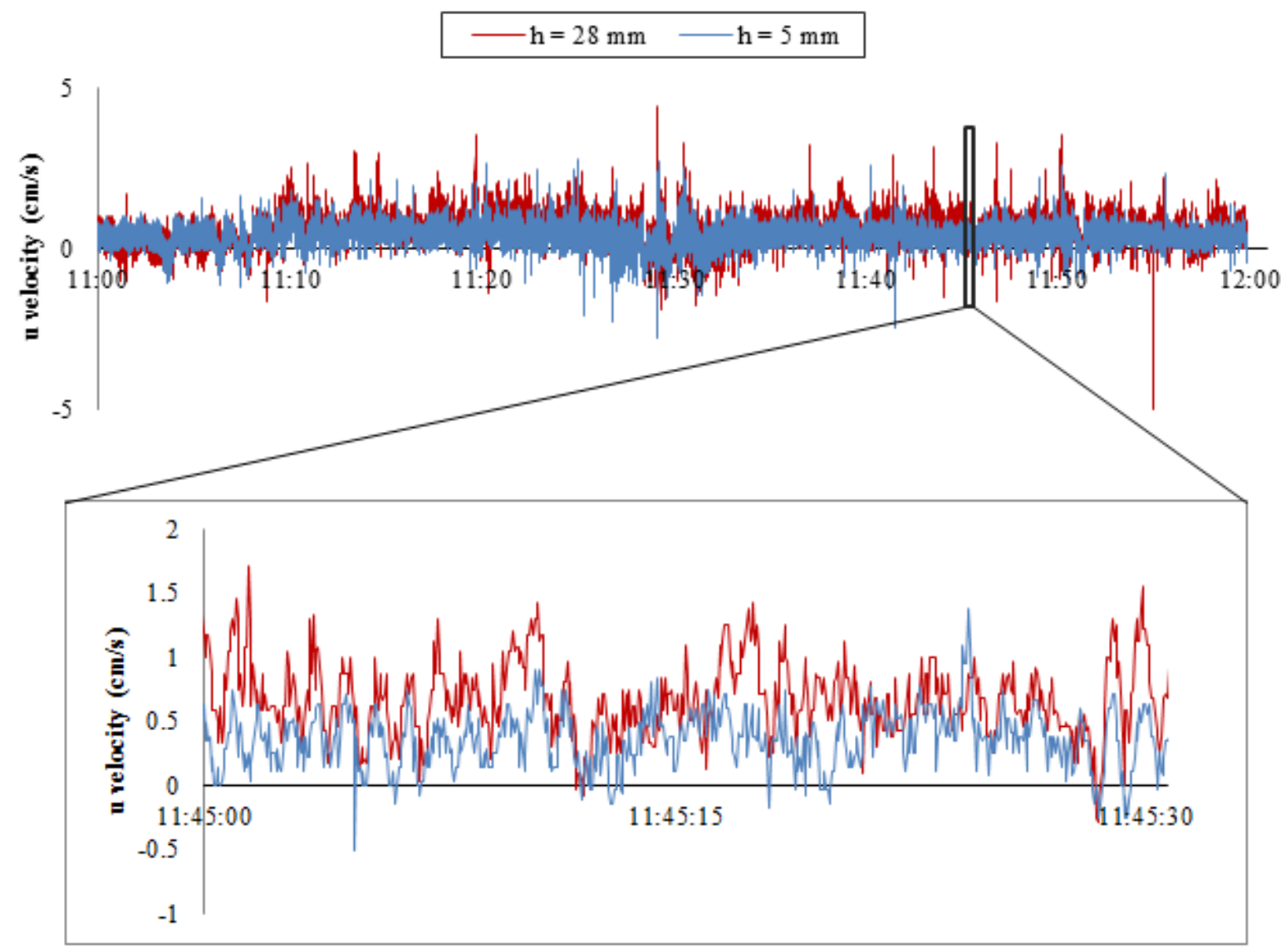

Figure 3.7: Velocity in the direction of mean flow recorded on July 13, 2012 from 11:00 through 12:00 at $5 \mathrm{~mm}$ (blue line) and $28 \mathrm{~mm}$ (red line) above the sea floor. Thirty seconds of data from 11:45:00 through 11:45:30, indicated by the black box in the top plot, are magnified in the bottom plot. 


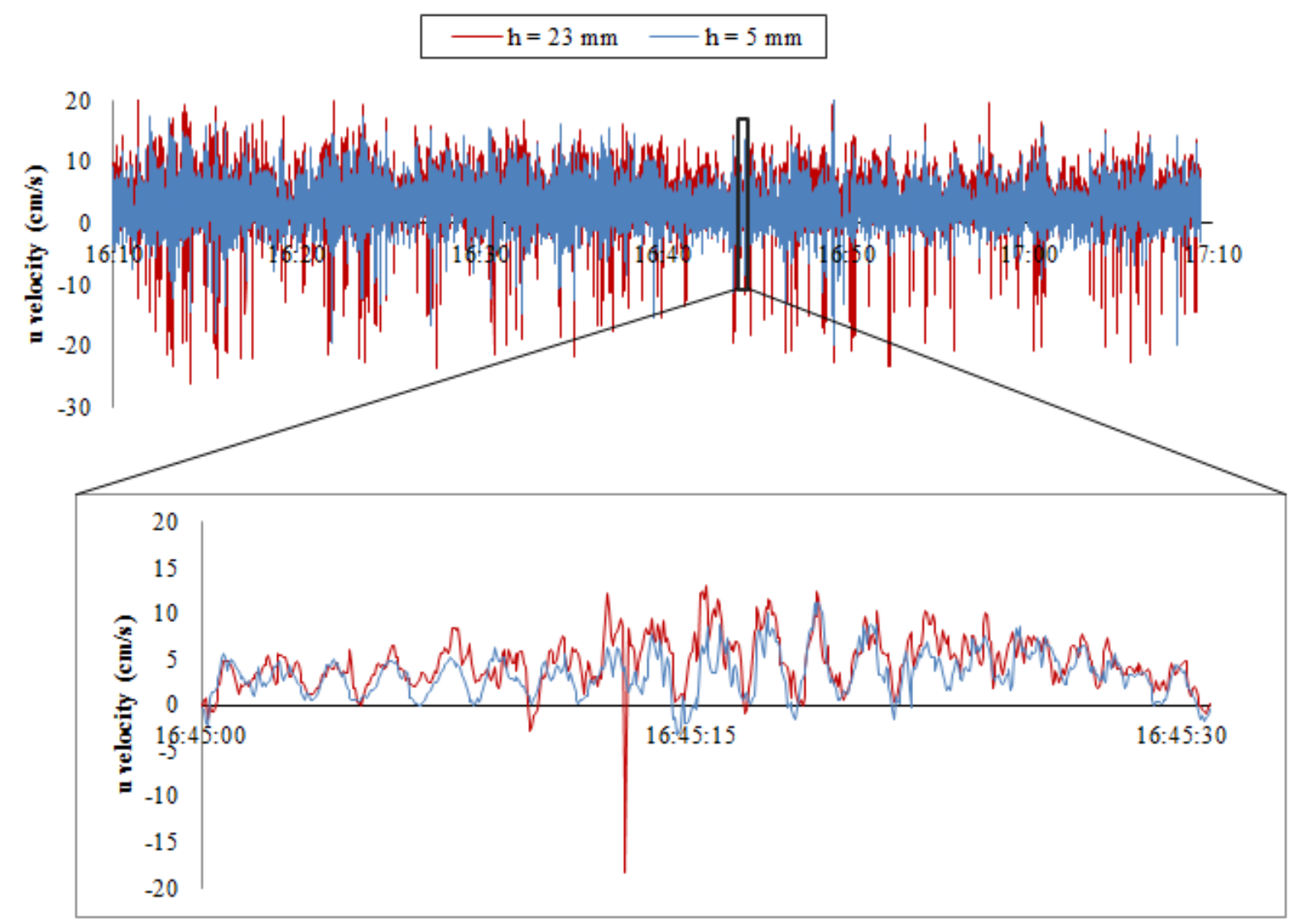

Figure 3.8: Velocity in the direction of mean flow recorded on July 24, 2012 from 16:10 through 17:10 at $5 \mathrm{~mm}$ (blue line) and $23 \mathrm{~mm}$ (red line) above the sea floor. Thirty seconds of data from 16:45:00 through 16:45:30, indicated by the black box in the top plot, are magnified in the bottom plot.

\subsubsection{Wave Conditions}

At the bare site, wave motion was evident during the high wave deployment on July 1, 2013, with a peak frequency of $0.73 \mathrm{~Hz}$. The low wave deployment on October 14, 2012 also exhibited a wave peak, however this peak was much lower than the waves from July 1, 2013, and had a slightly lower peak frequency of $0.62 \mathrm{~Hz}$. Wave spectra for both deployments are plotted together in Figure 3.9 for comparison. Energy in the turbulent portion of the spectrum was 
comparable between these two days, with slightly lower values in the high frequency range for the low wave deployment.

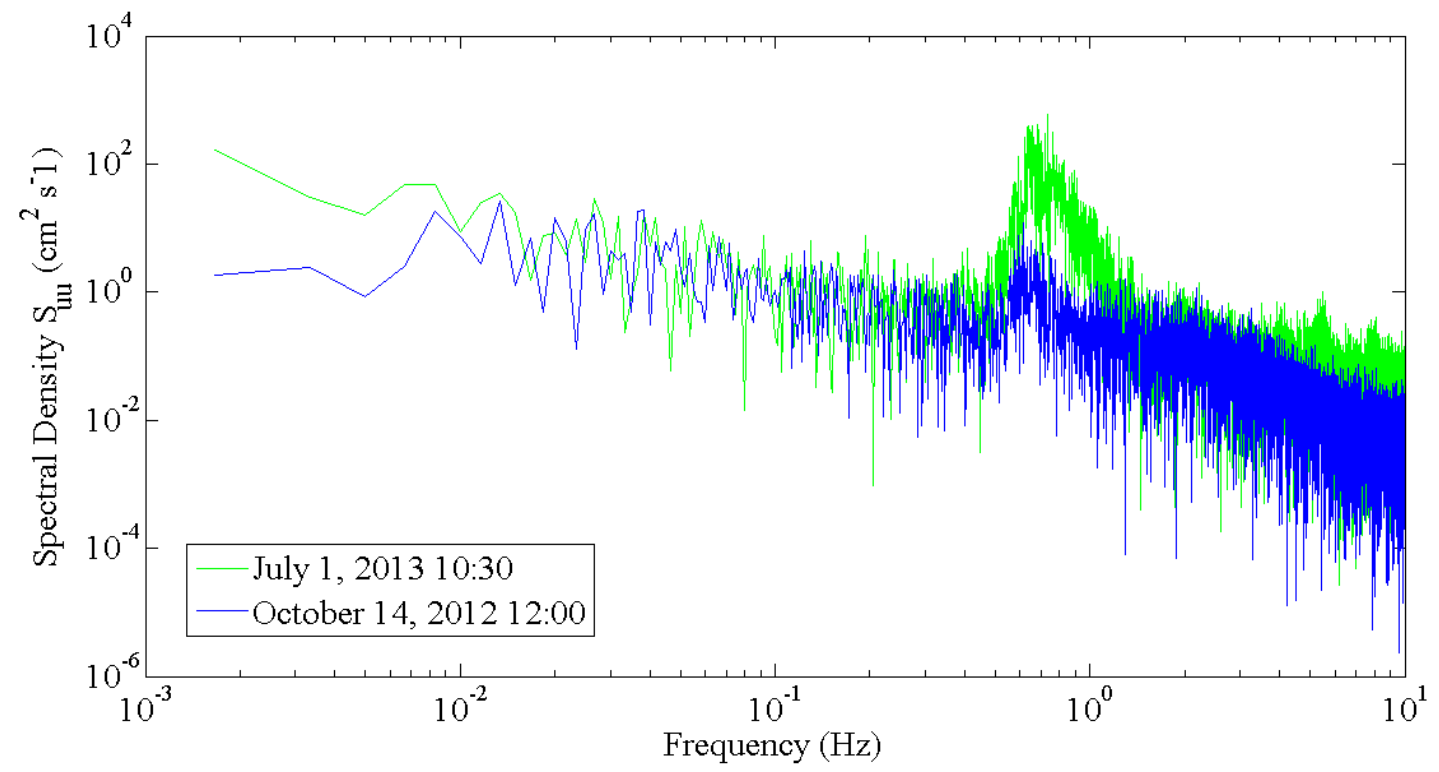

Figure 3.9: Spectral density across various frequencies for the two deployments at the unvegetated (bare) site on July 1, 2013 and October 14, 2012.

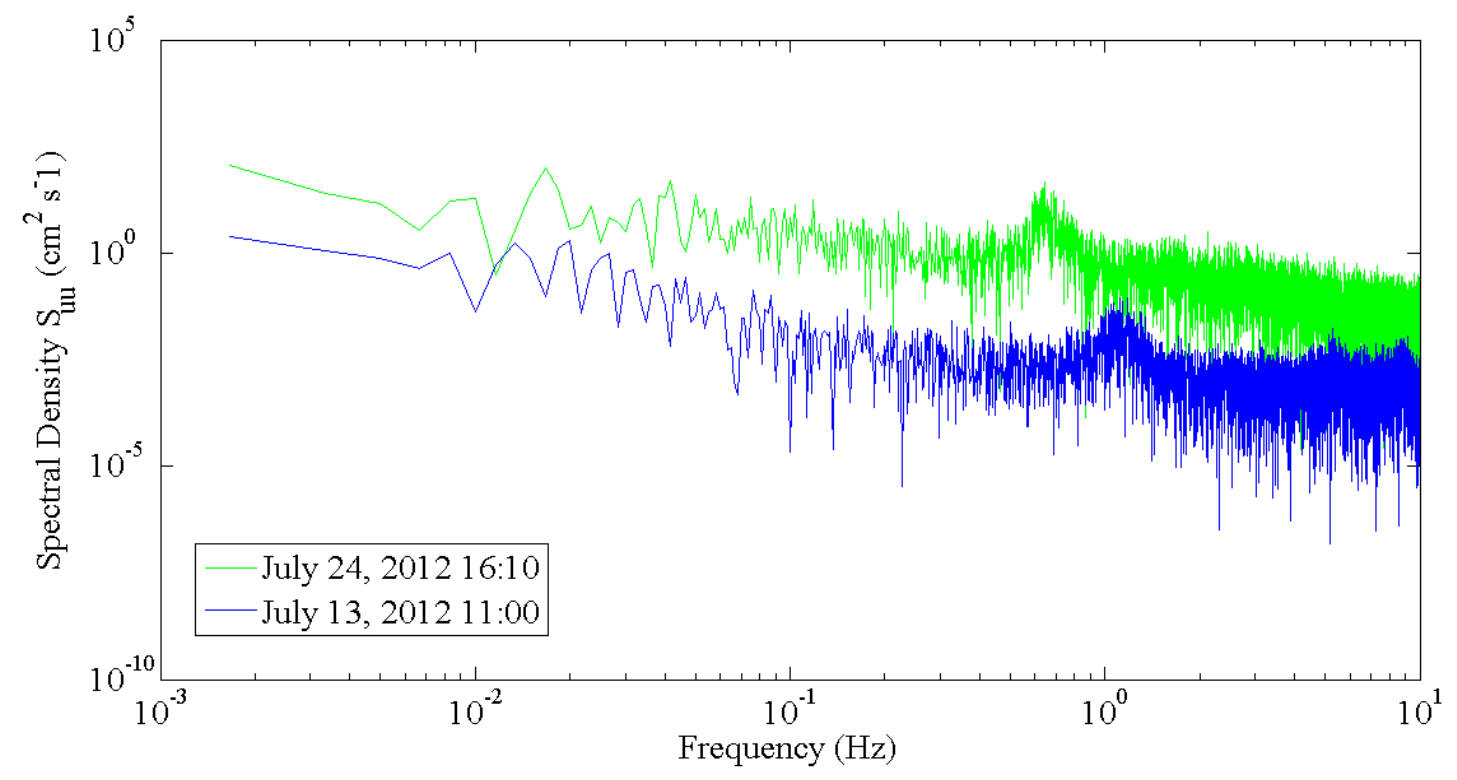

Figure 3.10: Spectral density across various frequencies for the two deployments at the seagrass site on July 13, 2012 and July 24, 2012. 
Data from July 13, 2012 showed a reduction in total energy measured in the flow compared to July 24, 2012, a reasonable expectation given the lower current velocities and wave heights observed during that deployment. A peak was present with a maximum frequency of $1.18 \mathrm{~Hz}$, however this was outside the range of frequencies typically observed as wave motion in South Bay $(0.5-1 \mathrm{~Hz})$, and reflects waves that are shorter and faster than observed in the high wave case ( $\mathrm{T}=0.85$ seconds). A small wave peak existed in the data from July 24, 2012 at a frequency of $0.64 \mathrm{~Hz}(\mathrm{~T}=1.56$ seconds). Both wave conditions in the seagrass bed are compared in Figure 3.10.

Spectral data confirm that oscillatory motion is present near the bed during the two high wave deployments of July 1, 2013 and July 24, 2012 (Figure 3.9 and 3.10), and that this motion is likely a result of wave motion translating vertically through the water column and interacting with the sea floor, as the periodicity of these oscillatory motions is similar to the average surface wave period. The reduced oscillatory signal in the low wave spectra (October 14, 2012 and July $13,2012)$ suggests that waves were partially attenuated prior to reaching the sea floor, and that different near bed flow characteristics will exist at these sites. This difference allowed comparison of near bed flows between conditions influenced by waves and those with reduced wave motion.

\subsubsection{Wave Orbital Velocities}

The magnitude of wave motion throughout the water column can be represented by the wave orbital velocity, the wave contribution to water motion at a given depth. Wave orbital velocity was calculated using a spectral method (Equation 3.10) from velocity data, and compared to a theoretical prediction of wave orbital velocity from linear wave theory (Equation 
3.11). At the sea floor, orbital velocities are compressed into a horizontal side to side motion, so it is appropriate to only consider the horizontal component of the orbital velocity in near bed situations, as done in Equation 3.11. Attenuation of horizontal wave orbital motion is expected when waves are in intermediate or deep water $(H>\lambda / 20)$, which is valid for these wave conditions (Table 3.1).

Wave orbital velocity magnitudes were larger at the bare site when compared with the seagrass site during both the high wave and the low wave case (Table 3.2). Orbital velocities were normalized by a single root mean squared velocity $\left(\mathrm{u}_{\mathrm{rms}}\right)$ from the top point of the Vectrino II profile (Figures 3.11 and 3.12). Theoretical values, calculated given the surface wave characteristics, were also normalized by this mean velocity. $\mathrm{u}_{\mathrm{orb}} / \mathrm{u}_{\mathrm{rms}}$ is larger for data collected under higher wave conditions at both the bare and seagrass site, indicating that a larger fraction of the total water motion is due to wave orbital motion when higher waves are present. All profiles also show a decrease in $\mathrm{u}_{\mathrm{orb}} / \mathrm{u}_{\mathrm{rms}}$ near the bed, indicating that wave orbital motion is attenuated near the boundary. This is likely a combination of a reduction in mean flow velocity closer to the bed due to friction, and attenuation of oscillatory motion with depth as orbits are flattened by the boundary.

For the high wave condition (Figure 3.11), the theoretical calculation of wave orbital velocity over predicts the orbital velocities recorded at both the bare and vegetated site. A closer relationship between linear wave theory and the measured values was expected. Linear wave theory does not take bed friction into account in the calculation of orbital velocity, so attenuation of wave orbital motion due to friction may cause a reduction in $\mathrm{u}_{\mathrm{orb}}$ in the observed data, especially in the region adjacent to the seafloor. This entire $3 \mathrm{~cm}$ profile may be within the range affected by bottom friction. The seagrass site observed value is $53 \%$ of the theoretical 
prediction, similar to the bare site, which is $51 \%$ of theoretical. The fact that both values under predict theory by a similar amount suggests that the seagrass meadow is not causing greater attenuation of orbital velocity than the bare site in high wave conditions. Significant wave heights recorded at the bare and seagrass sites were $0.114 \mathrm{~m}$ and $0.077 \mathrm{~m}$ respectively (Table 3.1), which likely explains the larger mean orbital velocities at the bare site presented in Table 3.2.

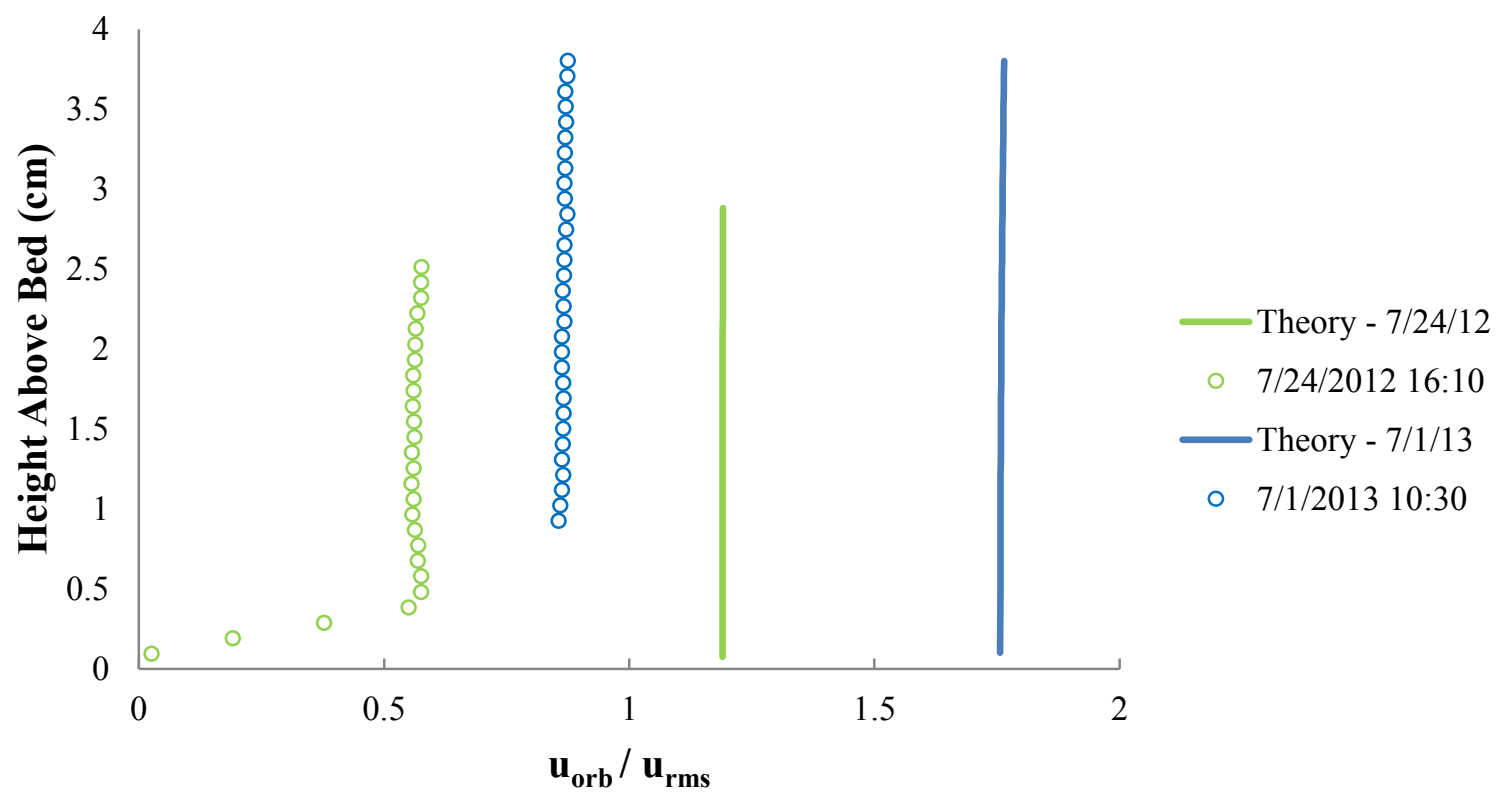

Figure 3.11: Orbital velocities $\left(\mathrm{u}_{\mathrm{orb}}\right)$ recorded at the vegetated center site (green) and unvegetated (bare) site (blue) normalized by the root mean squared velocity $\left(\mathrm{u}_{\mathrm{rms}}\right)$ at the highest point in the Vectrino II profile for high wave data. Wave orbital velocities as predicted by linear wave theory and also normalized by $\mathrm{u}_{\mathrm{rms}}$ are graphed as solid lines.

For the low wave conditions (Figure 3.12), measured orbital velocities agreed well with theory at the bare site, exceeding theory by only $6 \%$ for the majority of the profile. Orbital velocities decreased to zero directly above the sediment surface, which may be due to reduced 
motion near the bed, or simply sampling inaccuracies from the Vectrino II as a result of measuring within the wave boundary layer. At the seagrass site, theoretical values over predicted the measured values by about $42 \%$. Again, this may be because linear wave theory assumes the bed is frictionless, so a reduction in orbital velocity from both bed friction and dampening by interaction with the canopy could be expected.

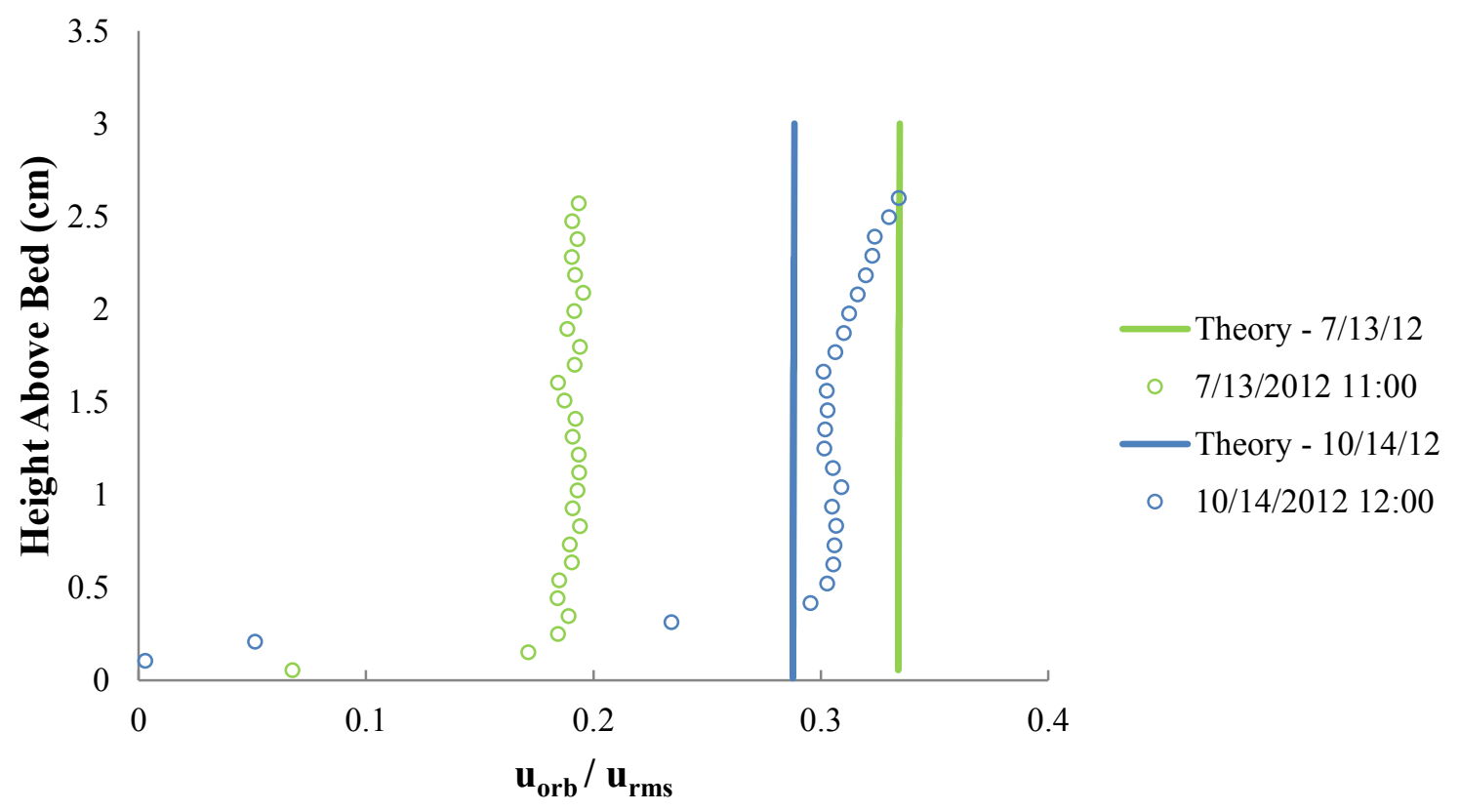

Figure 3.12: Orbital velocities $\left(\mathrm{u}_{\mathrm{orb}}\right)$ recorded at the seagrass site (green) and bare site (blue) normalized by the root mean squared velocity $\left(\mathrm{u}_{\mathrm{rms}}\right)$ for low wave conditions. Wave orbital velocities as predicted by linear wave theory are graphed as solid lines.

Wave motion for all four time periods should interact with the sea floor, as vertical attenuation of wave orbital velocities is expected at a depth of $\lambda / 2$ and wavelengths in all cases were greater than half the depth (Table 3.1). Theoretical predictions show a nearly constant wave orbital velocity with depth over these short near bed profiles, suggesting that additional 
attenuation of wave orbital motion would not be expected at these depths. Attenuation of wave orbital velocity is expected higher in the water column, as shown by the theoretical profiles solved over the entire water column depth, however this theoretical attenuation levels off near the sea floor (Figure 3.13). The deviation from theory for both the seagrass and bare sites in high wave conditions suggests that frictional interaction with the sea floor will reduce wave orbital motion, not interaction with the canopy. Orbital velocities at the bare site were $51 \%$ lower than theory, a value similar to the reduction found in the seagrass bed for both cases $(53 \%$ for high wave, $42 \%$ for low wave).

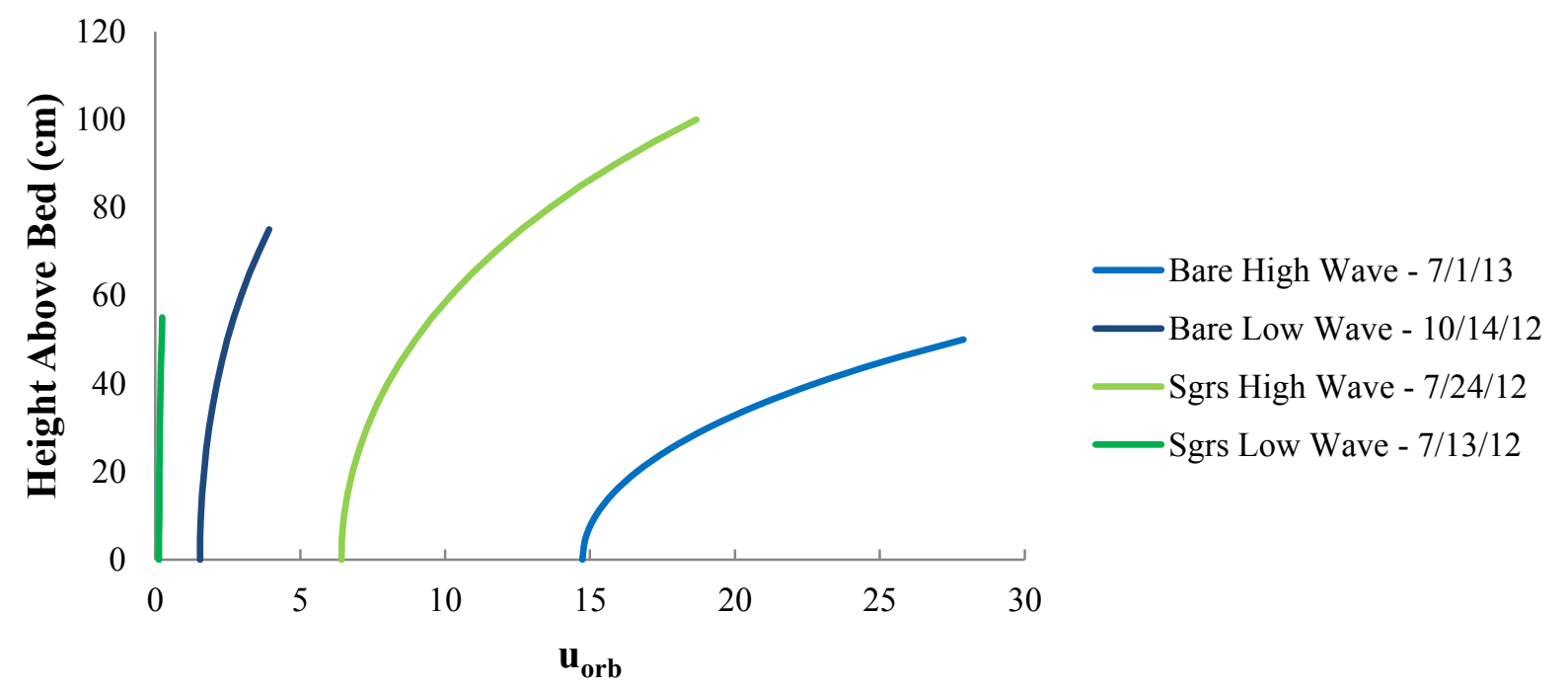

Figure 3.13: Theoretical wave orbital velocity profiles expanded to include the depth of the water column during each deployment. Greater attenuation is observed at the top of the profile, decreasing until the profile appears nearly vertical near the bed.

Hansen and Reidenbach (2013) found that seagrass did not attenuate wave orbital velocity with depth in the canopy, as measured orbital velocity values were not significantly different from orbital velocity values predicted by linear wave theory. Their measurements were 
recorded higher in the water column $(10 \mathrm{~cm}$ and $50 \mathrm{~cm}$ above the bed), so potentially attenuation effects are not visible until the velocities a few centimeters above the bed are compared. The near bed attenuation observed here could then be the result of bed friction and not attenuation by the canopy, as the deviation from theory was nearly the same between the seagrass and bare sites for wavy conditions. Lowe et al. (2005) also discussed the relationship between wave attenuation and the spacing between canopy elements. If the orbital excursion length is less than the spacing between individual seagrass plants, then the wave would not experience any additional drag due to vegetation, and therefore canopy effects on wave orbital velocity may be negligible. Considering flow conditions in Table 3.1 and 3.2, the orbital excursion length for these data sets would be between $0.4 \mathrm{~cm}$ and $10.8 \mathrm{~cm}$, with canopy elements during the most dense summer approximately $5.4 \mathrm{~cm}$ apart, assuming even spacing of plants across a square meter. Assumptions regarding plant spacing, fanning of blades above the seagrass sheath, and changing wave conditions complicate this analysis, but as a rough approximation, some wave orbitals will not interact with canopy elements and may explain the observed lack of increased attenuation at a vegetated site.

Overall, the water depth, near bed current velocity, and wave orbital velocity can be used to explain the difference in boundary layer development and bed shear stress between the four deployments that will be examined in the following sections. The flow conditions discussed in this section are summarized in Table 3.2. 
Table 3.2: Summary of flow conditions during each deployment, including the water depth, current velocities, and wave orbital velocities. Mean velocity data is not available at $0.5 \mathrm{~cm}$ for $7 / 1 / 2013$ at 10:30 because the profiler was positioned too high in the water column to measure this value.

\begin{tabular}{lccccc}
\hline & $\begin{array}{c}\text { Water Depth } \\
(\mathrm{cm})\end{array}$ & Tide & $\begin{array}{c}\bar{u} @ 2.5 \mathrm{~cm} \\
\left(\mathrm{~cm} \mathrm{~s}^{-1}\right)\end{array}$ & $\begin{array}{c}\bar{u} @ 0.5 \mathrm{~cm} \\
\left(\mathrm{~cm} \mathrm{~s}^{-1}\right)\end{array}$ & $\begin{array}{c}u_{\text {orb avg }} \\
\left(\mathrm{cm} \mathrm{s}^{-1}\right)\end{array}$ \\
\hline Bare \\
10/14/2012 12:00 & 79 & Ebb & 5.2 & 3.5 & 1.5 \\
$7 / 1 / 201310: 30$ & 55 & Ebb & 4.8 & 3.9 & 1.3 \\
$7 / 1 / 201311: 20$ & 53 & Slack & 3.0 & - & 7.3 \\
\hline & 66 & Flood & 16.0 & 12.5 & 5.7 \\
\hline $7 / 13 / 201211: 00$ & 56 & Flood & 0.24 & 0.33 & 0.2 \\
$7 / 13 / 201211: 50$ & 70 & Flood & 0.59 & 0.39 & 0.2 \\
$7 / 24 / 201216: 10$ & 103 & Ebb & 4.4 & 3.0 & 2.9 \\
$7 / 24 / 201217: 00$ & 83 & Ebb & 4.5 & 0.7 & 2.5 \\
\hline
\end{tabular}

\subsubsection{Experimental W-C BL Results}

Velocity profiles were measured directly above the sediment-water interface, rotated into the direction of mean flow, phase averaged to select only the maximum velocity across each wave period, and averaged over a10 minute collection period (Figure 3.14 and 3.15). Best fit lines were applied to the lower portions of the profiles, and friction velocity $\left(u^{*}\right)$ values were calculated using the log profile method discussed previously. Friction velocity values calculated in the lowest logarithmic region ranged from $0.630 \pm 0.093 \mathrm{~cm} \mathrm{~s}^{-1}$ at the bare site in high wave conditions to $0.048 \pm 0.068 \mathrm{~cm} \mathrm{~s}^{-1}$ at the seagrass site in low wave conditions (Table 3.3). 


\section{High Wave Conditions}
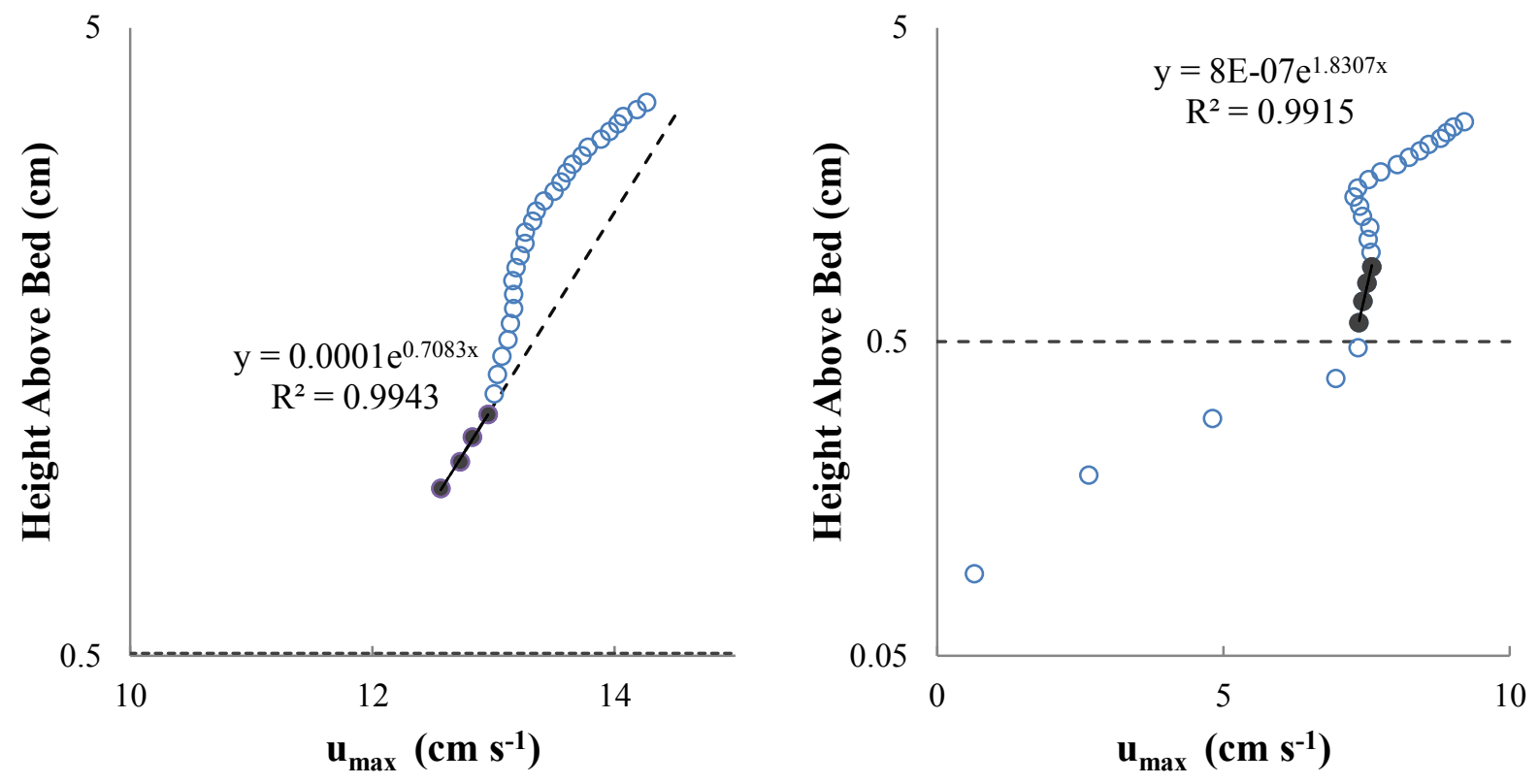

Figure 3.14: Logarithmic velocity profile for high wave conditions at the bare site on July 1, 2013 at 10:30 (left) and at the seagrass site on July 24, 2012 at 16:10 (right). Data used to fit trendline is indicated by the black dots, and the trendline is extended beyond the fit data as a dashed line. Dotted line indicates the lower limits of doppler profiler accuracy as identified by Hay et al. (2012a). 

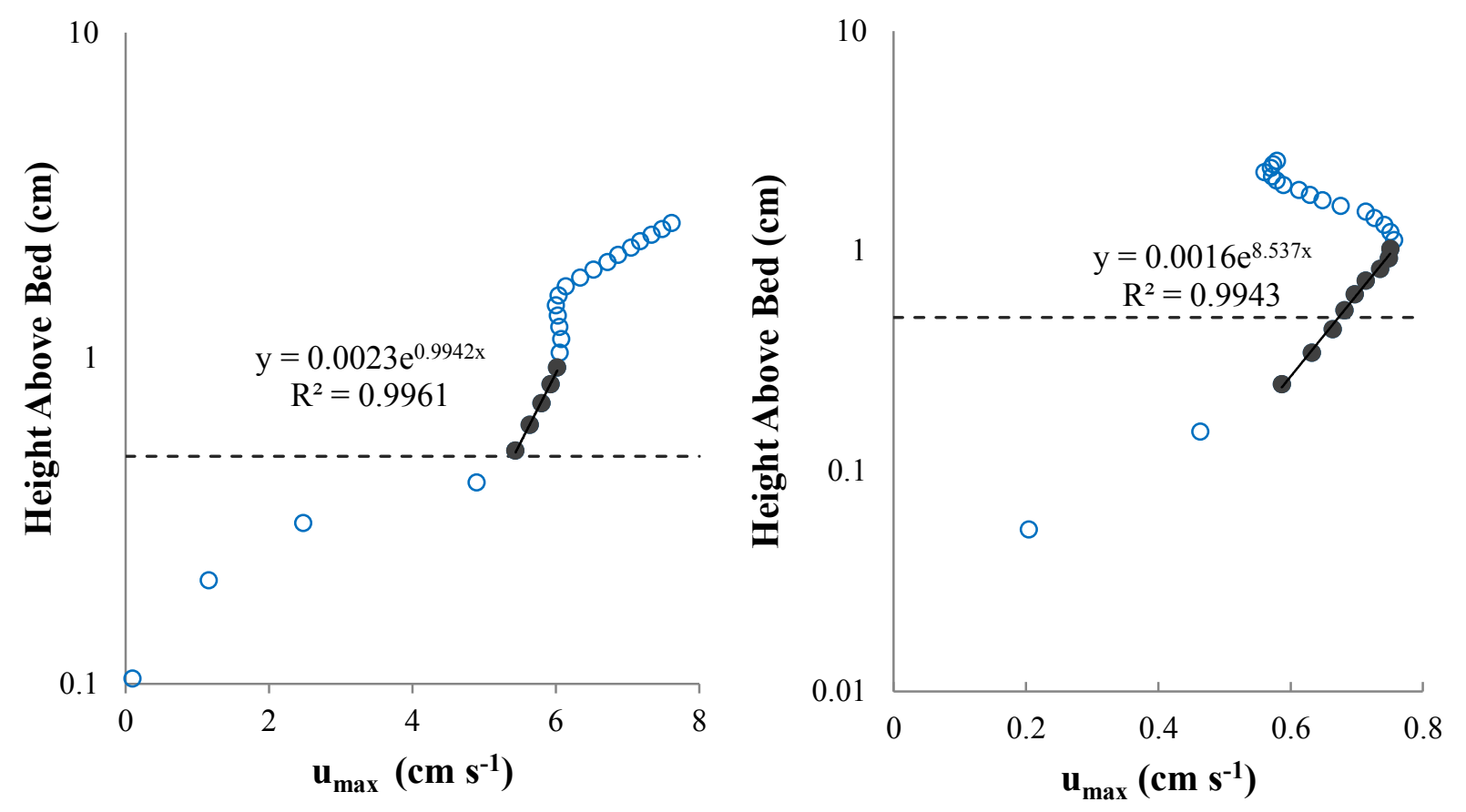

Figure 3.15: Logarithmic velocity profiles for low wave conditions at the bare site on October 14, 2012 at 12:00 (left) and the seagrass site on July 13, 2012 at 11:00 (right). Data used to fit trendline is indicated by the black dots. Dotted line indicates the lower limits of doppler profiler accuracy as identified by Hay et al. (2012a).

Velocity profiles from July 13, 2012 did not show a separate log layer in the same way as the other sites, but instead showed a flow reversal approximately $1 \mathrm{~cm}$ above the bed (Figure 3.15). This may be a result of waves opposing currents and creating a small region of opposing velocity near the bed (Holmedal et al. 2003), however the waves on July $13^{\text {th }}$ were so small $\left(H_{s}=\right.$ $0.001 \mathrm{~m}$, Table 3.1) that this seems unlikely. Because both the wave orbital velocities and current velocities were so small, with an orbital velocity of $0.2 \mathrm{~cm} \mathrm{~s}^{-1}$ and a current velocity of $0.24 \mathrm{~cm} \mathrm{~s}^{-1}$ at $3 \mathrm{~cm}$ above the bed (Table 3.2), this decreasing flow may just be a characteristic of the flow intensification seen in the less dense areas below the point where seagrass blades fan out 
from the sheaths to form the canopy. Plotting the data with non-log axes below (Figure 3.16), the velocity profiles appear closer to the flow intensification case shown by Ackerman and Okubo (1993) (Figure 3.1). For this reason, the flow reversal on 7/13/2012 was not considered to be a transition between logarithmic layers, and rather a result of low velocity conditions amplifying the near bottom flow intensification seen within $Z$. marina beds, so the $\delta_{c w}$ was omitted from Table 3.3.

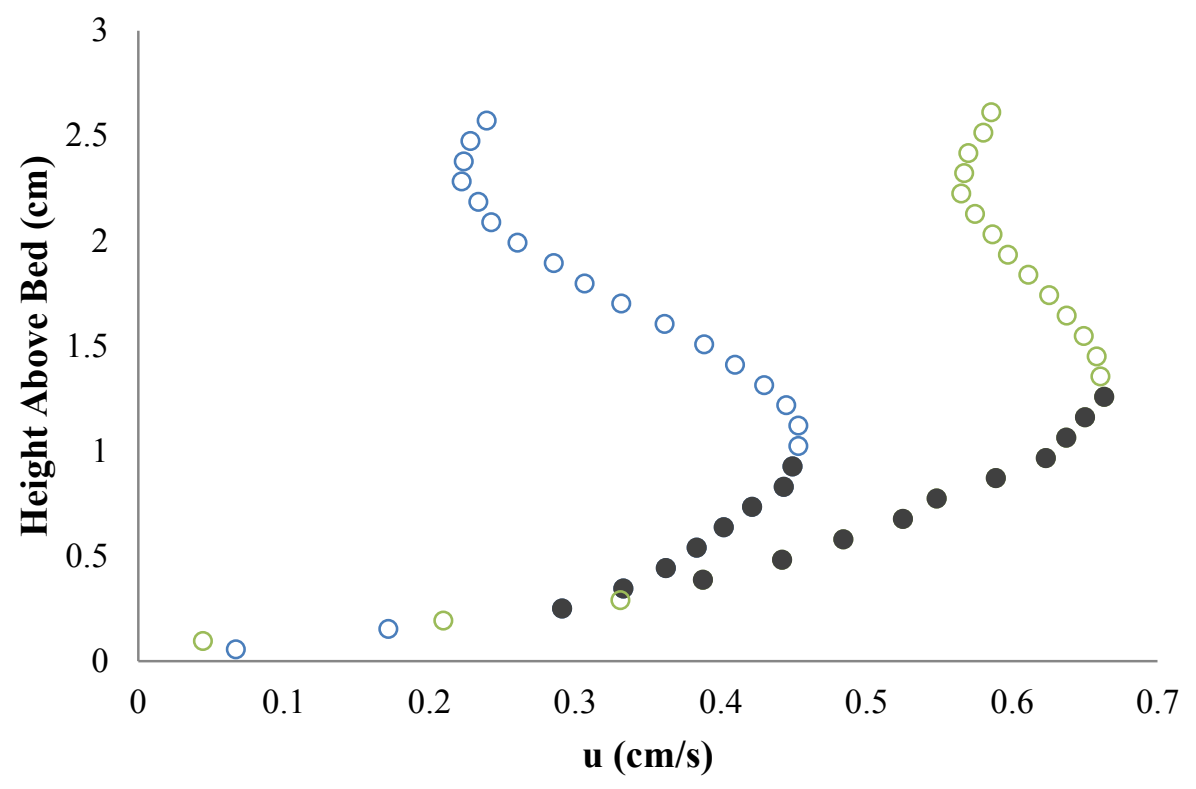

Figure 3.16: Average flow velocity on July 13, 2012 at 11:00 (blue dots) and 11:50 (green dots). Data included in calculation of shear velocity $\left(u^{*}\right)$ for each time period are marked by solid grey dots. 
Table 3.3: Experimental wave-current bounday layer properties, calculated from logarithmic profiles of near bed velocity data. No boundary layer thickness $\left(\delta_{c w}\right)$ is given if two significantly different logarithmic layers were not found within the data set. Shear velocity $\left(u_{*}\right)$ is reported $\pm 95 \%$ confidence bounds calculated following Grant et al. (1984) using a student's t distribution.

\begin{tabular}{llcc}
\hline & $u{ }^{*}\left(\mathrm{~cm} \mathrm{~s}^{-1}\right)$ & $\delta_{\mathrm{cw}}(\mathrm{cm})$ & $\mathrm{R}^{2}$ \\
\hline \multicolumn{1}{c}{ Bare } \\
\hline 10/14/2012 12:00 & $0.412 \pm 0.149$ & 0.94 & 0.9961 \\
$10 / 14 / 201212: 50$ & $0.322 \pm 0.179$ & 0.83 & 0.9906 \\
$7 / 1 / 201310: 30$ & $0.579 \pm 0.230$ & 1.21 & 0.9943 \\
$7 / 1 / 201311: 20$ & $0.630 \pm 0.093$ & 1.08 & 0.9935 \\
\hline $7 / 13 / 201211: 00$ & $0.048 \pm 0.068$ & - & 0.9943 \\
$7 / 13 / 201211: 50$ & $0.103 \pm 0.036$ & - & 0.9980 \\
$7 / 24 / 201216: 10$ & $0.224 \pm 0.282$ & 0.87 & 0.9915 \\
$7 / 24 / 201217: 00$ & $0.371 \pm 0.220$ & 0.95 & 0.9948 \\
\hline
\end{tabular}

Shear velocities in the near bed logarithmic layer are larger in high wave conditions compared to low wave conditions, and for similar wave conditions are larger at the bare site compared to the seagrass site (Table 3.3). The two high wave cases (7/1/2013 and 7/24/2012) showed the expected development of two logarithmic layers that were significantly different, however the bare low wave case also resulted in two significantly different log layers.

Ultimately, wave interaction with the sea floor is predicted by the wave length, not the wave height, and waves from each run had sufficiently long wavelengths to interact with the sea floor, even though for small wave heights it is unlikely there is adequate energy in the oscillatory flow to create a wave boundary layer. Other conditions could also lead to the development of two logarithmic layers such as differences in bottom topography or the superposition of multiple 
wave boundary layers, however isolating the exact cause of the second logarithmic layer at the bare site in low wave conditions would likely be impossible with this data set. Therefore, the lower profile was used similar to the other runs to calculate shear velocity and the upper profile was discarded.

Data recorded on 7/1/2013 for the high wave case at the bare site has the greatest WBL thickness of $1.21-1.08 \mathrm{~cm}$, while data for 7/24/2012 and 10/14/2012 showed similar thicknesses between 0.83 and $0.95 \mathrm{~cm}$ (Table 3.3). Boundary layer thickness should be a function of the wave period, as layers that have a longer time to develop before the flow is reversed will grow larger than layers that have less time to develop. Based on the theoretical boundary layer depth predictions (Equations 3.2 and 3.3), the thickness is also a function of shear velocity (Grant and Madsen 1986), free stream amplitude, and bed roughness (Fredsoe and Deigaard 1992). Wave period did not correlate well with the observed boundary layer thickness, as July 1, 2013 had the lowest $T_{s}$ of $1.48 \mathrm{~s}$, and October 14, 2012 had the largest $T_{s}$ of $1.65 \mathrm{~s}$, the opposite of what would be predicted (Table 3.1). The range of wave periods was quite small, so perhaps these were too similar to create any observable changes in the boundary layer. Shear velocity well predicted the boundary layer depth, which may reflect increased boundary layer growth due to high turbulence created by greater shear stress. Additional discussion of wave boundary layer thickness as well as theoretical WBL depth calculations occurs in Section 3.3.3.

The focus of this chapter has been to isolate and compare a high wave height and low wave height case for the bare and seagrass sites; however, it was shown in this section that wave boundary layer development can be influenced by additional wave parameters such as the wave length and period, and also the water depth. To isolate the difference in wave boundary layer development at a bare and vegetated site, two profiles were compared that were recorded in the 
most similar environmental (wave and depth) conditions, one at the bare site and one in the seagrass meadow (Figure 3.17).

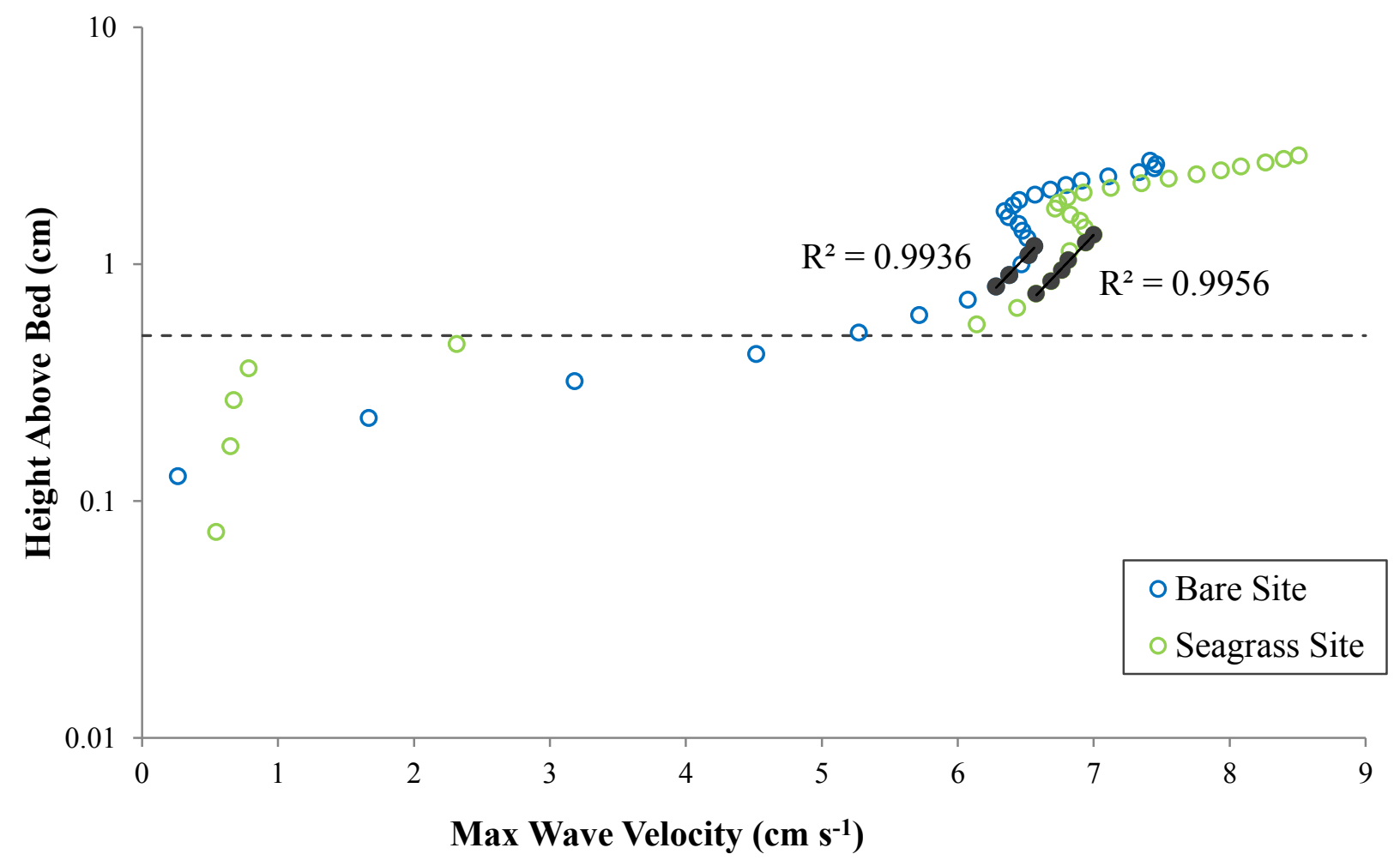

Figure 3.17: Comparison of maximum near bed velocity profiles for data collected on July 24, 2012 at 17:00 at the seagrass site, and on July 26, 2012 at 11:00 at the southern bare site.

Table 3.4: Quantification of the wave and depth characteristics of the two profiles compared in Figure 3.16 (July 24, 2012 at 17:00 at the seagrass site and July 26, 2012 at 11:00 at the southern bare site), and comparing the resulting boundary layer characteristics depicted in Figure 3.16 numerically.

\begin{tabular}{lcccccccc}
\hline & $\begin{array}{c}\text { Depth } \\
(\mathrm{m})\end{array}$ & $\begin{array}{c}u_{\text {avg,3cm }} \\
\left(\mathrm{cm} \mathrm{s}^{-1}\right)\end{array}$ & $H_{s}(\mathrm{~m})$ & $T_{s}(\mathrm{~s})$ & $\begin{array}{c}u_{o r b} \\
\left(\mathrm{~cm} \mathrm{~s}^{-1}\right)\end{array}$ & $\begin{array}{c}u_{c w} \\
\left(\mathrm{~cm} \mathrm{~s}^{-1}\right)\end{array}$ & $\delta_{c w}(\mathrm{~cm})$ & $z_{0}(\mathrm{~cm})$ \\
\hline $\begin{array}{l}\text { Seagrass } \\
(7 / 24 / 2012)\end{array}$ & 0.83 & 4.5 & 0.063 & 1.39 & 2.5 & $0.30 \pm 0.09$ & 1.33 & 0.00008 \\
$\begin{array}{l}\text { Bare } \\
(7 / 26 / 2012)\end{array}$ & 0.79 & 3.4 & 0.066 & 1.76 & 2.8 & $0.30 \pm 0.24$ & 1.19 & 0.0001 \\
\hline
\end{tabular}


Shear velocities calculated in the wave boundary layer for both profiles were surprisingly similar, with a $u *$ of $0.30 \pm 0.09$ at the seagrass site and $0.30 \pm 0.24$ at the bare site (Table 3.4). This suggests wave boundary layer shear velocities are highly dependent on wave and environmental conditions, but not strongly influenced by the physical presence of vegetation. Similar velocity profiles are reasonable if the orbital excursion length was less than the spacing between shoots, therefore individual waves would not necessarily be interacting with the canopy. The most substantial environmental differences between the profiles in the seagrass meadow on July 24, 2012 at 17:00 and the bare site on July 26, 2012 at 11:00 were the mean (or current) velocity and the significant wave period. Greater current velocity at the seagrass site (Table 3.4, $4.5 \mathrm{~cm} \mathrm{~s}^{-1}$ compared to $3.4 \mathrm{~cm} \mathrm{~s}^{-1}$ at the bare site) explains why the seagrass profile in Figure 3.17 is in advance of the bare profile by a nearly constant margin, however the general shape of the profile in unaffected. A longer wave period at the bare site, by about $0.37 \mathrm{sec}$, suggests a thicker boundary layer would form there, however we observed the opposite trend in the boundary layer thickness, with the seagrass site exceeding the thickness at the bare site by 0.14 $\mathrm{cm}$ (Table 3.4). This could be due to some small difference in surface roughness.

Comparing this single case of two boundary layer profiles with similar wave characteristics to the general data for low and high waves, Table 3.3 suggests that greater shear velocities will occur at the bare site, while Table 3.4 suggests that a vegetated and bare site will have the same shear velocities. This difference may be explained by the influence of larger scale meadow effects on wavelength and wave height. When wave and environmental conditions are the same, the wave boundary layer characteristics are also the same at a bare and vegetated site. Therefore the seagrass meadow does exert control over the conditions at the boundary, however this control is due to the horizontal attenuation of wave motion by drag induced from the 
seagrass over the expanse of the meadow, not vertical attenuation of wave motion in the water column. This horizontal attenuation results in overall lower wave heights (Chapter 2), such that average shear velocities at the seagrass site are lower than average shear velocities at the bare site (Table 3.3).

Finally, Vectrino II near bed velocity profile averages were compared to Aquadopp velocity profiles that extended $0.8 \mathrm{~m}$ from the sea floor and were averaged over ten minutes. Aquadopp profiles showed a velocity reduction within the canopy compared to above canopy flow and the development of a second logarithmic profile at the top of the canopy height (Figure 3.18). This is consistent with flow over dense beds of vegetation discussed in the literature. Average logarithmic velocity profiles determined from the bottom several centimeters of the water column over predict velocities within the seagrass bed, but under predict velocities above the maximum height of the seagrass blades. This is reasonable, as maximum velocities from the WBL should be greater than average velocities within the canopy, however once above the canopy mean current velocities should exceed within canopy flow. This further supports that shear within the WBL is greater than shear experienced outside this layer, and that under predictions of bed shear stress are possible if flow is sampled within the canopy, but outside of the WBL. 


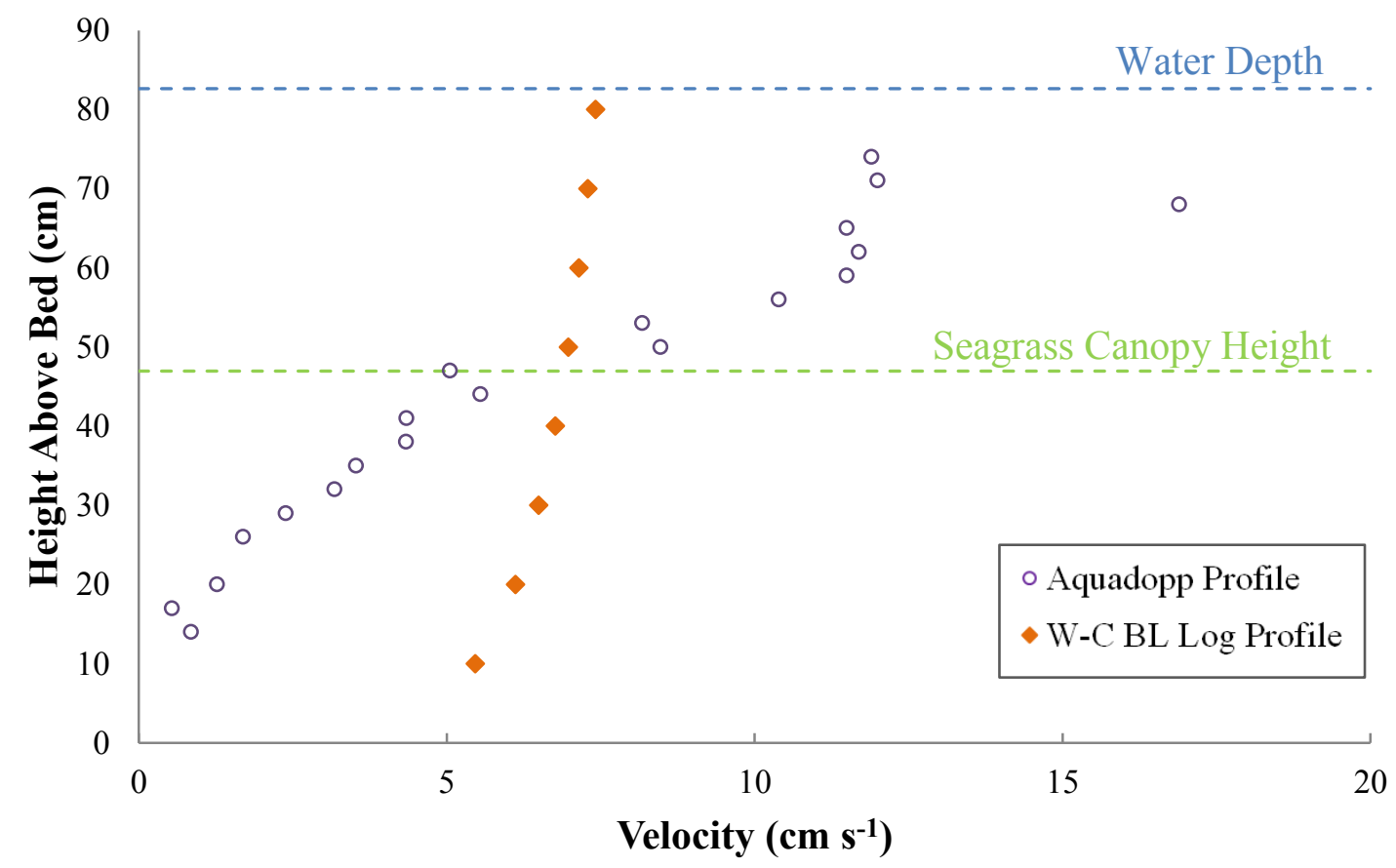

Figure 3.18: July 24, 2012 17:00 - Extrapolation of W-C BL log profile compared with velocity data recorded by the Aquadopp current profiler. Aquadopp data is represented by the open circles, log profiles by the solid diamonds. Aquadopp data with percent correlation below 80 was removed from the set. Seagrass canopy height shown on the figure (green dashed line) is equal to blade length, however bending of blades may result in a shorter canopy, so this should be considered a maximum possible canopy height.

\subsubsection{Theoretical WBL Thickness}

The theoretical depth of the wave boundary layer was calculated for each flow condition, and found to range between $0.41 \mathrm{~mm}$ and $1.39 \mathrm{~mm}$ using Equation 3.2 from Fredsoe and Deigaard (1992), and between $0.04 \mathrm{~mm}$ and $0.64 \mathrm{~mm}$ using Equation 3.3 from Grant and Madsen (1986) (Table 3.5). 
Table 3.5: Theoretical boundary layer depth, and parameters used in calculation of theoretical depth.

\begin{tabular}{|c|c|c|c|c|c|}
\hline & $\begin{array}{c}\text { Water } \\
\text { Depth }(\mathrm{m})\end{array}$ & $\begin{array}{c}\mathrm{u}_{\mathrm{orb}} \max ^{*} \\
\left(\mathrm{~cm} \mathrm{~s}^{-1}\right)\end{array}$ & $\mathrm{T}(\mathrm{s})$ & $\begin{array}{c}\text { Theoretical } \\
\text { WBL depth }^{1} \\
(\mathrm{~mm})\end{array}$ & $\begin{array}{c}\text { Theoretical } \\
\text { WBL depth }^{2} \\
(\mathrm{~mm})\end{array}$ \\
\hline \multicolumn{6}{|c|}{ Bare } \\
\hline 10/14/2012 12:00 & 0.79 & 7.62 & 1.428 & 0.98 & 0.38 \\
\hline $10 / 14 / 201212: 50$ & 0.55 & 6.70 & 1.250 & 0.60 & 0.26 \\
\hline 7/1/2013 10:30 & 0.53 & 14.27 & 1.221 & 0.80 & 0.51 \\
\hline 7/1/2013 11:20 & 0.66 & 23.54 & 1.567 & 1.39 & 0.64 \\
\hline \multicolumn{6}{|c|}{ Seagrass } \\
\hline 7/13/2012 11:00 & 0.56 & 0.76 & 1.465 & 0.41 & 0.04 \\
\hline $7 / 13 / 201211: 50$ & 0.70 & 0.99 & 2.897 & 0.60 & 0.14 \\
\hline $7 / 24 / 2012$ 16:10 & 1.03 & 9.21 & 1.569 & 1.18 & 0.23 \\
\hline $7 / 24 / 2012$ 17:00 & 0.83 & 8.51 & 1.421 & 0.91 & 0.34 \\
\hline
\end{tabular}

${ }^{*} \mathrm{u}_{\mathrm{orb}} \max$ is the maximum value of phase averaged velocity for each profile

${ }^{1}$ refers to calculation from the formula by Fredsoe and Deigaard (1992)

${ }^{2}$ refers to calculation from Grant and Madsen (1986) using friction velocities $\left(\mathrm{u}_{*_{\mathrm{cw}}}\right)$ from Section 3.3.2

All of the theoretical boundary layer thickness values were below the detection limits for the Vectrino II, which can only reliably measure distances greater than $5 \mathrm{~mm}$ from the bed. These theoretical predictions were also much lower than the observed break in the logarithmic profile, thought to be indicative of the top of the wave boundary layer, which was discussed in the experimental results (Section 3.3.2). Observed boundary layer thicknesses ranged from 8.3 $\mathrm{mm}$ to $12.1 \mathrm{~mm}$ (Table 3.3), an order of magnitude higher than the theoretical predictions. Between the two theoretical predictions, the Fredsoe and Deigaard (1992) method was on average $65 \%$ greater than the Grant and Madsen (1986) calculation.

Discrepancies may be due to error in the assumption that the logarithmic layer identified in the velocity profiles is the wave boundary layer, or error in the equations predicting boundary 
layer thickness. The equation provided by Fredsoe and Deigaard (1992) was difficult to implement in this situation for several reasons. Water velocities at one meter above the bed were not available for data collected as the Aquadopp profiler only measured up to 0.8 meters above the bed, and often showed poor correlation in higher measurement bins. Furthermore, even if the Aquadopp had been programmed to record higher in the water column, data at one meter was not available during any of these deployments except for 7/24/2012 at 16:10, as Vectrino II data was typically collected at low tide when water levels did not exceed $1 \mathrm{~m}$. The maximum water velocity recorded by the Aquadopp was used in place of the water velocity at $1 \mathrm{~m}$ in the boundary layer thickness equation, however a true free stream velocity may not have been attained during many of these deployments. This may be especially salient at the seagrass site, where the seagrass blades occupied a large fraction of the water column during low tide. Additionally, the wave period did not vary greatly between the high and low $\mathrm{H}_{\mathrm{s}}$ conditions, likely as a result of the limited wave development possible in a shallow coastal bay at low tide.

The equation from Fredsoe and Deigaard (1992) also addressed bottom topography, stating that the bottom roughness may alter the theoretical boundary layer thickness if $\mathrm{A} / \mathrm{k}_{\mathrm{s}}<50$, a situation in which oscillations cover such a small distance that individual sediment grains have a drastic effect on oscillatory motion. Due to the small scale of these measurements, A, which is directly proportional to the wave period $(T)$ and the free stream velocity $\left(u_{1 m}\right)$, was occasionally small enough such that $\mathrm{A} / \mathrm{k}_{\mathrm{s}}$ was less than 50 , implying that individual grains had an effect on boundary layer formation. Due to the lack of other data, these data were still included in the calculation of boundary layer thickness; however, this would likely cause increased thickness and may explain the difference between the Fredsoe and Deigaard (1992) predictions and those following Grant and Madsen (1986). 
More generally, the observed wave-current boundary layer could also be larger than predicted from theory due to bottom roughness. Small scale topography, even on the order of millimeters, could enhance mixing and cause growth of the boundary layer. Neither site had significant bedforms or other roughness elements, however some degree of roughness is characteristic of any natural bottom sediment, and this low roughness could have a disproportionate effect on a boundary layer that is at most centimeters thick. Due to the inherent variation in sediment and the strong effects it could have on boundary layer formation, it is reasonable that the WBL thickness determined from in situ velocity profiles is greater than the values predicted by theory.

\subsubsection{Division of Wave and Turbulent Motion}

Distributions of wave and turbulent motion were calculated for flow throughout the lower $3 \mathrm{~cm}$ of the water column at the bare and vegetated site for high and low wave conditions using the phase method of wave-turbulence decomposition (Figures 3.19 and 3.20). These distributions essentially indicate the relative contribution of wave and current motion to the total energy at each point in the water column, although they do not exactly match the units of energy and are instead equal to energy divided by weight $\left(\mathrm{cm}^{2} \mathrm{~s}^{-2}\right.$, or $\left.\mathrm{J} \mathrm{kg}^{-1}\right)$. Therefore, the exact value of these profiles is less meaningful than the relative relationships between the turbulent and wave components of the flow. 

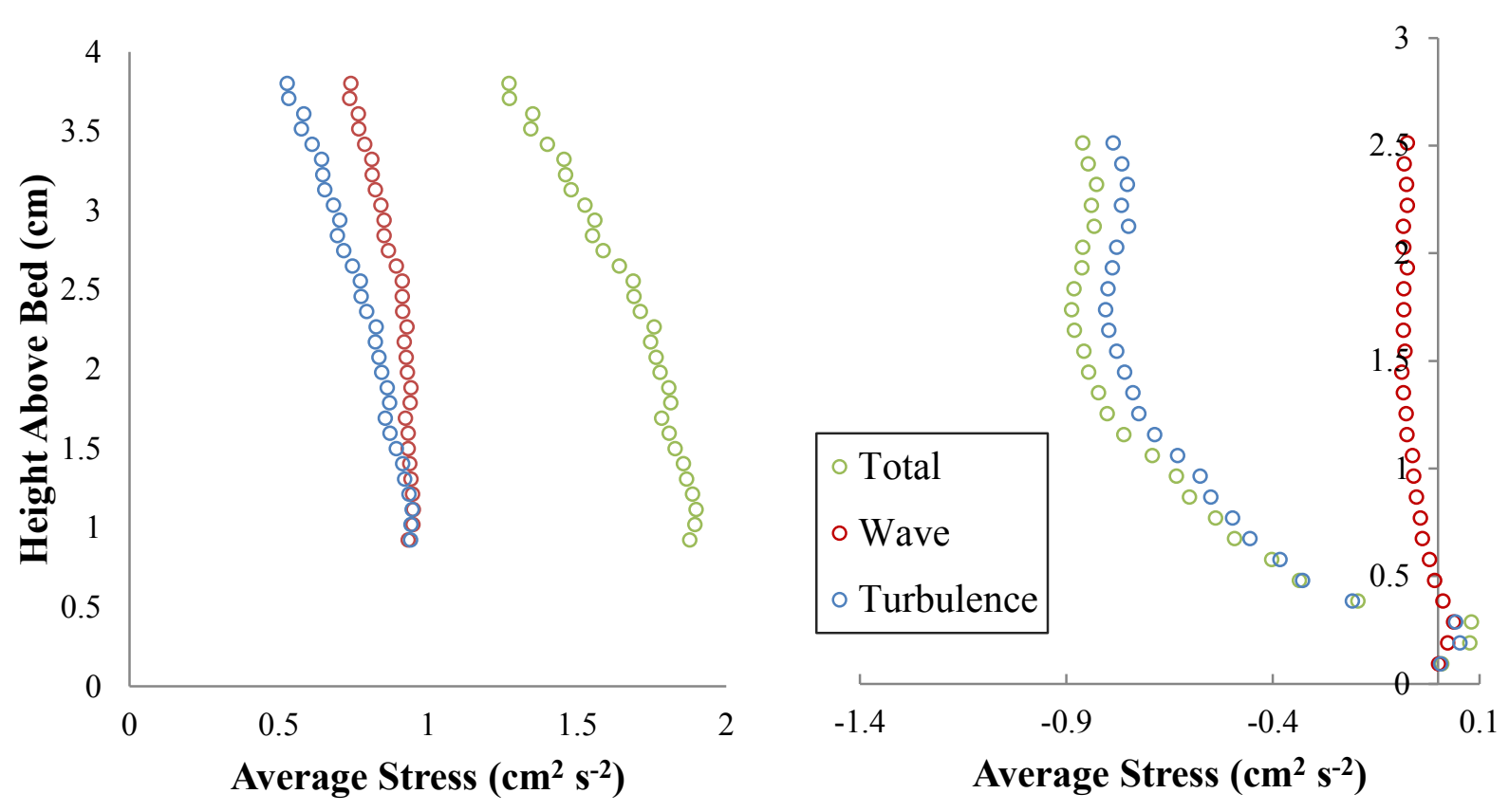

Figure 3.19: Ten minute average stress (per unit density) for July 1, 2013 from 10:30 to 10:40 at the bare site (left), and July 24, 2012 from 16:10 to 16:20 at the seagrass site (right).

Under high wave conditions, the bare site has a higher wave contribution to the total energy than any of the other flow conditions. The wave and turbulent contributions are nearly equal for the July 1, 2013 profile, with the wave component decreasing with greater depth, as would be expected from vertical wave attenuation. At the vegetated site, the turbulence contribution to the total flow motion is about 7 times greater than the wave contribution. This may either reflect a reduced amount of wave energy penetrating through the canopy with the presence of vegetation, or may indicate that there is significantly more turbulence generated within the canopy compared to a bare site, and therefore the turbulent contribution dominates the energy due to wave motion. 

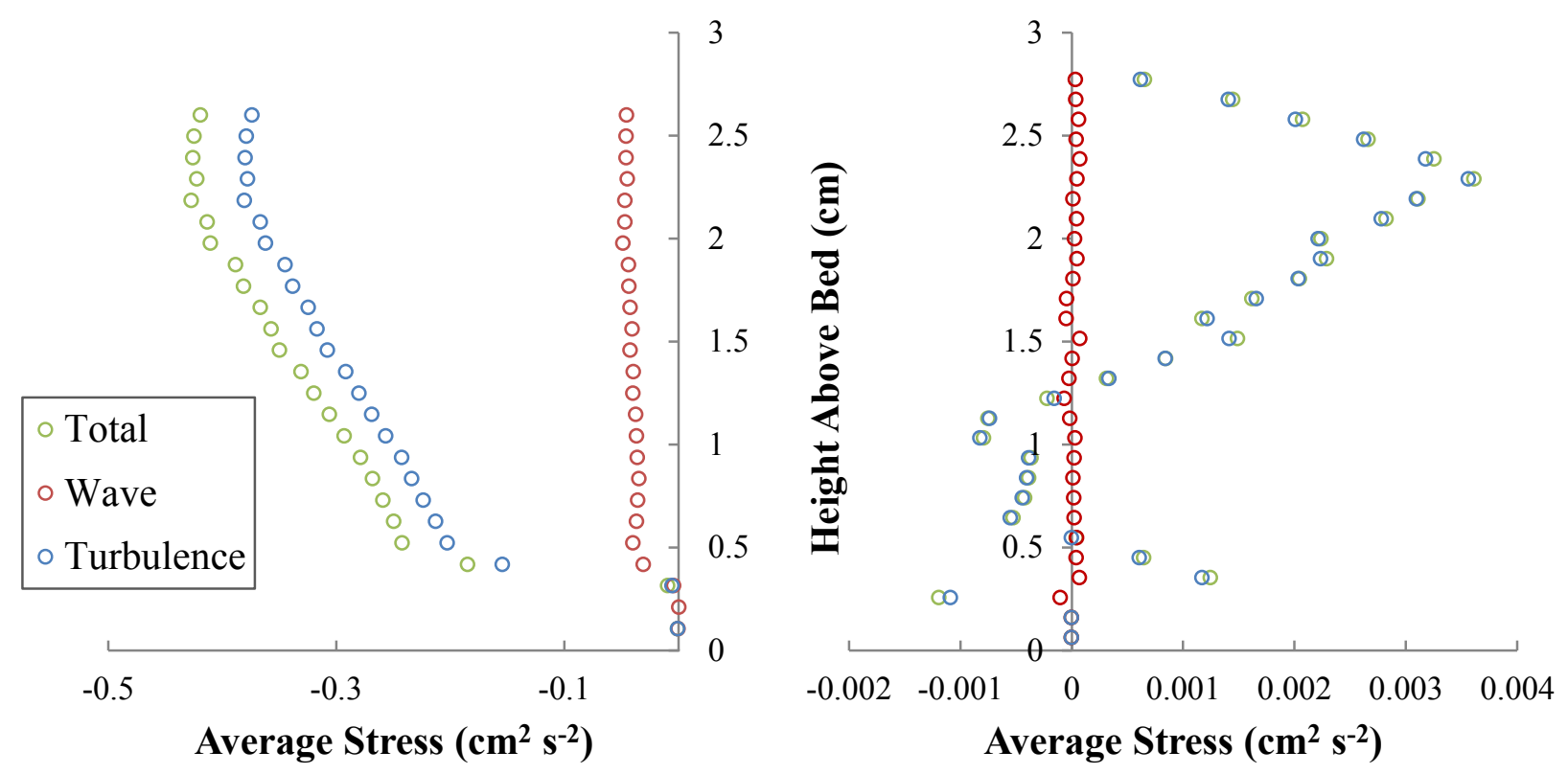

Figure 3.20: October 14, 2012, ten minute average stresses recorded at the bare site from 12:00 to 12:10 (left), and July 13, 2012 at the seagrass site from 11:00 to 11:10 (right). Green circles represent total stress, red circles represent wave component of stress, and blue circles represent the turbulent component.

In contrast to the high wave condition, low wave flows at the bare site are almost entirely dominated by turbulent energy, with wave motion now contributing less than $20 \%$ of the total energy (as compared to $\sim 50 \%$, Figure 3.19). Waves contributed almost no motion at all to the flows at the vegetated site in calm conditions.

\subsubsection{Turbulent Kinetic Energy}

Turbulent Kinetic Energy (TKE) was computed for each ten minute record using data that had been filtered of the wave portion of the frequency spectrum $\left(S_{\widetilde{u} \widetilde{w}}\right)$ to isolate the turbulent velocity fluctuations in the horizontal $\left(u^{\prime}\right.$ and $\left.v^{\prime}\right)$ and vertical $\left(w^{\prime}\right)$ orientations. 
Although wave motions were filtered from the data prior to the calculation of TKE, wave conditions appeared to have the greatest influence on near bed TKE, with higher average values present on 7/1/2013 (high wave case, bare site) and 7/24/2012 (high wave case, seagrass site) when the wave orbital velocities were also highest (Table 3.6).

Table 3.6: TKE averaged over ten minutes of velocity data across a $3 \mathrm{~cm}$ vertical profile at the start and end of each hourly deployment. Average wave orbital velocities are included for reference.

\begin{tabular}{ccc}
\hline & $\begin{array}{c}\text { Average TKE } \\
\left(\mathrm{cm}^{2} \mathrm{~s}^{-2}\right)\end{array}$ & $\begin{array}{c}\mathrm{u}_{\text {orb, avg }} \\
\left(\mathrm{cm} \mathrm{s}^{-1}\right)\end{array}$ \\
\hline 10/14/2012 12:00 & Bare & \\
10/14/2012 12:50 & 0.99 & 1.5 \\
$7 / 1 / 201310: 30$ & 0.91 & 1.3 \\
$7 / 1 / 201311: 20$ & 3.94 & 7.3 \\
\hline & Seagrass & 5.7 \\
\hline $7 / 13 / 201211: 00$ & 0.21 & 0.2 \\
$7 / 13 / 201211: 50$ & 0.18 & 0.2 \\
$7 / 24 / 201216: 10$ & 1.81 & 2.9 \\
$7 / 24 / 201217: 00$ & 1.61 & 2.5 \\
\hline
\end{tabular}

Koch and Gust (1999) found that vegetation in tide dominated environments created skimming flows, resulting in higher TKE above the canopy while within canopy flows were shielded and had lower turbulence intensity. At a tide dominated site during windy conditions, oscillatory motion increased and caused higher turbulence intensities within the meadow. These conditions were more similar to a wave dominated site, where the oscillations of seagrass blades with wave motion generated higher turbulence within the canopy. Conditions in South Bay align more closely with a tidal dominated system, as individual seagrass blades were not observed to 
oscillate with passing waves and instead remained elongated in the direction of the tide, switching direction only over the course of the tidal cycle. This suggests that lower TKE values would be observed within the canopy compared to a bare location due to the shielding effects of tidally dominated flow, matching the observations show in Table 3.6. The conclusions of Koch and Gust (1999) also support the higher values of TKE observed at the seagrass site in the high wave condition. Although greater TKE is expected at the seagrass site when wave activity is higher compared to the seagrass site in low wave conditions, in similarly high wave conditions greater orbital velocity and TKE was observed at the bare site (Table 3.6, Figure 3.21). This was likely due to the shielding effects of seagrass, which was still influential if not dominating during wavy conditions.

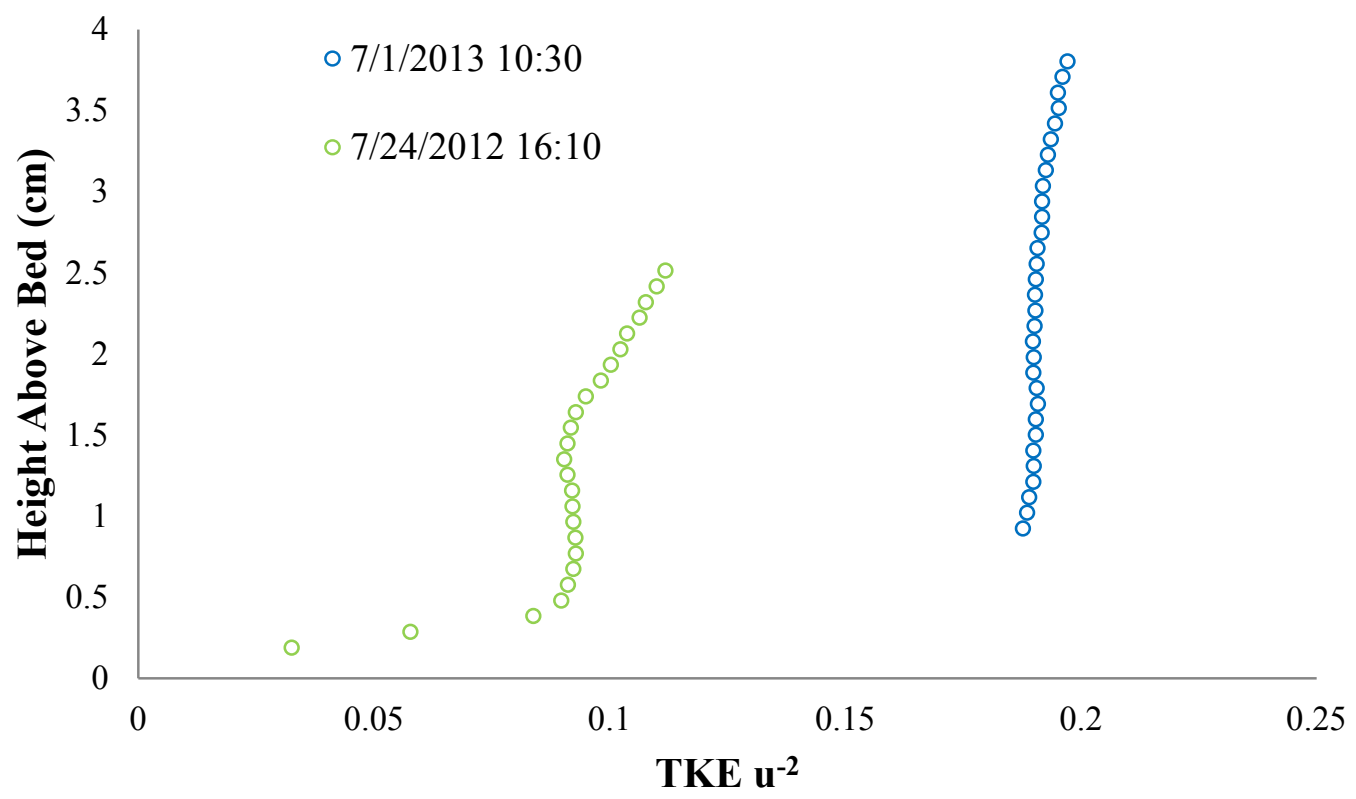

Figure 3.21: TKE profiles normalized by flow velocity at the top point of the Vectrino II profile, averaged over 10 minutes from 10:30 to 10:40 on July 1, 2013 at the bare site (blue dots) and from 16:10 to 16:20 on July 24, 2012 at the vegetated site (green dots), both for high wave conditions. 


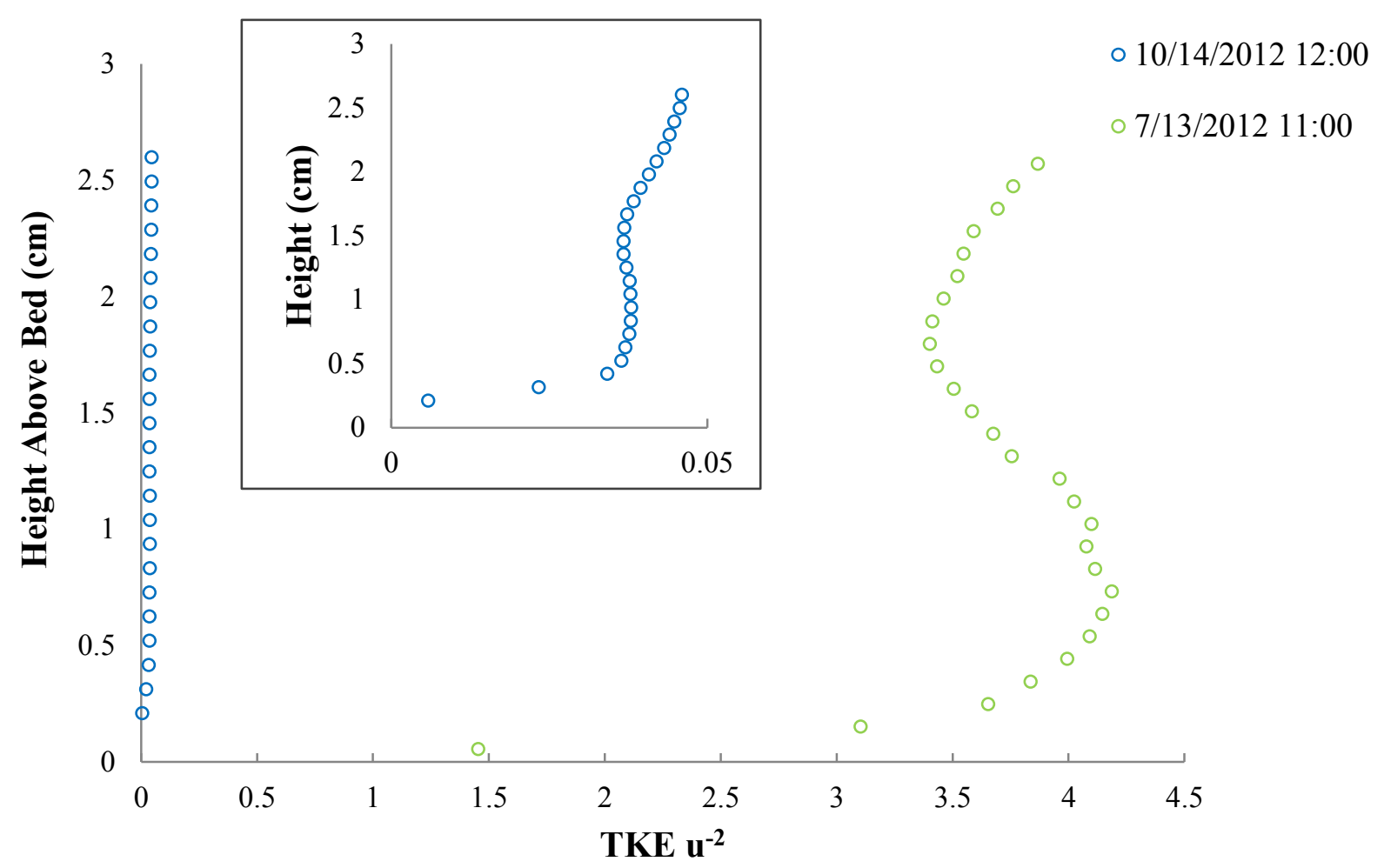

Figure 3.22: TKE profiles normalized by flow velocity at the top point of the Vectrino II profile, averaged over 10 minutes from 12:00 to 12:10 on October 14, 2012 at the bare site (blue dots) and from 11:00 to 11:10 on July 13, 2012 at the vegetated site (green dots), both for low wave conditions.

TKE $\mathrm{u}^{-2}$ for July 13, 2012 was high due to dividing by low mean near bed velocities $\left(\mathrm{u}_{3 \mathrm{~cm}}\right.$ $=0.24 \mathrm{~cm} \mathrm{~s}^{-1}$, Table 3.2) during that time period. The actual magnitude of TKE was low, with an average value $0.21 \mathrm{~cm}^{2} \mathrm{~s}^{-2}$ (Table 3.6), however this value was large relative to the total velocity. Due to these large values, the profile from the bare site was obscured in Figure 3.22, and was therefore magnified in the inset to show that an intensification of TKE also exists near the bed for the bare site on October 14, 2012. This near bed intensification of turbulence is present at both the bare and vegetated sites under high and low wave conditions, and suggests some universal tendency for high turbulence near the bed, regardless of wave conditions. Additionally, Hay et al. (2012b) found that turbulence was generated at the bed and diffused 
upward into the water column, and therefore the highest values of turbulence intensity were near the boundary.

High turbulence production near the bed may be due to bed shear generated turbulence. Nepf et al. (1997) found that bed shear processes controlled turbulence production for $\mathrm{z} / \mathrm{h}<0.1$, where $\mathrm{z}$ is the height above the bottom and $\mathrm{h}$ is the depth of the water column. $\mathrm{z} / \mathrm{h}=0.02$ and 0.05 for the highest measurement in the Vectrino II profile on July $13^{\text {th }}$ and July $24^{\text {th }}$ respectively, which would be well within the range of shear generated turbulence. Higher in the water column within a vegetated bed, Neph et al. (1997) found that turbulence production was dominated by stem-wake interaction, however the scope of this work does not allow comparison between the magnitude of higher column and near bed TKE. Following Nepf et al. (1997), measurements would be necessary above $10.3 \mathrm{~cm}$ and $5.6 \mathrm{~cm}$ on July 13 and $24^{\text {th }}$ respectively to see stem-wake dominated TKE production.

\subsubsection{Bed Shear Stress}

Bed shear stress $\left(\tau_{b}\right)$ exerted by water on the sea floor is the driver of sediment suspension. Three methods were used to calculate $\tau_{\mathrm{b}}$, the root of the sum of the squares of the wave bed stress and current bed stress $\left(\sqrt{\tau_{\text {wave }}^{2}+\tau_{\text {current }}^{2}}\right.$, combined $)$, the log profile method (LP), and the modified TKE method (TKE-w'). Bed shear stress values were greatest for the high wave case at the bare site for all three of the methods, with maximum bed stress values of $0.073 \mathrm{~N} \mathrm{~m}^{-2}$ from the combined method, $0.040 \mathrm{~N} \mathrm{~m}^{-2}$ using LP, and $0.227 \mathrm{~N} \mathrm{~m}^{-2}$ from TKE-w' (Table 3.7).

The combined method uses variables that are defined for the entire water column at one point in time such as the bed orbital velocity, the surface wave period, sediment roughness, and 
the average TKE. Similarly, the log profile method integrates the bottom several centimeters of the water column to calculate a $u^{*}$ value that is used to determine bed shear, effectively considering the entire boundary layer in the computation of the bed shear stress. Unlike the first two methods, TKE-w' calculates bed shear at each in space and time using vertical velocity fluctuations, so the height at which TKE-w' measurements are taken influences the magnitude of the calculated bed shear. If utilized within the constant stress layer, this method is independent of height off the bed, however the height of this layer must be determined in order to predict a single value of bed shear stress. Figure 3.23 and Figure 3.24 show that the magnitude of the calculated bed shear can increase up to 2.6 times if the shear is calculated using values $2.5 \mathrm{~mm}$ off the bed compared to $0.5 \mathrm{~mm}$ off the bed, which indicates that one or both of these elevations is outside the constant stress layer. The resulting bed shear stresses also depend on the averaging interval used for w'. Averaging $20 \mathrm{~Hz}$ Vectrino II data over each second for a 10 minute period across a $3 \mathrm{~cm}$ vertical profile, the changes in bed shear with depth using the modified TKE method are shown in Figure 3.23. Figure 3.23 and 3.24 show the value of bed shear stress that was calculated from the $w^{\prime}$ conditions at that elevation in the water column, and therefore do represent a bed shear stress and not a fluid shear stress. 


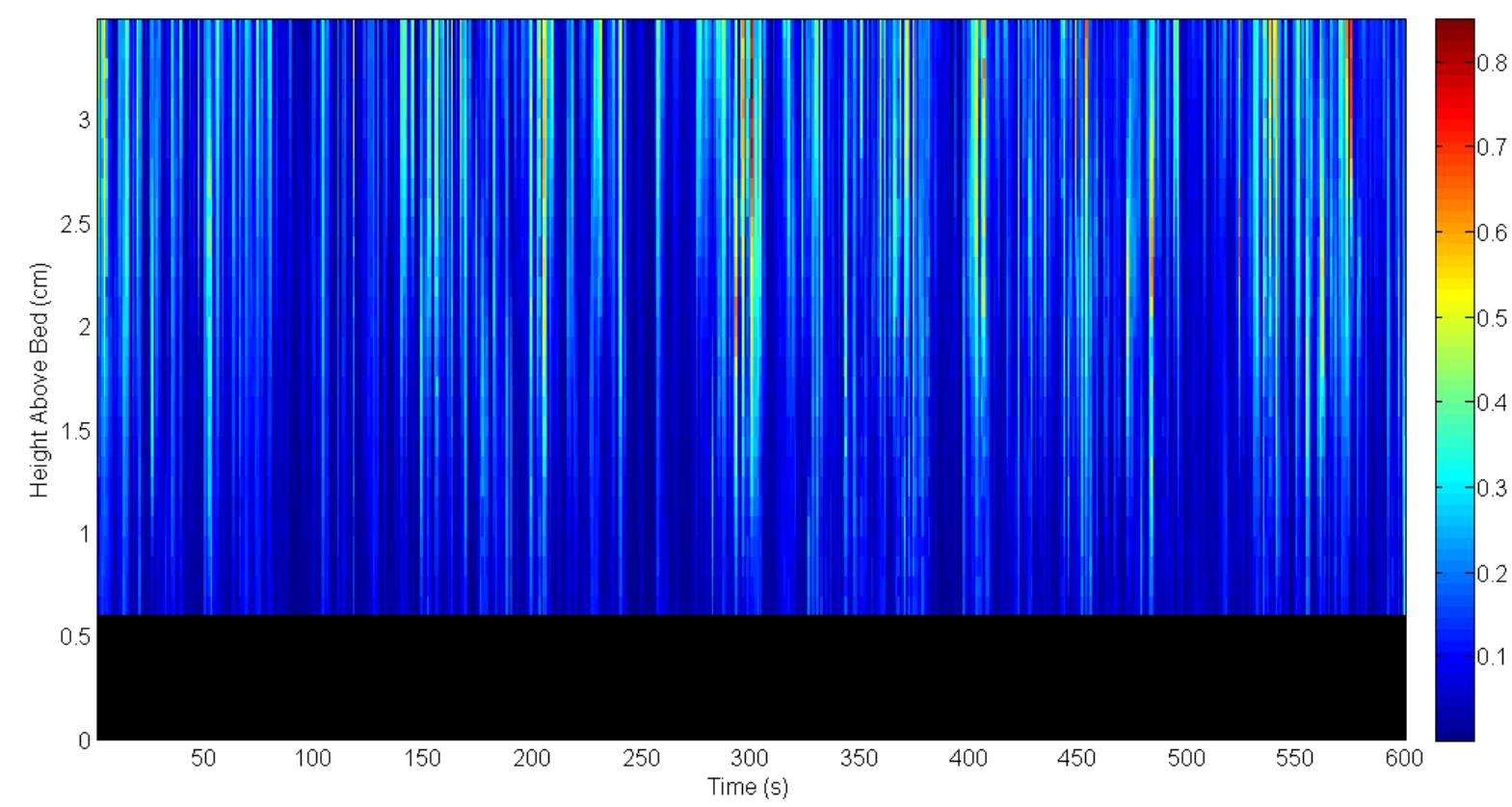

Figure 3.23: Bed shear stress (colorbar $-\mathrm{N} \mathrm{m}^{-2}$ ) calculated using vertical turbulent fluctuations (w') at different depths in the water column on July 1, 2013 at 10:30 at the bare site. Black area on bottom indicates that profiles did not extend all the way to the bed.

Spikes in the vertical turbulent fluctuations $\left(w^{\prime}\right)$ are apparent in the time series shown in Figure 3.23. These may be indicative of turbulence generation at the bed rising through the water column and dissipating. The intermittent nature of the peaks in $w^{\prime}$ may be due to generation of turbulence by irregularities on the sea floor, or perhaps vertical advection of turbulence out of the wave boundary layer as a result of bottom topography. In either case, it is apparent that the valuation of bed shear stress will vary depending on what height in the water column the vertical turbulence fluctuations are considered. No particular range of depths appears to result in a constant prediction of bed shear, therefore if there is a constant stress layer present, this profile is above it. Taking a value very close to the bed and comparing with a value farther from the bed, the average bed shear over the 10 minute deployment at $25 \mathrm{~mm}$ off the bottom is $0.13 \mathrm{~N} \mathrm{~m}^{-2}$; however, it is only $0.06 \mathrm{~N} \mathrm{~m}^{-2}$ calculated using the vertical turbulent fluctuations at 7 
$\mathrm{mm}$ above the bed. This amounts to a 2.17 fold increase in the average calculated bed shear over a $2.3 \mathrm{~cm}$ difference in height. A similar consideration of the vertical distribution of turbulence and the resulting effects on bed shear stress calculation is considered for the vegetated site below (Figure 3.24).

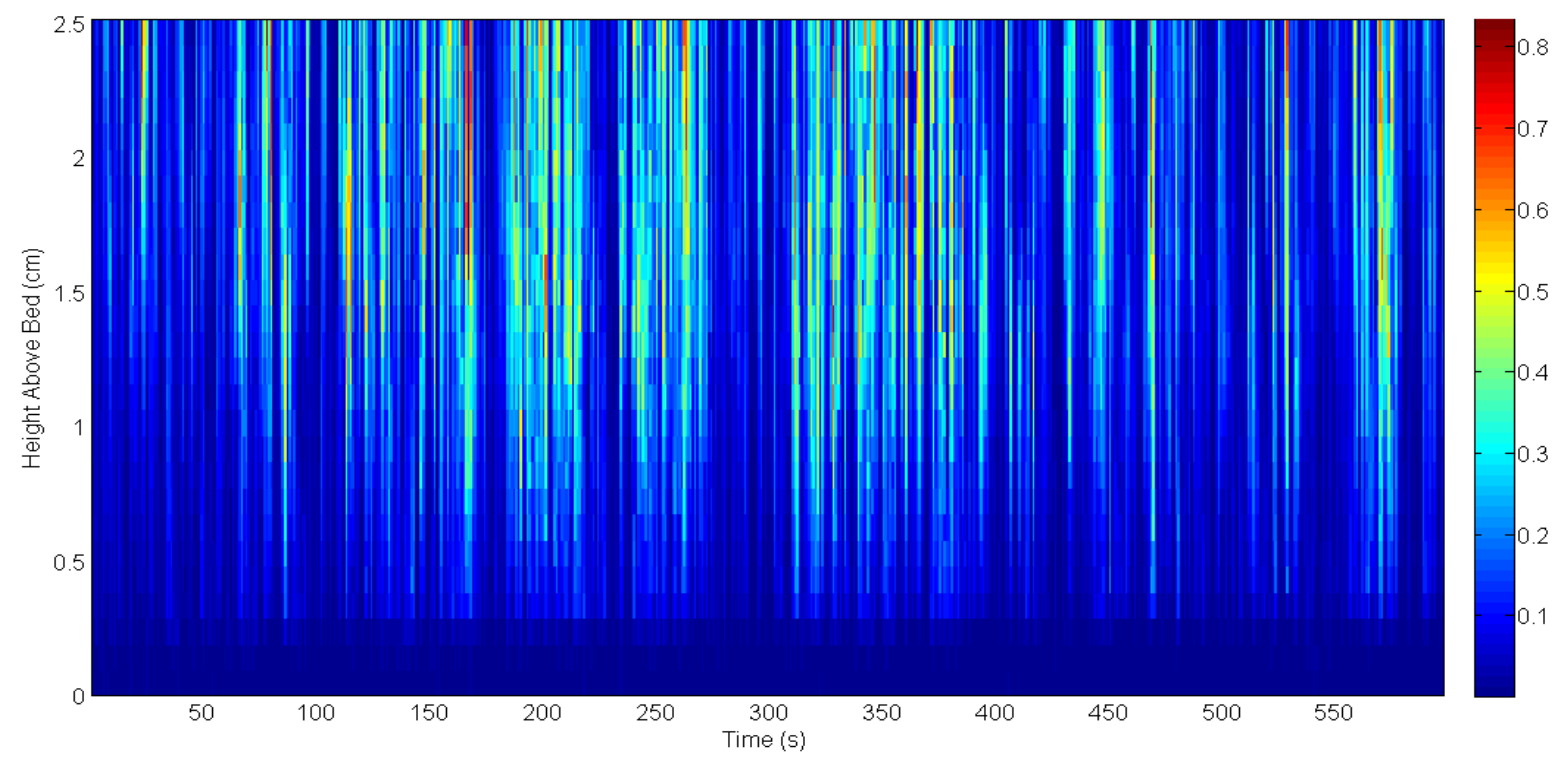

Figure 3.24: Bed shear stress distribution calculated using vertical turbulence fluctuations (w') at 16:10 on July 24, 2012 at the seagrass site. Magnitudes of bed shear stress in $\left(\mathrm{N} \mathrm{m}^{-2}\right)$ are shown in the colorbar.

Increased vertical turbulence $\left(w^{\prime}\right)$ higher in the water column at the seagrass site may be due to stem wake interaction within the seagrass canopy. This turbulence generated within the vegetation may be advecting downward into the near bed region. The average bed shear stress calculated from vertical turbulence $5 \mathrm{~mm}$ above the bed was $0.068 \mathrm{~N} \mathrm{~m}^{-2}$, and calculated using data $25 \mathrm{~mm}$ above the bed was $0.185 \mathrm{~N} \mathrm{~m}^{-2}$. The value higher in the water column predicts a bed shear 2.57 times greater than the lower estimate. Data collected during periods of low wave activity also exhibits similar variation in vertical turbulence over a depth profile. On October 14, 2012 at 12:00 at the bare site, bed shear calculated using values at $5 \mathrm{~mm}$ above the sediment was 
$0.030 \mathrm{~N} \mathrm{~m}^{-2}$, whereas shear calculated from turbulence values at $25 \mathrm{~mm}$ was $0.07 \mathrm{~N} \mathrm{~m}^{-2}, 2.3$ times greater. The July 13, 2012 deployment at 11:00 at the seagrass site had a bed shear of $0.0006 \mathrm{~N} \mathrm{~m}^{-2}$ calcualted at $5 \mathrm{~mm}$ above the bed, and $0.001 \mathrm{~N} \mathrm{~m}^{-2}$ calculated at $25 \mathrm{~mm}$ off the bed (an increase of 1.7 times the bed shear from $5 \mathrm{~mm}$ ).

The appropriate height to use in calculating bed shear for the modified TKE method is therefore an important question, especially as the values of bed shear obtained from just a $3 \mathrm{~cm}$ profile of vertical turbulence fluctuations vary drastically. Theoretically, within a constant stress layer this method would predict the same value of bed shear stress across a range of heights, however this is not observed in these profiles. Flow conditions at the bed are the most important in considering the shear stress experienced by individual sediment grains, however a combination of low flow velocities in this near bed region and instrument inaccuracy next to the bed limit the practicality of obtaining accurate measurements directly adjacent to the sediment surface. To reduce the potential for both the dampening of vertical velocity fluctuations due to the sea floor and instrument error due to Doppler backscatter (Anderson et al. 2007), and also to represent the wide range of bed shear values obtained through the $3 \mathrm{~cm}$ profile, TKE-W' values used to calculate bed shear in Table 3.7 were taken at $1 \mathrm{~cm}$ above the bed. 
Table 3.7: Comparison of bed shear stresses calculated using the separation of wave and current shear from Wiberg and Smith (1983) (column 1), the log profile method (column 2), and the modified TKE method (column 3). High wave conditions occurred on July 1, 2013 and July 24, 2012, and low wave conditions occurred on October 14,2012 and July 13, 2012. Ten minute average TSS concentrations are given where available.

\begin{tabular}{lcccc}
\hline $\begin{array}{l}\text { Bed Shear } \\
\text { Calculated Using: }\end{array}$ & $\begin{array}{c}\sqrt{\tau_{\text {wave }}^{2}+\tau_{\text {current }}^{2}} \\
\left(\mathrm{~N} \mathrm{~m}^{-2}\right)\end{array}$ & $\begin{array}{c}\text { Log Profile } \\
\left(\mathrm{N} \mathrm{m}^{-2}\right)\end{array}$ & $\begin{array}{c}\text { TKE - w } \\
\left(\mathrm{N} \mathrm{m}^{-2}\right)\end{array}$ & $\begin{array}{c}\text { TSS } \\
\left(\mathrm{mg} \mathrm{L}^{-1}\right)\end{array}$ \\
\hline Bare & Bare & - \\
10/14/2012 12:50 & 0.019 & 0.017 & 0.075 & - \\
$7 / 1 / 201310: 30$ & 0.018 & 0.011 & 0.058 & - \\
$7 / 1 / 201311: 20$ & 0.073 & 0.034 & 0.062 & - \\
\hline & 0.067 & 0.040 & 0.227 & 32.5 \\
\hline $7 / 13 / 201211: 00$ & 0.004 & Seagrass & & 28.5 \\
$7 / 13 / 201211: 50$ & 0.003 & 0.0002 & 0.001 & 74.1 \\
$7 / 24 / 201216: 10$ & 0.036 & 0.001 & 0.001 & 113.0 \\
$7 / 24 / 201217: 00$ & 0.032 & 0.005 & 0.119 & 0.110 \\
\hline
\end{tabular}

Anderson (2007) found good agreement between the LP and TKE-w' methods during periods of low wave activity, but found that the TKE-w' method underestimated bed shear stress when waves were present. This was attributed to either the dampening of vertical velocity fluctuations due to the proximity to the bed, or increased Doppler noise due to near bed suspended sediment concentrations interfering with the accuracy of the profiler. Data from this deployment does not show the same agreement. While the different methods follow the same trend of being highest at the bare site under high wave conditions, then at the seagrass site under high wave conditions, the bare site under low wave conditions, and finally lowest at the seagrass site under low wave conditions, the values of the bed shear stress vary in some cases by an order of magnitude. The TKE-w' method returns the highest values of bed shear stress, however this 
was highly dependent on the height chosen for the calculation. The LP method returns the lowest values of bed shear. Overall, the $\sqrt{\tau_{\text {wave }}^{2}+\tau_{\text {current }}^{2}}$ method (combined method) from Wiberg and Smith (1983) seemed the most reasonable bed shear stress measurement for this combined wave and current interactions in these data sets.

Assuming the combined method provides the most accurate representation of bed shear stress, sediment suspension should occur only at the bare site under high wave conditions. Total suspended solids (TSS) records were compared to the bed shear stress to determine if shear accurately predicted the suspended sediment load. Average TSS across the entire summer 2012 deployment was $65.8 \mathrm{mg} \mathrm{L}^{-1}$ (Table 3.8), therefore the calm conditions on July 13, 2012 resulted in TSS levels approximately half of the seasonal average whereas the wavy conditions on July 24, 2012 corresponded with TSS concentrations that were 1.1 to 1.6 times the average. However, the shear stresses estimated for both of these deployments were below the estimated critical shear value of $0.04 \mathrm{~N} \mathrm{~m}^{-2}$ (Lawson 2007). Elevated suspended sediment concentrations on July 24, 2012 over the seasonal average would either suggest that the critical shear stress for the meadow is closer to the values presented in Table 3.7, or that the TKE-w' method is a more accurate prediction of bed shear stresses. Using the bed shear stress values derived from the TKE-w' method, the shear experienced during the high wave event on July $24,2012\left(\tau_{\mathrm{b}}=0.11 \mathrm{~N}\right.$ $\mathrm{m}^{-2}$ ) did exceed the critical shear threshold, while the bed shear experienced during calm conditions on July 13, 2012 did not. The TKE-w' method also shows suspension conditions during both the high and low wave deployment at the bare site, while the combined method only shows values surpassing the critical shear at the bare site for the high wave condition.

Another possibility is that sediment may have been advected into the meadow from nearby sites that experienced a critical shear stress greater than $0.04 \mathrm{~N} \mathrm{~m}^{-2}$. Potential evidence 
that sediment is being transported from outside the meadow can be found in Figure 3.25, where elevated wave heights precede elevated suspended sediment concentrations by approximately 30 minutes. The bed shear stress within the seagrass meadow, calculated using the combined method, is below the critical shear threshold during this time period, suggesting that the suspended sediment was not derived locally from within the bed.

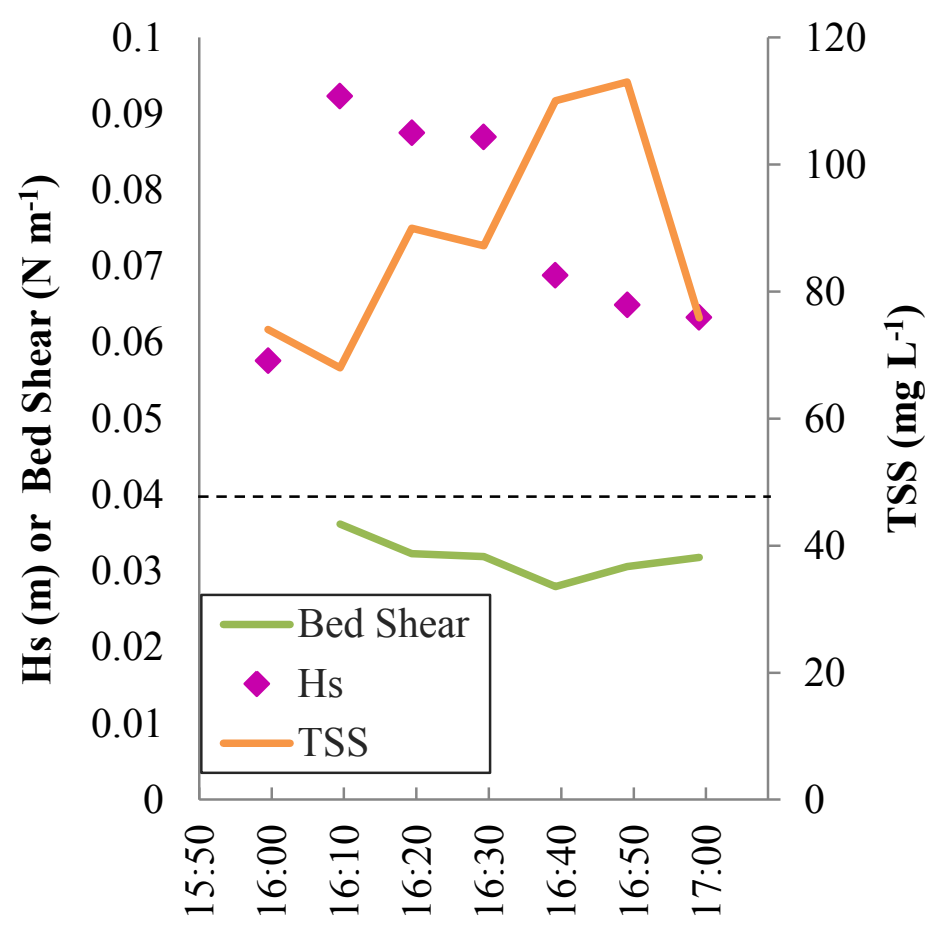

Figure 3.25: Significant wave height $\left(\mathrm{H}_{\mathrm{s}}\right)$, total suspended solids (TSS), and bed shear stress calculated using the combined method for the high wave case at the seagrass site on July 24, 2012. Dashed line represents critical shear stress of $0.04 \mathrm{~N} \mathrm{~m}^{-1}$. 
Table 3.8: Suspended sediment concentrations recorded at the center seagrass site in South Bay with calibrated OBS sensors. Concentrations were averaged across each seasonal deployment after filtering the data set, and data that showed evidence of instrument fouling was removed from the average. Distinct suspension events were counted as storm events for each season using the OBS record.

\begin{tabular}{lcccc}
\hline & April 2012 & July 2012 & October 2012 & January 2013 \\
\hline Center Site & $94.2 \mathrm{mg} \mathrm{L}^{-1}$ & $65.8 \mathrm{mg} \mathrm{L}^{-1}$ & $106.0 \mathrm{mg} \mathrm{L}^{-1}$ & $38.0 \mathrm{mg} \mathrm{L}^{-1}$ \\
Bare Site & - & $55.1 \mathrm{mg} \mathrm{L}^{-1}$ & - & - \\
\hline Storm Events & $2-3$ & $2-3$ & $4-5$ & 1 \\
\hline
\end{tabular}

January 2013 showed the lowest suspended sediment concentrations within the seagrass meadow, although bed shear stress and therefore sediment suspended is expected to be greater when the protective cover of a seagrass canopy is absent compared to high density conditions. Although Vectrino II data was not available to quantify bed shear stress during the January 2013 deployment, data suggests that a bare site would have higher bed shear stress than a vegetated site given similar wave conditions (Table 3.7). The lower average TSS in January 2013 may be the result of flushing that occurs when the meadow is sparse. Overall, seasonally averaged sediment suspension records do not accurately reflect seasonally averaged bed shear values due to the high variation in suspended sediment concentrations (Figure 3.26), as well as the typically lower settling velocities which cause suspension events to persist in the water column. 


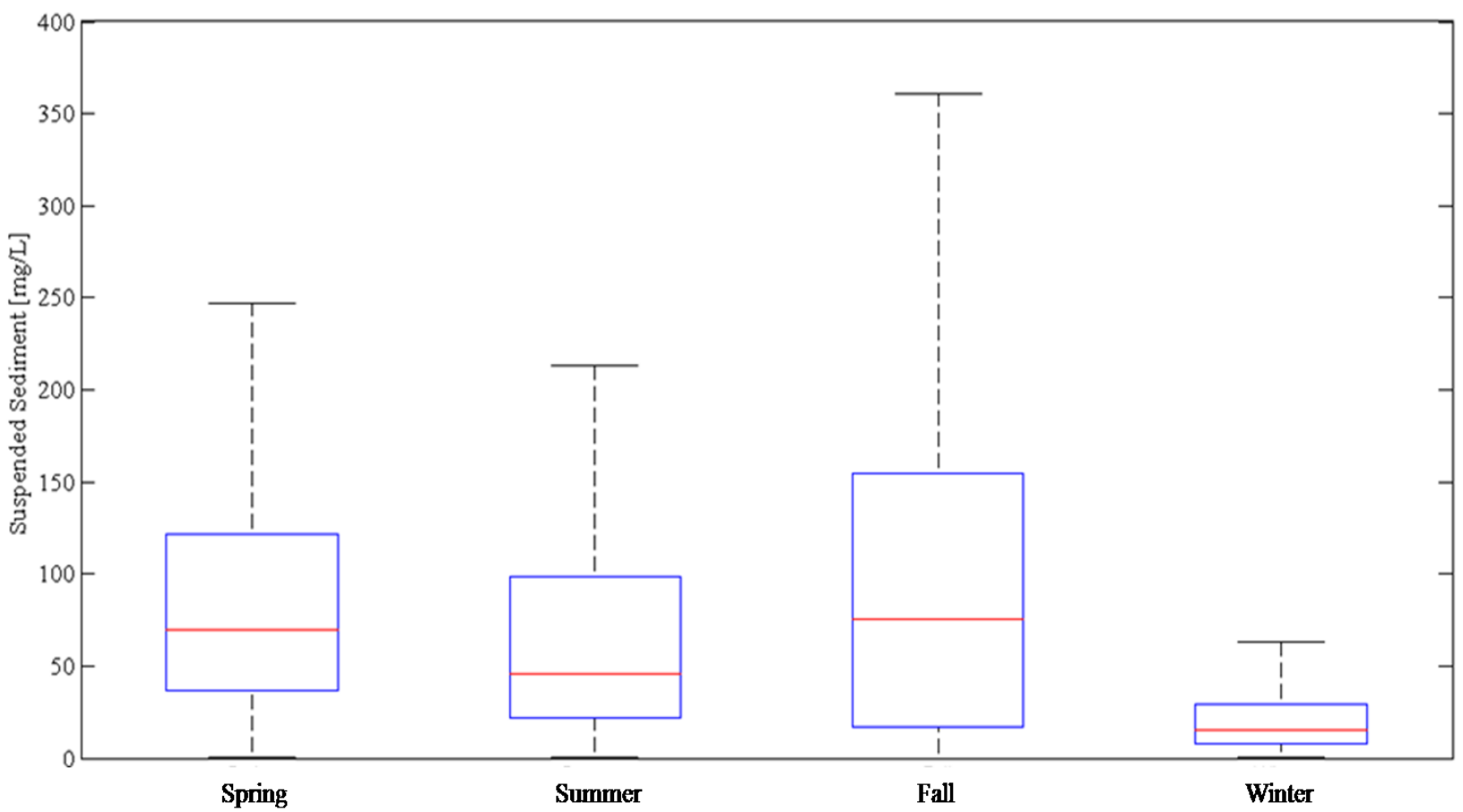

Figure 3.26: Average suspended sediment concentrations displayed for each season within the South Bay seagrass meadow. Red line represents median, blue box represents $25^{\text {th }}$ and $75^{\text {th }}$ percentiles. 


\subsection{Summary}

This chapter presents wave-current boundary layer structure under high wave and low wave conditions. Near bed velocity profiles contained two logarithmic layers where waves were predicted to interact with the sediment. This matches theoretical predictions of Grant and Madsen (1979) regarding wave-current flow. The thickness of the wave boundary layer was determined experimentally and using two theoretical predictions, however both theoretical predictions under predicted the observed thickness by an order of magnitude. Boundary layer development may be enhanced in a natural environment with a rough, random bed that promotes turbulent expansion of the layer, which is not reflected in the theories applied in Section 3.3.3.

Energy distributions and turbulent kinetic energy profiles were quantified for a high and low wave case. No discrepancies potentially related to the top of the wave boundary layer were observed, although an increase in turbulence at the interface between the WBL and CBL was expected (Hackett et al. 2011). A higher percent of the total water motion was within wave oscillations for the high wave case at the bare site; however, turbulence dominated water movement at the seagrass site in both wave conditions. This seemed independent of the depth of the wave boundary layer, and may reflect a general trend of increased turbulence within a seagrass meadow due to flow interaction with vegetation. The overall magnitude of TKE was larger at the bare site compared to the seagrass site, however so were the average values of wave orbital velocity (Table 3.6), so although the seagrass bed experiences lower magnitudes of both wave and turbulent motions, the distribution is skewed towards turbulence.

Bed shear stress was determined and compared to suspended sediment concentrations.

Bed shear stress values at the seagrass site calculated using the combined $\left(\sqrt{\tau_{\text {wave }}^{2}+\tau_{\text {current }}^{2}}\right)$ method resulted in TSS concentrations above the seasonal mean, however these values of bed 
shear stress $\left(0.036\right.$ and $\left.0.032 \mathrm{~N} \mathrm{~m}^{-2}\right)$ were below the $0.04 \mathrm{~N} \mathrm{~m}^{-2}$ previously defined to initiate sediment suspension in similar sediment environments. This can be explained by the advection of suspended sediment into the meadow from outside locations experiencing a higher bed shear stress, or may indicate that the TKE-w' method is more accurate for predicting bed shear stress than the combined method in this case. Further analysis comparing bed shear and sediment suspension on a finer temporal scale is necessary to expand this discussion of critical bed shear stress.

Few accurate in situ velocity measurements are available in the literature less than $1 \mathrm{~cm}$ above sediment due to difficulties that were also encountered in this research. As outlined in Hay et al. (2012a), instruments that use Doppler to measure velocities are contaminated by backscatter effects near hard boundaries. Matching the laboratory results of Hay et al. (2012a), velocity measurements from the Vectrino II declined at $5 \mathrm{~mm}$ above the bed. While limiting, this does indicate that Doppler limitations of the Vectrino II in the field were the same as Hay et al.'s (2012a) Doppler based profiler in the laboratory, which shows potential for the Vectrino II in future field investigations of near bed flow.

Additional complications arise from the complexity of the natural environment. Theoretical assumptions of a flat boundary, or even a boundary of fixed roughness, do not represent the natural variation in sediment features within an ecosystem. While the sediment $\mathrm{D}_{84}$ was shown to be similar across seasons and sites (Table 2.4), there are countless other influences on bed topography that can affect a wave boundary layer only centimeters thick. Small ripples, a sloped bed, organic particles that are removed during grain size analysis, and perturbations from benthic organisms are just a few examples of potential bed roughness that are both random and not accounted for in laboratory experiments. Although sites were cleared of seagrass, smoothed, 
and the Vectrino II was adjusted to be parallel with the sediment, there will always be confounding influences in the natural environment that cause results to deviate from theory.

Overall, this work shows that observed near bed flows do not correlate well with theoretical wave boundary layer predictions. Despite this deviation from boundary layer characteristics, several conclusions can be drawn regarding near bed flows within a seagrass meadow. First, near bed flows in seagrass meadows have a greater percent of fluid motion due to turbulence, however also have, on average, a lower magnitude of TKE compared to a bare site with similar wave conditions. Near bed profiles with similar wave conditions at the bare and seagrass site were found to have similar values of shear velocity despite the presence of vegetation at one site. This suggests that a seagrass meadow does exert control over conditions at the sediment boundary; however, the variation in near bed flow between the bare and seagrass sites is due to horizontal wave height attenuation caused by the meadow, and not by a vertical dissipation of wave energy in the water column. This conclusion supports the interconnectedness of meadow scale flows with conditions at the sea floor. 


\section{CHAPTER 4: Conclusion}

\subsection{Summary of Main Findings}

The goal of this thesis was to relate hydrodynamic processes that occur on different scales within a seagrass meadow to better understand the interactions between currents, waves, and vegetation. Chapter 2 described large scale modification of flow characteristics by the meadow, which occurred on the order of kilometers. Chapter 3 narrowed to focus on the fine scale hydrodynamic processes that control sediment suspension within the wave-current boundary layer, on the order of centimeters. Connecting these mechanisms is important to obtain a complete understanding of seagrass systems.

The link between meadow scale and boundary layer scale flows is highlighted in a discussion of wave height modification. Wave heights within the seagrass meadow were reduced by $25-49 \%$ compared to an adjacent bare site, and $-19-64 \%$ compared to an analytical model of wave attenuation over an unvegetated seafloor within the same area. Seasonal effects were also explored, with the lowest attenuation occurring in the sparse winter canopy and the highest reduction occurring in the high density summer meadow. Chapter 3 shows the strong dependence of near bed flows on wave height. Larger significant wave heights result in higher shear velocity (Table 3.3), thicker boundary layers- both observed and predicted by theory (Table 3.3 and 3.5 respectively), higher near bed turbulent kinetic energy (Table 3.6) and greater bed shear stress (Table 3.7). While near bed profiles were only collected in the summer, this dependence on wave height should translate to predict near bed characteristics in other seasons, although some near bed flow characteristics may also change as vegetation density decreases. 
While seagrass appears to strongly influence the horizontal attenuation of wave motion, there is no difference in wave boundary layer shear velocity $(u *)$ at the vegetated site and bare site when waves of equal significant wave height occur at each location (Figure 3.17). This may be due to the introduction of a profiling instrument into the meadow, and the clearing of the surrounding seagrass to prevent seagrass blade interference with the profiler head. Little attenuation may be observed if the cleared area is greater than the orbital excursion length, which is on the order of centimeters for the relatively small waves in South Bay. A deeper study site with a larger variety of wave conditions may better characterize the effects of vertical attenuation of wave orbital velocities by seagrass. However, this is also an interesting finding for shallow coastal systems. A patchy seagrass meadow may serve to reduce sediment suspension even in bare spots within the meadow if the bed shear conditions are primarily modified by the horizontal attenuation of wave height. That is, as waves propagate across the meadow they will decrease in height, creating lower bed shear conditions further into the meadow regardless of small changes in density.

In addition to exploring the interconnectedness of multi scale flow processes, this work also highlights the complexities present in environmental field data. Processes observed in situ are more complex than laboratory studies, and underscore the limitations of using flume based theory to explain natural systems.

\subsection{Broader Implications}

Seagrass alters the wave energy and sediment flux to adjacent ecosystems, which is important in salt marsh - lagoon - barrier island coastal systems such as the VCR LTER. The total wave energy impacting the edge of a marsh, which is also affected by depth variation, is the 
primary driver of lateral marsh erosion (Mariotti et al. 2010), so a reduction in wave height caused by seagrass is expected to reduce the rate at which marshes recede. This research highlights that in temperate systems, it is also critical to acknowledge that the protection offered by a seagrass bed varies seasonally. While wave attenuation can be substantial in the summer, protection is minimal in the winter. This variation may be beneficial to the marsh system in terms of providing sediment flux when vegetation density is low; however, also shows that marshes that are buffered by temperate seagrass meadows in the summer are at greater risk of erosion during winter storms.

Overall, seagrass meadows modify hydrodynamics in a substantial way and have potential implications for coastal erosion processes; however, seagrasses are only a small part of many processes which together influence the coastline.

\subsection{Recommendations and Future Directions}

This work was limited in several ways that could be addressed in future studies. Vectrino II near bed profiles were found to be highly influenced by bottom roughness, which may have obscured near bed flow characteristics. Although bed roughness is important to consider in natural environments, it could be standardized by recording velocity profiles over a surface of known roughness deployed in the field below the Vectrino II, and compared to near bed profiles recorded over the natural sediment. If natural roughness characteristics are desired, the sediment surface below the profiler should be photographed prior to data collection. Sediment grain size is not a specific enough metric to explain the true bottom roughness characteristics. 
In future work, additional velocity data higher in the water column above the Vectrino II near bed profiles would also be beneficial for comparing flows within and above the canopy, and determining the free stream velocity. This is important for theoretical calculations as well as determining the dominant current direction during each deployment. The interaction between current and wave direction on boundary layer development was an additional complication that was not addressed in this research, but has been identified in previous work. Models have predicted that waves and currents acting in the same direction will have amplifying effects on boundary layer development, which are modified when waves and currents interact at an angle (Holmedal et al. 2003). More careful measurements of the wave and current direction could be used to compare WBL conditions with waves and currents propagating in the same direction versus conditions in which waves are propagating opposite to the current direction to determine the effect on near boundary flows.

Overall, better methods to define the transition between the wave and current boundary layer in natural conditions are necessary to further understanding of in situ boundary layer characteristics. This work identified the transition by fitting data closest to the bed to a logarithmic profile and determining where data deviated from this profile, however the WBL thickness defined by this technique did not match with other defined characteristics of the top of the WBL, such as increased turbulence generation. Other methods that have been used to define wave boundary layer thickness that rely on separating out different phases of the wave are difficult in natural environments due to the non-uniform wave frequencies. Instruments like the Vectrino II have been developed that record accurate near bed velocity measurements on the millimeter range, so further development of the best ways to use this data to identify the WBL despite environmental noise will be beneficial for future boundary layer research. 


\section{REFERENCES}

Ackerman, J. D., \& Okubo, A. (1993). Reduced mixing in a marine macrophyte canopy. Functional Ecology, 7(3), 305-309.

Andersen, T. J., Fredsoe, J., \& Pejrup, M. (2007). In situ estimation of erosion and deposition thresholds by Acoustic Doppler Velocimeter (ADV). Estuarine, Coastal and Shelf Science, 75(3), 327-336. doi:10.1016/j.ecss.2007.04.039

Benliov, A.Y. \& B. N. Filyushkin.(1970). Application of methods of linear filtration to an analysis of fluctuations in the surface layer of the sea. Izvestiya, Atmospheric and oceanic physics $6,810-819$.

Bradley, K. \& C. Houser. (2009). Relative velocity of seagrass blades: Implications for wave attenuation in low-energy environments. Journal of Geophysical Research 114, F01004.

Bretschneider, C. L. (1957). Revisions in wave forecasting: deep and shallow water. Coastal Engineering Proceedings, 1(6), 3.

Bretschneider, C. L., \& Reid, R. O. (1954). Modification of wave height due to bottom friction, percolation, and refraction. Texas A \& M Research Foundation, College Station.

Bricker, J.D. \& S.G. Monismith. (2007). Spectral Wave-Turbulence Decomposition. Journal of Atmospheric and Oceanic Technology 24, 1479 - 1487.

Carr, J., P. D’Odorico, K. McGlathery, \& P. Wiberg, (2010). Stability and bistability of seagrass ecosystems in shallow coastal lagoons: Role of feedbacks with sediment resuspension and light attenuation. Journal of Geophysical Research 115: G03011,

Coastal Engineering Research Center (CERC). (1984). Shore Protection Manual, U.S. Army Coastal Eng. Res. Cent., Vicksburg, Miss. 
Chen, S. N., Sanford, L. P., Koch, E. W., Shi, F., \& North, E. W. (2007). A Nearshore Model to Investigate the Effects of Seagrass Bed Geometry on Wave Attenuation and Suspended Sediment Transport. Estuaries and Coasts, 30(2), 296-310.

Dalrymple, R. A., Kirby, J. T., Hwang, P. A., ASCE, M., \& Associate Members, A. (1984). Wave Diffraction Due To Areas of Energy Dissipation. J. Waterway, Port, Coastal and Ocean Eng, 110, 67-79.

De Boer, W.F. (2007). Seagrass-sediment interactions, positive feedbacks and critical thresholds for occurrence: a review. Hydrobiologica 591, 5- 24.

Dean, R. G., \& Dalrymple, R. A. (1991). Water wave mechanics for scientists and engineers. Advanced Series on Ocean Engineering, World Scientific, 2.

Drake, D. E., Cacchione, D. A., \& Grant, W. D. (1992). Shear Stress and Bed Roughness Estimates for Combined Wave and Current Flows Over a Rippled Bed. Journal of Geophysical Research, 97, 2319-2326.

Fagherazzi, S., \& P. L. Wiberg. (2009). Importance of wind conditions, fetch, and water levels on wave-generated shear stresses in shallow intertidal basins. Journal of Geophysical Research 114, F03022, doi:10.1029/2008JF001139.

Fonseca, M.S. \& J.A. Cahalan. (1992). A preliminary evaluation of wave attenuation by four species of seagrass. Estuarine, Coastal and Shelf Science 35, 565 - 576.

Fonseca, M.S. \& J.S. Fisher. (1986). A comparison of canopy friction and sediment movement between four species of seagrass with reference to their ecology and restoration. Marine Ecology Progress Series 29: 15 - 22.

Foster, D. L. (2000). Field observations of the wave bottom boundary layer. Journal of Geophysical Research, 105. 
Fourqurean, J.W., C. M. Duarte, H. Kennedy, N. Marbà, M. Holmer, M. A. Mateo, E.T. Apostolaki, G.A. Kendrick, D. Krause-Jensen, K.J. McGlathery, \& O. Serrano. (2012). Seagrass ecosystems as a globally significant carbon stock. Nature Geoscience 5: 505509.

Fredsoe, J., and R. Deigaard. (1992). Mechanics of Coastal Sediment Trans- port, World Sci., p 369.

Gacia, E., Granata, T. C., \& Duarte, C. M. (1999). An approach to measurement of particle flux and sediment retention within seagrass (Posidonia oceanica) meadows. Aquatic Botany, 65(1), 255-268.

Gacia E. \& Duarte C.M. (2001). Sediment retention by a Mediteranean Posidonia oceanica meadow: the balance between deposition and resuspension. Estuar Coast Shelf Sci $52: 505-514$

Gambi, M., A. Nowell, \& P. Jumars. (1990). Flume observations on flowdynamics in Zostera marina (eelgrass) beds. Mar. Ecol. Prog. Ser., 61,159-169.

Granata, T.C., T. Serrra, J. Colomer, X. Casamitjana, C.M. Duarte, \& E. Garcia. (2001). Flow and particle distributions in a nearshore seagrass meadow before and after a storm. Marine Ecology Progress Series 218: 95 - 106.

Grant, W.D. and O.S. Madsen. (1979). Combined wave and current interaction with a rough bottom. Journal of Geophysical Research 84: 1797 - 1808.

Grant, W. D., Williams III, A. J., \& Glenn, S. M. (1984). Bottom stress estimates and their prediction on the northern California continental shelf during CODE-1: The importance of wave-current interaction. Journal of Physical Oceanography, 14(3), 506-527. 
Grant, W. D., \& Madsen, O. S. (1986). The continental-shelf bottom boundary layer. Annual Review of Fluid Mechanics, 18(1), 265-305.

Hackett, E. E., Luznik, L., Nayak, A. R., Katz, J., \& Osborn, T. R. (2011). Field measurements of turbulence at an unstable interface between current and wave bottom boundary layers. Journal of Geophysical Research, 116(C2), C02022. doi:10.1029/2010JC006138

Hansen, J.C.R. \& M.A. Reidenbach. (2012). Wave and tidally driven flows in eelgrass beds and their effect on sediment suspension. Marine Ecology Progress Series 488: 271 - 287.

Hansen, J. C. R., \& Reidenbach, M.A. (2013). Seasonal Growth and Senescence of a Zostera marina Seagrass Meadow Alters Wave-Dominated Flow and Sediment Suspension Within a Coastal Bay. Estuaries and Coasts, 36(6), 1099-1114. doi:10.1007/s12237-013$9620-5$

Hay, A.E., L. Zedel, R. Cheel, \& J. Dillon. (2012a). Observations of the vertical structure of turbulent oscillatory boundary layers above fixed roughness beds using a prototype wideband coherent Doppler profiler: 1. The oscillatory component of the flow. Journal of Geophysical Research 117, C03005.

Hay, A.E., L. Zedel, R. Cheel, \& J. Dillon. (2012b). Observations of the vertical structure of turbulent oscillatory boundary layers above fixed roughness beds using a prototype wideband coherent Doppler profiler: 2. Turbulence and stress. Journal of Geophysical Research 117, C03006.

Holmedal, L. E., Myrhaug, D., \& Rue, H. (2003). The sea bed boundary layer under random waves plus current. Continental Shelf Research, 23(7), 717-750. doi:10.1016/S02784343(03)00020-7 
Kim, S.C., C.T. Friedrichs, J.P.Y Maa, L.D. Wright. (2000). Estimating Bottom Stress in Tidal Boundary From Acoustic Doppler Velocimeter Data. Journal of Hydraulic Engineering: $399-406$

Koyabashi, N., A.W. Raichle, \& T. Asano. (1993). Wave attenuation by vegetation. Journal of Waterway Port Coastal and Ocean Engineering-ASCE 119:30-48.

Koch E.W., Ackerman J.D., Verduin J., van Keulen M. (2006). Fluid dynamics in seagrass ecology: from molecules to ecosystems. In: Seagrasses: biology, ecology and conservation. Springer, Amsterdam, p 193-225

Koch, E.W. \& G. Gust. (1999). Water flow in tide- and wave-dominated beds of the seagrass Thalassia testudinum. Marine Ecology Progress Series 184: 63 - 72.

Kundu, PK and Cohen, IM. (2008). Fluid Mechanics, 4th ed. Academic Press, San Diego

Lacy, J.R. and S. Wyllie-Echeverria. (2011). The influence of current speed and vegetation density on flow structure in two macrotidal eelgrass canopies. Limnology and Oceanography: Fluids and Environments 1: 38 - 55.

Lawson, S.E., P.L. Wiberg, K.J. McGlathery, \& D.C. Fugate. (2007). Wind-driven sediment suspension controls light availability in a shallow coastal lagoon. Estuaries and Coasts 30: $102-112$.

Lowe, R. J., Falter, J. L., Koseff, J. R., Monismith, S. G., \& Atkinson, M. J. (2007). Spectral wave flow attenuation within submerged canopies: Implications for wave energy dissipation. Journal of Geophysical Research, 112(C5), C05018.

Lowe, R. J, Koseff J.R. \& Monismith, S.G. (2005). Oscillatory flow through submerged canopies: 1. Velocity structure. Journal of Geophysical Research, 110(C10), C10016. 
Mariotti, G., \& Fagherazzi, S. (2013). Wind waves on a mudflat: The influence of fetch and depth on bed shear stresses. Continental Shelf Research, 60, S99-S110.

Mariotti, G., Fagherazzi, S., Wiberg, P. L., McGlathery, K. J., Carniello, L., \& Defina, a. (2010). Influence of storm surges and sea level on shallow tidal basin erosive processes. Journal of Geophysical Research, 115(C11), C11012. doi:10.1029/2009JC005892

Maza, M., Lara, J. L., \& Losada, I. J. (2013). A coupled model of submerged vegetation under oscillatory flow using Navier-Stokes equations. Coastal Engineering, 80, 16-34. doi:10.1016/j.coastaleng.2013.04.009

Mazda, Y., Wolanski, E., King, B., Sase, A., Ohtsuka, D., \& Magi, M. (1997). Drag force due to vegetation in mangrove swamps. Mangroves and Salt Marshes, 1, 193-199.

McGlathery, K.J., M.A. Reidenbach, P. D'Odorico, S. Fagherazzi, M.L. Pace, \& J.H. Porter. (2013). Nonlinear dynamics and alternative stable states in shallow coastal systems. Oceanography 26(3):220-231.

Mendez, F. J., \& Losada, I. J. (2004). An empirical model to estimate the propagation of random breaking and nonbreaking waves over vegetation fields. Coastal Engineering, 51(2), 103-118. doi:10.1016/j.coastaleng.2003.11.003

Nepf, H. M., J. A. Sullivan \& R. A. Zavistoski. (1997). A model for diffusion within emergent vegetation. Limnology and Oceanography 42 (8): 1735 - 1745.

Nepf, H.M. (1999). Drag, turbulence, and diffusion in flow through emergent vegetation. Water Resources Research 35 (2), 479 - 489.

Nepf, H.M. (2004). The Ecogeomorphology of Tidal Marshes. American Geophysical Union Coastal and Estuarine Studies 59. 
Orth, R.J., M.L Luckenbach, S.R. Marion, K.A. Moore, \& D.J. Wilcox. (2006). Seagrass Recovery in the Delmarva Coastal Bays, USA. Aquatic Botany 84: 26 - 36.

Orth, R.J., K.A. Moore, S.R. Marion, D.J. Wilcox, D.B. Parris. (2012). Seed addition facilitates eelgrass recovery in a coastal bay ecosystem. Marine Ecology Progress Series 448: 177 195.

Paul, M., \& Amos, C. L. (2011). Spatial and seasonal variation in wave attenuation over Zostera noltii. Journal of Geophysical Research, 116(C8), C08019. doi:10.1029/2010JC006797

Paul, M., Bouma, T., \& Amos, C. (2012). Wave attenuation by submerged vegetation: combining the effect of organism traits and tidal current. Marine Ecology Progress Series, 444, 31-41.

Quartel, S., Kroon, A., Augustinus, P. G. E. F., Van Santen, P., \& Tri, N. H. (2007). Wave attenuation in coastal mangroves in the Red River Delta, Vietnam. Journal of Asian Earth Sciences, 29(4), 576-584.

Salehi, M., \& Strom, K. (2012). Measurement of critical shear stress for mud mixtures in the San Jacinto estuary under different wave and current combinations. Continental Shelf Research, 47, 78-92. doi:10.1016/j.csr.2012.07.004

Short, F., T. Carruthers, W. Dennison, \& M. Waycott. (2007). Global seagrass distribution and diversity: a bioregional model. Journal of Experimental Marine Biology and Ecology 350: 3-20.

Sleath, J. F. A. (1987). Turbulent oscillatory flow over rough beds. Journal of Fluid Mechanics, $182,369-409$.

Spalding, M.D, M.L. Taylor, S. Martins, E.P. Green and M. Edwards. (2001). The global distribution and status of seagrass ecosystems. UNEP-WCMC Global Seagrass Workshop. 
Trowbridge, J.H. (1998). On a technique for measurement of turbulent shear stress in the presence of surface waves. Journal of Atmospheric and Oceanic Technology 15, 290 298.

van derHeide, T., E.H. van Nes, G.W. Geerling, A.J.P. Smolders, T.J. Bouma, and M.M. van Katwijk, 2007. Positive feedbacks in seagrass ecosystems: Implications for success in conservation and restoration. Ecosystems 10, 1311 - 1322.

Wiberg, P.L. \& Smith, J.D. (1983). A comparison of field data and theoretical models for wavecurrent interactions at the bed on the continental shelf. Continental Shelf Research, 2(2), 147-162.

Wiberg, P. L. (1995). A theoretical investigation of boundary layer flow and bottom shear stress for smooth, transitional, and rough flow under waves, Journal of Geophysical Research, $100(95)$.

Wiberg, P. L. \& C. R. Sherwood. (2008). Calculating wave-generated bottom orbital velocities from surface-wave parameters. Computers \& Geosciences 34, 1243 - 1262.

Widdows J, Pope ND, Brinsley MD, Asmus H, Asmus RM. (2008). Effects of seagrass beds (Zostera noltii and Z. marina) on near-bed hydrodynamics and sediment resuspension. Mar Ecol Prog Ser 358:125-136.

Williams, S. L. (1990). Experimental studies of Caribbean seagrass bed development. Ecological Monographs, 449-469.

Young, I.R. \& L.A. Verhagen. (1996). The growth of fetch limited waves in water of finite depth. Part 1. Total energy and peak frequency. Coastal Engineering, 29: 47-78. 